\title{
Recent Advances in Biodegradable Polymers
}

\author{
Sunil Dhamaniya ${ }^{a}$, Virendrakumar Gupta ${ }^{\mathrm{a},}{ }^{\star}$ and Rucha Kakatkar ${ }^{\mathrm{b}}$
}

\author{
${ }^{a}$ Polymer Synthesis \& Catalysis, Reliance Research \& Development Centre, Reliance Industries Limited, \\ Ghansoli 400701, Navi Mumbai, India \\ ${ }^{b}$ Department of Fibres \& Textile Processing Technology, Institute of Chemical Technology, Mumbai, India
}

\begin{abstract}
Biodegradable polymers are important as an alternative to conventional non-degradable polymers for sustainable eco-system. The recent trends indicate that the new developments in biodegradable polymers focus on novel polymer systems that can cater the need of biomedical and packaging applications in-terms of performance and economics. The new interest is rapidly moving toward reducing carbon footprint through utilization of carbon dioxide and developing new methods of manufacturing such as $3 \mathrm{D}$ printing for specific purposes. This review focus on the present state-of-art and recent developments in biodegradable polymers covering their sources, synthetic methodologies, salient properties, degradation patterns, polymer blends and nanocomposites. As well as biodegradable polymers as a 3D printing material and the use of carbon dioxide as a renewable raw material for biomedical and packaging applications.
\end{abstract}

Keywords: Biodegradable polymers, polymer blends, 3D printing, carbon dioxide, renewable resources.

\section{INTRODUCTION}

Conventional plastics have a variety of applications in different forms and have always been the focus of major industrial and research areas. In the present scenario, these non-degradable conventional polymers have become a serious environmental concern because of their high durability. One of the main challenges of polymer research is to substitute existing non-degradable polymers with degradable polymers having comparable mechanical properties. Poly(lactide) (PLA) is certainly the most promising biodegradable polymer today, has become a commercial reality and is produced at world-scale plants. Its mechanical properties and cost-performance balance have made it suitable for applications like packaging, agriculture and disposable molded articles. Biodegradable polymers can provide a solution to managing packaging waste, textile waste and also holds great promise in biomedical and pharmaceutical applications, since they combine the features of biocompatibility and biodegradability. For example, aliphatic polyesters, such as polylactic acid (PLA), poly(glycolide) (PGA), poly ( $\beta$-hydroxy butyrate) (PHB), poly( $\varepsilon$-capolactone) etc. are extensively used in biomedical and pharmaceutical applications. The diversity of the application of biodegradable polymers gives the impetus for development of a wide range of new biomaterials [1-12].

As an alternative to conventional non-degradable polymers the interest has increased in developing and

*Address correspondence to this author at the Polymer Synthesis \& Catalysis, Reliance Research \& Development Centre, Reliance Industries Limited, Ghansoli 400701, Navi Mumbai, India; Tel: +912279650368;

E-mail: Virendrakumar.gupta@ril.com exploring more suitable biodegradable polymers. Firstly, non-biodegradable polymers are not environment benign. Secondly, governmental regulations and consumer appeal to eco-friendly materials have encouraged the use of biodegradable polymers. The biodegradable polymers could be sourced from nature or laboratory. The natural based biodegradable polymers such as cellulose, starch, chitin, chitosan, find applications in various fields due to their biocompatibility, lower cost, sustainability, availability and biodegradability [13-20].

The chemical synthesis of biodegradable polymers is an attractive approach to prepare novel biopolymers. Synthetic biopolymers have advantage over naturally produced biopolymers because chemical modification of later is difficult and former can be easily tailored. Apart from this, biodegradable polymers based on renewable resources have equal importance. Nowadays, the most of the commodity polymers have emerged from fossil fuels. However, these reserves are limited and will deplete in near future. In this contrast, synthetic polymers based on renewable resources have ample scope for sustainable development [9-12]

This review focus on recent developments in biodegradable polymers covering their sources, synthetic methodologies and salient properties. Moreover, the review covers the major attention points in the development of biodegradable polymers either as exploiting monomer which are available in abundance or targeting the application which are entirely novel in terms of futuristic manufacturing. Recently, the research focus has shifted to synthesizing polymers or modifying the existing polymers to reduce the carbon footprints of the 
polymers in the form of their final product or application. Various methods have been devised to achieve this object. In accordance to this, $\mathrm{CO}_{2}$, an abundantly available gas as well as a pollutant, has been considered one of the prime monomers used for producing biodegradable polycarbonates which find applications in scaffolds, grafts and other tissue engineering uses and also in producing packaging materials [21-29].

3D printing is a form of additive manufacturing based on methods such as selective laser sintering, stereo-lithography and Fused Deposition Modelling. PLA has been extensively used as a filament for 3D printing. 3D printing has a major application in the formation of scaffolds and in other tissue engineering applications where it can be synthesized as per the requirement of the patient which makes it advantageous as compared to conventional manufacturing process. The review also focus on the latest developments in bionanocomposites having application in biomedical filed and novel biodegradable polymers blends for medical as well as packaging applications. The recent development in polymers biodegradation and applications have also been documented [30-34].

\section{SOURCES OF BIODEGRADABLE POLYMERS}

\subsection{Natural Biodegradable Polymers}

Natural polymers find applications in various fields due to their biocompatibility, lower cost, sustainability, availability and biodegradability. Natural polymer sources can be broadly classified into polysaccharides and protein sources. This review mainly covers the two easily available sources, namely, starch and cellulose. Starch and cellulose are crystalline in nature and hence, they need to be modified using various chemicals to make them easy to process [11-12]. They can further be combined with other synthetic biodegradable polymers in order to overcome their individual drawbacks and prepare multi-functional biodegradable polymer blends or composites [14, 20, 35].

\subsubsection{Starch Based Biodegradable Polymers}

Nishat et al. prepared starch based polymer complexes utilizing transition elements such as $\mathrm{Zn}(\mathrm{II})$, $\mathrm{Mn}(\mathrm{II}), \mathrm{Cu}(\mathrm{II}), \mathrm{Co}(\mathrm{II})$, and $\mathrm{Ni}(\mathrm{II})$. Pure starch has poor mechanical properties and this limitation can be overcome by crosslinking starch using agents like glutaraldehyde. This crosslinked starch is further reacted with transition metals to form coordination bonds in the composite. Thus the complex formed will exhibit enhanced mechanical strength, thermal stability and other mechanical properties. Thus, as the crosslinking or the coordination bonds increased, the biodegradability decreased, however, the thermal stability of the composite increased. The synthesized composites have applications in waste water treatment, biomedical field and drug delivery devices [13]. In continuation with the previous work, Nishat et al. modified the polymeric starch using thiourea which aids in the formation of transition metal complexes. The incorporation of metal ions in the polymer matrix increased the thermal stability of the matrix. It was observed that complexes containing $\mathrm{Cu}$ (II) exhibited highest antibacterial properties amongst all the other starch-metal complexes. Thus, the synthesized polymer complexes can be used for bioplastic manufacturing and waste water treatment [36].

Moreover, biodegradable films derived from cassava starch could be used for food packaging and transportation applications as reported by Souza et al. Since, pure cassava starch exhibits high brittleness, plasticizers such as sugars and glycerol are added to the films. The plasticizers enhance the film flexibility and prevent cracks in the film. However, the addition of plasticizer leads to increase in the permeability of the films above the optimum level. To overcome the high permeability limitation, easily available, inexpensive nanoclay particles are added to the film. The biodegradable films can be used in food packaging and transportation application [37]. Thiol-ene click reaction was carried out between ally starch (AS) and thiol starch (St-SH) reported by $\mathrm{Li}$ et al. to give a novel starch based hydrogel. It was demonstrated that the mechanical properties of the hydrogel could be varied by the thiolene molar ratio. It was shown that the degradation process of the hydrogel took place by two mechanisms combined, namely, surface erosion and diffusion mechanisms. Thus, the synthesized hydrogel is most suitable for tissue engineering and other biomedical applications [38].

On the other hand, tetraethylhydrosilicates (TEOS) incorporated in the carioca starch based film using in situ condensation technique to improve the mechanical properties and to reduce the overall hydrophilicity of the film were prepared by Lima et al. This improvement in the properties can be because of migration of silica to the boundaries of the film and due to the interaction between starch and TEOS. It was demonstrated that incorporation of $40 \%$ TEOS in the film gave optimum 
film properties [14]. Mendes et al. synthesized polymer blends containing thermoplastic cornstarch (TPS) matrix and thermoplastic chitosan (TPC) as the reinforcement using melt extrusion technique. Chitosan decreased the tensile strength, however, it enhanced the thermal stability of the matrix. It was observed that an optimum of 5 to $10 \mathrm{wt} \%$ of chitosan gave a plasticizing effect to the matrix, thus, further enhancing its properties and making them suitable for applications in packaging [15].

Whereas, Golacki et al. used thermoplastic starch derived from potato along with plant glycerol and incorporated two additives in the film, namely, polyvinyl alcohol and keratin separately to study the final film properties. These additives perform the function of a plasticizer in the film thereby enhancing the mechanical properties of the film. In the first stage of production, a starch pellet was prepared by mixing the components and in the second stage of production, the film was blown from the previously formed starch pellet [16]. Dual modified films which are used in packaging applications were prepared by Biduski et al. These films were synthesized from sorghum starch and further modified the film using either or both of acid and oxidation modification to improve the film properties. Acid modification was carried out using an optimum of $3 \%$ lactic acid, whereas oxidation modification was done in the presence of $1.5 \%$ active chlorine. In the case of modification using both the techniques, acid modification was carried out first followed by further oxidation. It was demonstrated that upon oxidation treatment in the form of single or dual treatment, the film mechanical properties improved to a much greater extent as compared to single acid treatment. Also, increasing the amount of sorghum starch gave enhanced properties to the film [39].

Arolkar et al. prepared biocomposite films from corn starch and poly ( $\varepsilon$-caprolactone) (CPSCL) and further modified them using air-plasma treatment. The modified films exhibited enhanced biodegradability, surface roughness, hydrophilicity and adhesion between the two film components as compared to the original biocomposite films. It was demonstrated that films when subjected to 2 minutes of air plasma treatment gave optimum mechanical as well as barrier properties. Thus, depending on the need, air plasma treatment for different time periods can be given to the film for suitable use as packaging material [40]. On the other hand, starch/PBAT blend biodegradable films could be prepared by adopting two techniques based on blown extrusion method as reported by Brandelero et al. PBAT was added to the starch polymer in order to give strength to the film. In the first technique, starch and plasticizer (glycerol) pellets were extruded with PBAT pellets to give the films. In the second technique, starch granules were extruded with plasticizer (glycerol) pellets and PBAT pellets to produce the film. It was demonstrated that for starch concentration upto $50 \%$, first technique was used for synthesis, whereas for starch concentration above $50 \%$, second technique was used for synthesis to give optimum mechanical and structural properties [41].

\subsubsection{Cellulose Based Biodegradable Polymers}

Norain et al. synthesized biocomposite films based on regenerated cellulose (RC) matrix and lignocellulosic biomass fillers such as coconut shells (CS) fillers. It was observed that $3 w t \%$ CS gave optimum strength properties to the biocomposite. The tensile strength and other mechanical properties of the biocomposite film could be further improved by chemically treating the cellulose with butyl methacrylate acid (BMA). Also, incorporation of BMA in the film aided in formation of a uniform dispersion and increased the adhesion between CS and the RC matrix [17]. Liyana et al. synthesized a novel biocomposite film based on regenerated cellulose derived from lignocellulosic material using the casting technique. Oil palm empty fruit bunch (OPEFB) and microcrystalline cellulose (MCC) were dissolved in $\mathrm{N}$ dimethylacetamide/lithium chloride. (DMAc/LiCl) solution and regenerated to produce the regenerated cellulose. It was demonstrated that $2 \mathrm{wt} \%$ of OPEFB gave optimum mechanical properties and dispersion properties to the film due to the uniform dissolution and dispersion of OPEFB fibers in the OPEFB matrix [18]. Mostafa et al. synthesized bioplastics using inexpensive raw materials such as cotton linters and flax fibers. The bioplastics were in the form of cellulose acetates produced by acetylation reaction of the raw materials using sulphuric acid. The prepared bioplastics had chemical resistance comparable to the petroleum based polymers such as polypropylene and polyethylene. Thus, these bioplastics can be a suitable substitute for petroleum based polymers because of biodegradability, cost efficiency, safe-to-use properties. It was observed that flax fibers gave a higher yield as compared to the cotton linters. The synthesized bioplastics find application in biomedical field and food packaging [19].

Mahecha et al. synthesized novel biodegradable nanofibers from fibrous residues. These residues were 
obtained from various extraction processes and pretreatments applied on achira rhizomes to obtain starch as the product. Processes used for the extraction included use of chlorine bleach, mechanical treatment under high pressure, acid of different concentrations and hydrolysis. It was observed that the nanofibers produced from mechanical treatments led to development of electronegative surface charges on the nanofibers, thus, giving good dispersion and mechanical properties. Sulfuric acid treatment lead to formation of highly crystalline nanofibers. These fibers exhibited low water permeability properties. Thus, depending on the pre-treatments, nanofibers with specific requirements can be obtained [42]. Barari et al. synthesized novel bionanocomposites using bio-based epoxy resin as the matrix and anisotropic and isotropic nanocellulose fibers (CNF) as reinforcement using modified liquid composite molding technique. The epoxy resin is subjected to thermosetting reaction to produce a net shaped matrix for the composite. Silane treatment was further given to nanocellulose to improve the mechanical properties of the bionanocomposites. The composites prepared from anisotropic CNFs demonstrated better properties than those synthesized using isotropic CNFs [43]. Balakrishnan et al. synthesized nanocomposites from potato starch and cellulose nanofibers derived from pineapple leaves using the casting technique. Glycerol was added to the system as a plasticizer giving flexibility to the starch matrix. By the addition of glycerol, the starch and cellulose interaction also increases, since, the cellulose fillers have a tendency to move towards glycerol rich starch phase in the composite. The prepared biocomposites can used for packaging purposes [44].

\subsubsection{Starch and Cellulose Based Biodegradable Polymers}

Pelisaari et al. synthesized inexpensive novel nanocomposites with banana starch as the polymer matrix and cellulose nanofibers derived from easily available banana fibers as the reinforcement using solution casting method. The extraction process for cellulose nanofibers should not include extreme mechanical treatments which may cause defects in the nanofibers and subsequently in the nanocomposite. Extraction using chemical treatments followed by an optimum of 5 passages through the high pressure homogenizer is found to be the most suitable treatment for nanofibers extraction. Since both the matrix and reinforcements were obtained from banana fibers, they were chemically similar and thus, the prepared nanocomposites demonstrated good mechanical properties and thermal stability. The synthesized nanocomposites can suitable for food packaging applications [20].

Thermocavity foam molding technique was adopted by Zhang et al. to prepare open cell membrane structured bionanocomposites over modified starch and plant fibers to. In order to improve the properties and compatibility of the composite, additives such as thermoplastic starch (TPS), oxidized starch (OS) and thermoplastic oxidized starch (TPOS) were incorporated in the composite Glycerol or modified glycol were used as the plasticizer to prepare TPS whereas, hydroxyl peroxide and copper sulphate were used as the oxidizing agent and catalyst respectively for synthesis of OS. Both the plasticizer and oxidizing agent were used for preparing TPOS. It was demonstrated that with the incorporation of TPOS, the re-crystallization of starch reduced, tensile strength and mechanical properties of the composite increased substantially due to the hydrogen bond formation between the starch and the fibers [45]. Cellulose/PHB bionanocomposites which are used in packaging materials in food and agricultural field were prepared by Seoane et al. The author synthesized bilayer bionanocomposites using cellulose cardboard in fiber form and $\mathrm{PHB}$ in solution form using compression moulding and solution casting technique. It was demonstrated that pressed composite gave a better performance and exhibited enhanced properties as compared to composite produced from solution casting technique. PHB being expensive, its amount was optimized to $15 \mathrm{wt} \%$ for compression moulding and 10 $w t \%$ for solution casting technique to give good films [35].

\subsection{Synthetic Biodegradable Polymer}

Biodegradable polymers can be synthesized by conventional methods, such as polycondensation and ring opening polymerization of lactones or lactides. Enzyme catalyzed polymerization has also attracted a great deal of interest as this is in contrast with conventional method a high regiospecificity as well as high stereospecificity can be achieved by enzyme catalyzed polymerizations [7].

\subsubsection{Step Growth Polymerization}

Step-growth polymerization of various diacids and diols traces back to pioneer work of Carothers in the 1930s [46]. This is the traditional synthetic route to aliphatic polyesters that usually proceeds by the reaction between two different functional groups, for 
example, isocyanate and hydroxyl groups, or hydroxyl and carboxyl groups. Diesters or diacids and their derivatives are used for the synthesis of aliphatic polyesters in step-growth polymerization.

2.2.1.1. Step Growth Polymerization/Polycondensation: Method and Catalyst Systems

Step-growth polymerization reactions for polyesters are commonly referred to as polycondensation since they form small molecules such as water or methanol as byproduct. Generally, it is difficult to achieve high molecular weights in step polymerization reactions, since a very high conversions (>98-99\%) is required for this. Since esterification reactions are equilibrium processes, therefore, achieving high conversions are very challenging. The polycondensation reactions are carried out in a driven system, accomplished by the use of high temperature, high vacuum, and high pressure of inert gas to remove the byproduct [47-50].

The other drawback of polycondensation is the high polydispersity index of synthesized polymers. The value of polydispersity index for polycondensation is generally $>2$ and depends on the extent of reaction. In general, a bulk polycondensation reaction accomplish with a two-step procedure, esterification and polycondensation. Esterification is the first step of bulk polycondensation that complete with an oligomeric product. In this step monomers are heated at moderate temperatures without the application of vacuum. Esterification is considered to be accomplished after the collection of almost the theoretical amount of byproducts such as water and methanol, which can be removed by distillation from the reaction mixture. Esterification is followed by the polycondensation and in this step, oligomers prepared from the former step are subjected to heat at high temperature with the application of vacuum. The high molecular weight polymers are achieved in polycondensation step. The progress of reaction can be monitored by the change in viscosity, which gradually increases to an extent where stirring of reaction mixture cease [47-50].

Many disadvantages of the bulk polycondensation can be overcome by the solution polycondensation method. Thermal control is easier in solution polycondensation because the solvent assists in the transfer of the heat of polymerization. Additionally, solvent acts as a diluent and allows easier stirring, since the viscosity of the reaction is low even at higher molecular weight. On the other hand, solvent may cause other complexities, such as chain transfer to solvent and impurities because of residual solvent.
Solution polycondensation is carried out in presence of proton traps such as, tertiary amines and pyridine, molecular sieves to facilitate the removal of byproducts [48-50].

Different metal acetates are employed to catalyze the polycondensation reactions for example zinc acetate $\left[\left(\mathrm{CH}_{3} \mathrm{COO}\right)_{2} \mathrm{Zn}\right]$, manganese acetate $\left[\left(\mathrm{CH}_{3} \mathrm{COO}\right)_{2} \mathrm{Mn}\right]$ and lead acetate $\left[\left(\mathrm{CH}_{3} \mathrm{COO}\right)_{2} \mathrm{~Pb}\right]$. For a polycondensation reaction, the temperature, pressure and solution concentration depends on the nature of catalyst. Titanium-based catalyst $\left[\mathrm{KTiO}_{x}, \mathrm{Ti}\left(\mathrm{OC}_{4} \mathrm{H}_{9}\right)_{4}\right]$, tin based catalyst [(But $)_{2} \mathrm{SnO}$ ] and antimony based catalyst $\left[\mathrm{Sb}_{2} \mathrm{O}_{3}\right]$ are also reported as the efficient catalyst systems for the polycondensation of polyesters [50-53].

\subsubsection{Functionalized Polymers from Step-Growth} Polymerization

Various classes of functional polymers such as polyesters, polycarbonates, polyaminoacids, polyamides etc. have been synthesized by step-growth polymerization. Polyaminoacids or polypeptides are biodegradable and biocompatible polymers comprehensively reviewed by Deming [54]. Yu et al. have synthesized a nonionic water soluble polypeptide having mono and diethyleneglycol functionalities using polycondensation reaction [55]. Guo et al. have introduced copolymers with functional groups like chloro, azido, allyl or propargyl in poly(g-benzyl-Lglutamate) [PBLG] based copolymers through ester exchange reactions [56]. Dhamaniya et. al. reported on a novel class of functional aliphatic polyesters derived from natural resources, namely, tartaric acid derivatives. These functional polyesters could have applications in controlled drug delivery and synthesized through polycondensation methodology via a protection and deprotection of functional groups that resulted in hydroxyl functionalized polymers [57-58].

\subsubsection{Biodegradable Polymers Based on Renewable Cyclic Sugar Diol Monomers}

1,4:3,6-Dianhydrohexitols have been served as a potential bio-based renewable monomer for the synthesis of variety of biodegradable polymers, such as polyesters, poly(ester anhydride)s, poly (ester amide)s, poly(ester carbonate)s, polyurethane etc. 1,4:3,6dianhydrohexitols sugar diols exist in three different isomeric forms i.e. isosorbide, isomannide and isoidide (Figure 1). Among the three isomers, isosorbide is commercially produced, however impurities of its isomers as well as high cost restrict its polymers to be commercialized [12, 59]. 


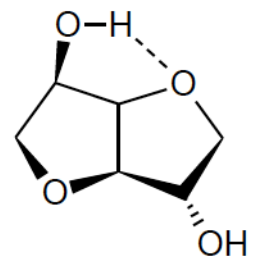

Isosorbide

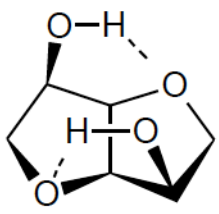

Isomannide

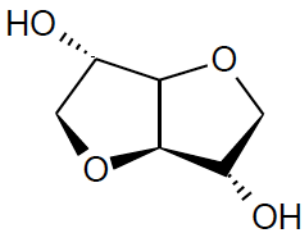

Isoidide

Figure 1: Different isomeric forms of 1,4:3,6-dianhydrohexitols sugar diols [12,59].

1,4:3,6-dianhydrohexitols based different polymers can be synthesized by step-growth polymerization or solution polycondensation method. For polymer synthesis acid chlorides are an attractive choice because of its high reactivity, since 1,4:3,6dianhydrohexitols based sugar diols have secondary hydroxyl groups that make it less reactive. As a monomer 1,4:3,6-dianhydrohexitols based sugar diols have interesting properties like non-toxicity and high rigidity that encourage its incorporation in biodegradable polymers to enhance the thermomechanical properties [12].

Okada et al. have reported a series of biodegradable polyesters based on 1,4:3,6dianhydrohexitols and various diacid chlorides with methylene units ranging from 2 to 10 (Figure 2). The polymers were synthesized by bulk polycondensation at $140-180{ }^{\circ} \mathrm{C}$ without catalyst. The polymers were collected after precipitation in methanol and high molecular weight lie in the range of $7000-30000 \mathrm{~g} / \mathrm{mol}$ were obtained. Various degradation studies such as soil burial, enzymatic degradation and hydrolytic degradation in presence of phosphate buffers were conducted to evaluate the degradability of the polymers [60-63].

Moreover, Kricheldorf et al. have reported the synthesis of biodegradable copolyesters based on silylated isosorbide and sebacoyl chloride [64-65]. Biodegradable polyesters and copolyesters having furan moieties were reported by Okada et al. where transesterification approach was employed and titanium isopropoxide was used as a catalyst. These polymers were synthesized in high molecular weight and their biodegradability was demonstrated by enzymatic degradation method [66-67]. Isosorbide base polymers were not only demonstrated biodegradability but also employed in bone tissue engineering as porous scaffolds [68]. Noordover et al. have reported on the another interesting property of 1,4:3,6-dianhydrohexitols based polyesters as a powder-coating resins [69-71]. 1,4:3,6-dianhydrohexitols based biodegradable poly(ester amide)s (Figure 2) were reported by Okada and Kricheldorf [72-73]. The method consist two steps, in the first step 1,4:3,6-dianhydrohexitols reacts with $\alpha$ amino acids in the presence of $p$-toluenesulfonic acid monohydrates. The second step is the polycondensation of $p$-toluenesulfonic acid salts of $0, O^{\prime}$-bis( $\alpha$-aminoacyl)-isosorbide with $\operatorname{bis}(p$ nitrophenyl)esters of aliphatic dicarboxylic acid. The polycondensation was carried in the presence of trimethylamine in NMP at $40{ }^{\circ} \mathrm{C}$ [73]. Okada et al. investigated the thermal properties and biodegradability of the synthesized poly(ester amide)s. These polymers were found amorphous in nature and different degradation method such as soil burial and enzymatic degradation method has confirmed the biodegradability and revealed its dependence over the molecular structure [72].

The biodegradability of the isosorbide based poly(esters carbonate)s were studied by Okada et al. [53] The copolymers were synthesized by polycondensation of isosorbide, diphenyl sebacate and diphenyl carbonate in the presence of $\mathrm{Zn}$ acetate catalyst. The biodegradability were determined by soil burial test and it was found that the polymers containing high amount of carbonate $(26 \%)$ degraded rapidly as compared to polymers containing less amount of carbonate (4\%) [74].

Yokoe et al. have published a series of paper describing synthesis and degradation of copolycarbonate based on 1,4:3,6-dianhydrohexitols [75-77]. In their work, at first sugar carbonates, namely 1,4:3,6-dianhydrohexitols diphenyl carbonates were synthesized followed by the bulk polycondensation with various alkanediols in the presence of $\mathrm{Zn}$ acetate and titanium tetraisopropoxide as catalyst. The copolycarbonates were synthesized in high molecular weight lie in the range of $10000-20000 \mathrm{~g} / \mathrm{mol}$ and their biodegradability were evaluated by the environmental and enzymatic degradation studies [77]. Moreover, Yokoe et al. have prepared polycondensates of 1,4:3,6- 


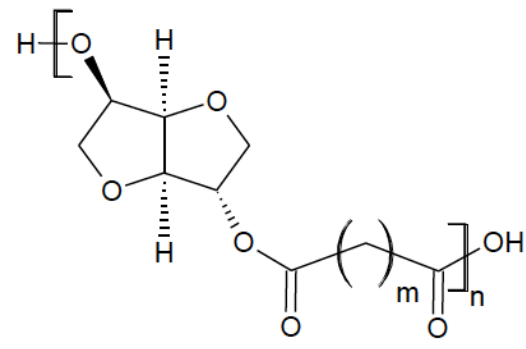

$m=2,3,4,5,6,7,8,10,12,14$

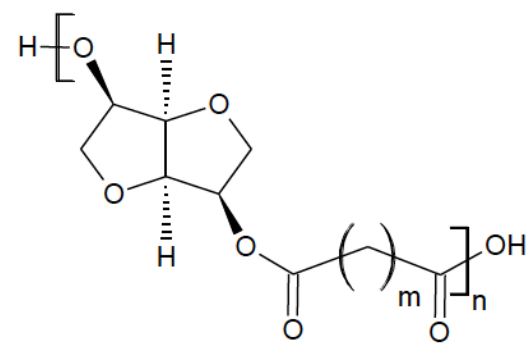

$m=2,3,4,8$

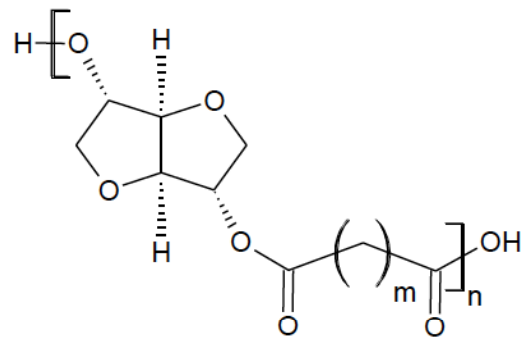

$\mathrm{m}=3,4,8$

1,4:3,6-Dianhydrohexitols based biodegradable polyesters

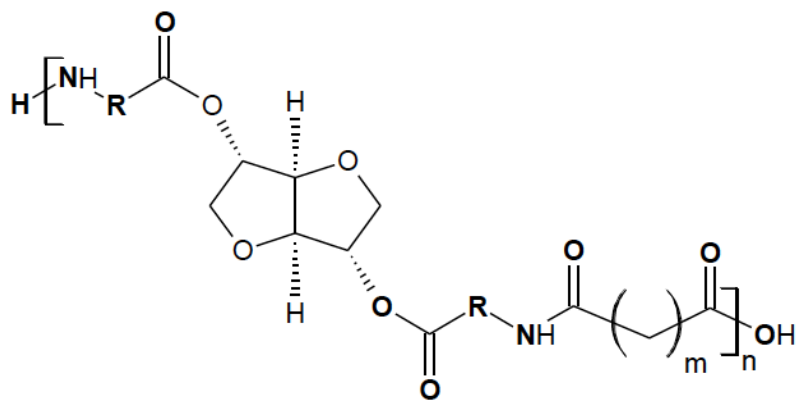

$\mathrm{m}=4,6,8,10$

\section{1,4:3,6-Dianhydrohexitols based biodegradable poly(ester amide)s}

Figure 2: 1,4:3,6-dianhydrohexitols based polyesters and poly(ester amide)s [72,73].

dianhydrohexitols and oligo(ethylene glycol)s. It was found that the polycondensates were amorphous in nature and $T_{\mathrm{g}}$ decreases with increasing chain length. The trend of biodegradation correlated with the $T_{\mathrm{g}}$ values and found that the polymers which are having high $T_{\mathrm{g}}$ as compared to the test temperature shown less degradability, because at the glassy state polymer chains remain less mobile [78]. Yokoe et al. have also synthesized a biodegradable functionalized polycarbonate based on L-tartaric acid and 1,4:3,6dianhydrohexitols. L-tartaric acid has introduced hydroxyl functionality as well as enhanced the biodegradability of the polycarbonates [79]. The functionalized polycarbonates were synthesized by a protection-deprotection method, in the first step hydroxyl groups of tartaric acid were protected with acetal groups and after polymerization acetal deprotection was employed using trifluoroacetic acid to generate a series of polycarbonate with pendent hydroxyl groups [80].

\subsubsection{Ring Opening Polymerization}

The ring opening polymerization of lactones is a striking method to synthesize aliphatic polyesters. This method has potential advantages relative to the condensation polymerization process. The former does 
not require equimolar balance of functional groups that is essential for the synthesis of high molecular weight polymer by the latter. Moreover, it shows the characteristics of a living polymerization, by this means a polymer with controlled molecular weight can be prepared. Ring opening polymerization has been widely used for the polymerization of cyclic esters and diesters, such as butyrolactone, valerolactone, $\varepsilon$ caprolactone, lactide and glycolide.

\subsubsection{Ring Opening Polymerization: Method and}

\section{Catalyst Systems}

Most commonly used mechanism is coordinationinsertion mechanism as ring opening polymerization proceeds in a 'living' manner. Although different kind of mechanisms for ring opening polymerization have been accepted this involves initiation by either an anionic, cationic, coordination-insertion or an activated monomer mechanism. Various metal alkoxides such as $\mathrm{Mg}, \mathrm{Sn}, \mathrm{Ti}, \mathrm{Zr}, \mathrm{Zn}$ alkoxides are used as catalysts where metal atoms contain free $p$ or $d$ orbitals of favorable energy involve in mechanistic pathway [8186].

The mechanism involves the coordination of the carbonyl oxygen of lactone to the Lewis acidic metal alkoxide complex as shown in Figure 3 [81]. Thereby the nucleophilicity of the alkoxide part as well as the electrophilicity of the carbonyl group increases. Subsequently, the alkoxide moiety attacks at the carbonyl carbon and the cleavage of the acyl-oxygen bond initiate the ring opening of lactone. It generates a new metal alkoxide species that can re-initiate the cycle [81, 83-84].

Different kind of metal complexes such as Sn (IV), Al (III), Zn (II), Fe (II), Ti (IV), and Y (III) have been found to be suitable for ring opening polymerization. In general, the catalyst employed for the ring opening polymerization mainly consists of organometallic compounds, lewis acids and different salts of metals [82, 84-94].

The tin complexes such as tin(II) 2-ethylhexanoate or stannous octoate $\left[\mathrm{Sn}(\mathrm{Oct})_{2}\right]$ is found to be efficient catalysts for ring opening polymerization of lactone since it gives high conversion of monomer with high yield and have low cost and low toxicity [95-97]. The other examples of catalysts explored for ring opening polymerization are titanium biphenoxy-alkoxide, tin alkoxides and phenoxides, aluminum alkoxides, zinc alkoxides, zinc lactate, yttrium and lanthanum alkoxides [77-79, 82-84].

\subsubsection{Functionalized Polymers from ROP}

Functional biodegradable polymers have attracted a great deal of attention, since it is the class of materials that combines the features of enhanced hydrophilicity, high degree of chemical functionality, tunable biodegradability and bioadhesion. These striking properties make these materials more suitable for applications such as controlled drug delivery and pharmaceuticals. Various functional aliphatic polymers by ring opening polymerization are shown in Chart 1.

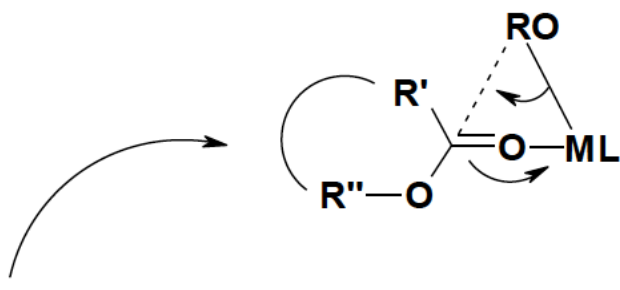<smiles>[R]OC(=[R])O[R]</smiles>

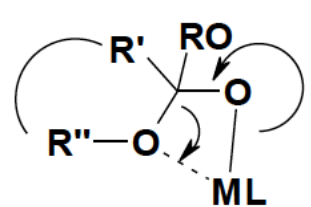<smiles>[R]O[R]CC[R]C(=O)O[R]</smiles>

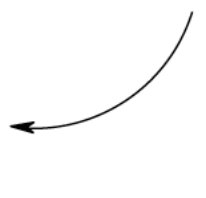

Figure 3: Generalized mechanism for ring opening polymerization [81]. 
<smiles>CCOC(=O)C[C@@]1(CC(=O)O)C(=O)C[C@@H](O)[C@@H]1O</smiles><smiles>CC(O)C(=O)OC(CCCCN)C(=O)O</smiles><smiles>CC(O)C(=O)OC(CCC(=O)O)C(=O)O</smiles><smiles>CCCCC(CCOCC(=O)O)C(=O)O</smiles><smiles>CC(C)CCC(O)CCOCCO</smiles><smiles>[CH]OCCC(CCC(C)=O)OC(=O)C(C)(CO)CO</smiles><smiles>CC(O)CCNCCOCCO</smiles><smiles>CCOCC(C)(CCl)C(=O)CC(C)(C)O</smiles><smiles>CC(=O)CCC(=O)CCOCCO</smiles><smiles>CC(=O)CCC(O)CCOCCO</smiles><smiles>COCCC(CCC(C)=O)OC(=O)C(C)(C)Br</smiles><smiles>C=CC(=O)OC(CCOCC)CCC(=O)O</smiles>

Chart 1: Various functional aliphatic polymers by ring opening polymerization [77-87].

The synthesis of glycolide based poly(ester) with pendant carboxylic acid by the ring opening polymerization of 3(S)-[(benzyloxycarbonyl)-methyl]1,4-dioxane-2,5-dione have been reported. A benzyl deprotection method was employed to generate carboxylic groups alone the polymer chain that enhanced the rate of polyester hydrolysis as compared to PLA [98-99]. Trollsas et al. were prepared PCLs with pendent carboxylic acids by the ring opening polymerization of benzyl $\mathrm{y}$-( $\varepsilon$-caprolactone)carboxylate followed by acid deprotection [100].

The side-chain-functionalized lactide analogues from commercially available amino acids have been synthesized and the resulting functionalized cyclic monomers can be homopolymerized and copolymerized with lactides using stannous octoate as a catalyst. A quantitative deprotection approach gave new functional poly(lactide)-based materials with amino, hydroxyl or carboxyl side chains along a poly(lactide) [98, 101].

Tian et al. have reported a series of papers on the synthesis of aliphatic polyesters having keto group by the ring opening polymerization of 5-ethylene ketal $\varepsilon$ caprolactone followed by deprotection [102-105]. Moreover, Tian et al. have also demonstrated that the keto groups were reduced into hydroxyl groups by using $\mathrm{NaBH}_{4}$ resulting in the aliphatic polyester with hydroxyl pendent groups [103].

Liu et al. synthesized a chloro-substituted lactone ( $\alpha$-chloromethyl- $\alpha$-methyl- $\beta$-propionolactone) and polymerized with $\varepsilon$-caprolactone. Subsequently, these chloro functionalized polymers were reacted with pyridine to convert chloromethyl groups into quaternary ammonium salts [106]. Hedrick et al. were reported on the synthesis of aliphatic polyesters with pendent 
bromide groups by the ring opening polymerization of bromo substituted cyclic ester $\mathrm{Y}$-(2-bromo-2-methyl [propionyl)- $\varepsilon$-caprolactone [107].

Aliphatic polycarbonates show biodegradability, biocompatibility and low toxicity, which are essential requirement for biomaterials. Furthermore, presence of functional groups along the polycarbonate chain can make these materials a potential candidate for biomedical filed. Al-Azemi et al. have reported on the synthesis of water soluble polycarbonates having pendent carboxylic groups by enzyme-catalyzed ringopening polymerization of 5-methyl-5benzyloxycarbonyl-1,3-dioxan-2-one. Catalytic hydrogenation to remove benzyl groups yields polycarbonate having pendent carboxyl substituents on the main chain [108]. Liu et al. have also reported on carboxyl functionalized polycarbonates by ring opening polymerization of cyclic carbonate monomers, 5methyl-5-methoxycarbonyl-1,3-dioxan-2-one and 5methyl-5-ethoxy carbonyl-1,3-dioxan-2-one [109]. Aliphatic polycarbonates, poly(ester-carbonate)s with pendent amino groups and water soluble polycarbonates with pendent amino and carboxylic groups were reported by using ROP [110-112].

Moreover, Wang et al. have reported on the hydroxyl functionalized polycarbonate by the ring opening polymerization of 5-benzyloxy-trimethylene carbonate followed by the benzyl deprotection [113]. Yang et al. synthesized a biodegradable aliphatic poly(ester-carbonate) bearing functionalizable carbonate building blocks [114]. Guan et al. have reported on the biodegradable block copolymer with pendent carboxyl groups based on L-lactide, 2-methyl2-benzoxycarbonyl-propylene carbonate, poly(ethylene glycol) using diethyl zinc as a catalyst [115]. Also, many researchers for example, Xie et al., Hu et al., and Xie et al. have synthesized different functionalities with carboxyl, cinnamate and hydroxyl functionalities, respectively [116-118]. The poly(ester-carbonates) synthesized by Xie et al. have photolablie 2-nitrobenzyl protecting groups which deprotect on the application of UV irradiation [116].

Various groups have reported on the synthesis of aliphatic polycarbonate with pendent groups having double or triple bond. For example the synthesis of a biodegradable aliphatic poly(L-lactide-co-carbonate) bearing pendant acetylene groups prepared by ringopening copolymerization of L-lactide with 5-methyl-5propargyloxycarbonyl-1,3-dioxan-2-one in the presence of benzyl alcohol as initiator with $\mathrm{ZnEt}_{2}$ as catalyst [119-121].
Chen et al. reported a functional polycarbonate with cyclohexene side chains by the ring opening polymerization of 2,2-(2-pentene-1,5-diyl)trimethylene carbonate using various organometallic catalysts [119]. $\mathrm{He}$ et al. reported on the synthesis of a functional polycarbonate with pendent allyl ether groups by the ring opening polymerization of a six-membered cyclic carbonate, namely 5-allyloxy-1,3-dioxan-2-one. Moreover, a post-polymerization approach was employed for the epoxidation of allyl groups by $m$ chloroperoxybenzoic acid [121].

\subsubsection{Other Developments in Functionalized Polymers \& Combination of Different Methodologies}

Cunningham et al. reported on a novel stimuli responsive tri-block copolymer PEG-b-(PLA-ss-PLA)-bPEG (ssBCP) consisting of polyethylene glycol (PEG) and polylactic acid (PLA) by combining facile carbodiimide coupling reaction and ring opening polymerization. Glutathione reducing agent causes an increase in the micelle size and enhanced reductive bond cleavage in the co-polymer thus, aiding in drug release. The micelles have PEG corona thereby, improving the interaction tendency and colloid stability [122].

Xu et al. used novel mPEG based macroinitiatiors to synthesize PLA via ring opening polymerization to give $\mathrm{pH}$ stimuli sensitive and amphiphilic co-polymer (mPEG-Hyd-PLA). The polymer was loaded with 2.4$3.5 \%$ of two drugs namely Doxorubicin (DOX) and paclitaxel (PTX). These polymers exhibited $\mathrm{pH}$ sensitivity by the cleave-dissociate-release process and have applications in drug delivery [123]. Petrova et al. prepared a novel triblock co-polymer. The first step was the modification of a-methoxy- $\omega$ hydroxypoly(ethylene oxide) (MPEO) with p-toluenesulfonyl chloride. Second step was to form a hydrophilic diblock polymer MPEO-b-PEtOx via ring opening polymerization of 2-ethyl-2-oxazoline (EtOx) using tosyl-MPEO as the macroinitiator. In the final step, the double hydrophilic triblock co-polymer was formed by carry out polymerization of $\varepsilon$-caprolactone via ring opening polymerization using the diblock co-polymer as the macroinitiator. Further, self-assembling, thermosensitive nanoparticles were synthesized using the synthesized polymer which find application in biomedical field [124].

Recently, studies have been reported on biodegradable polymers prepared through combination of two different methodologies namely, ROP and 
ATRP. Xiong et al. combined two polymerization techniques, continuous activators regenerated by electron transfer atom transfer radical polymerization (ARGET ATRP) and ring opening polymerization to synthesize a novel $\mathrm{pH} /$ redox stimuli-responsive and amphiphilic cross-linked polymer [poly( $\varepsilon$-caprolactone)b-poly(poly(ethylene glycol) methyl ether methacrylateco-p-(2 methacryloxyethoxy) benzaldehyde) $]_{4}$ [4-ASPCL-P(PEGMA-co-MAEBA)]. The polymer have application in insoluble chemotherapeutic delivery for cancer treatment [125].

Wang et al. combined ring opening polymerization to give PLA and atom transfer radical polymerization to give further hydrogentation with $\mathrm{Pd} / \mathrm{C}$ under normal pressure to synthesize block co-polymer poly(lactic acid)-block-poly(ascorbyl acrylate) (PLA-block-PAAA) consisting of hydrophobic poly(lactic acid) and hydrophilic poly(ascorbyl acrylate) (PAAA). The polymer exhibited self-assembling and amphiphilic properties [126]. Guo et al. used N-isopropylacrylamide (NIPAAm), tert-butyl methacrylate (tBMA) and caprolactone $(C L)$ via ring opening polymerization (ROP) and atom transfer radical polymerization (ATRP) to synthesize self-assembling stimuli responsive support materials for pectinase enzyme immobilization by electrostatic interaction [127].

Many researcher have recently worked on in-situ ROP methodology for novel biodegradable polymers. Kim et al. synthesized novel honeycomb patterned thin films using a composite of poly( 3-caprolactone) matrix and reinforced with oleic acid-capped magnetic nanoparticles via in-situ ring opening polymerization followed by solution casting. The synthesized films find application in molecular electronics in the film form [128]. Mao et al. prepared layered double hydroxides (LDHs) /PCL nanocomposites by carrying out in situ ring opening polymerization to form LDHs-g-PCL followed by solution casting of the blend film containing LDHs-g-PCL and pure PCL films under humid conditions. These synthesized films can be effectively used as packaging material due to the enhanced physical and biodegradation properties [129]. Park et al. used in situ ring opening polymerization using tin(II) octoate as an initiator followed by solution casting method under humid conditions to synthesize novel photosensitive honeycomb pattern composite films containing PCL and 4-dimethylamino-40-(6-hydroxy hexyloxy) azobenzene (Azo) [130].

Recently researcher have also reported novel catalysts for ROP to produce biodegradable polymers.
Yuan et al. synthesized a novel catalyst, complex of cerium (IV) diolate, to polymerize $\varepsilon$-caprolactone with narrow molecular weight distribution. The catalyst was formed using a core of 13-nuclear cerium (IV)-oxo and a shell of $18 \mathrm{~N}$-phenylaminedienthanolate [131]. Njogu et al. carried out ROP of $\varepsilon$-caprolactone using a novel catalyst of the composition $\left[\left(\mathrm{AgO}_{2} \mathrm{C}_{2} \mathrm{~F}_{3}\right)_{2} \cdot \mathrm{L}_{2}\right]$ formed by reaction of 2-pyridinyl Schiff base ligands with $\mathrm{AgO}_{2} \mathrm{C}_{2} \mathrm{~F}_{3}$ to form silver based complexes. The ligands used for this purpose were prepared by a mechanochemical technique which formed coordination bonds with silver (I) using nitrogen atoms in imine and pyridinyl [132]. Roymuhury et al. used novel complexes of dimethyl aluminium containing bidentate aminophenolate ligands as a catalyst to polymerize Llactide and rac-lactide via ring opening polymerization [133]. Rosen synthesized hexablocks of poly(lactic acid) of defined lengths through ROP using a novel magnesium based catalyst. The catalyst used had a bipyrrolidine backbone which was in a complex with benzyl magnesium chloride. Thus, a tailor made polymer with modifiable properties was synthesized [134].

Phillips et al. have reported a high molecular weight biodegradable polymers derived from RAFT (Reversible Addition Fragmentation Chain Transfer) polymerization. The biodegradable polymers with pyridyl disulfide end-group were prepared and the described method have the applicability to polycondense a variety of monomer having functionalities such as (meth)acrylates and acrylamides [135]. Gatti et al. have reported the controlled radical polymerization of 2-hydroxyethyl methacrylate functionalized with a controlled no. of $\varepsilon$-caprolactone units through RAFT polymerization. The method allows a good control over the molar mass of the final polymer with a low PDI and polymer solution produces nanoparticles suitable for drug delivery applications [136]. Hu et al. have reported a light responsive copolymer poly(spiropyrane)-block-poly(ethylene glycol) based on RAFT polymerization. The copolymer has the ability to self-assemble into spherical micelles and the light controlled released was studied as well. The spherical micelles of copolymers have a potential application in drug delivery [137]. Sponchioni et al. have reported a thermo responsive amphiphilic block copolymers via RAFT and ROP polymerization. The copolymers possess a temperature dependant selfassembly behaviour that forms nanoparticles at temperature below lower critical solution temperature and have potential application in drug release [138]. 
Cui et al. have prepared biodegradable and $\mathrm{pH}$ responsive polymer capsules through silica particles as templates for surface grafting of poly (acrylic acid) (PAA) and PAA-co-poly(polyethylene glycol) acrylate) (PAA-PPEGA) block polymers via RAFT polymerization. The reported capsules were non-toxic, water soluble and biocompatible and have application in controlled drug release [139]. Guégain et al. have reported two class of degradable polymers, first based on methyl methacrylate (MMA) and 2-methylene-4phenyl-1,3-dioxolane (MPDL) and second based on oligo(ethylene glycol) methyl ether methacrylate (OEGMA) and MPDL through NMP and ROP polymerization. The tenable degradation studies of copolymers P(MMA-co-MPDL) and P(OEGMA-coMPDL) have been carried out and have application in controlled drug delivery [140]. Kukut et al. have reported a biodegradable microspheres based on graft copolymers for long-term sustained release of a drug. The graft copolymers prepared by combination of NMP and ROP polymerization and have polystyrene backbone and pendant chain of I-lactic acid and glycolic acid [141].

\subsubsection{Enzyme Catalyzed Polymerization}

Enzyme is a sophisticated biocatalyst with threedimensional structure that catalyzes a bio-chemical reaction with high efficiency and selectivity. Enzyme catalyzed polymerization can be either step polymerization or ring opening polymerization. However, here it has been discussed separately, since enzyme catalyzed polymerization has its distinct characteristics. Enzyme catalyzed polymerization offers several advantages over chemical catalysis since in latter process various organometallic catalysts are used which are hazardous in biomedical applications. Various advantages of an enzyme catalyzed polymerization are listed below [142-143].

1. The resultant polymers are obtained with high enantio and regio selectivity with a good substrate conversion efficiency

2. Enzyme catalyzed polymerizations end up with polymers having well-defined structures

3. The polymerization is carried out under mild reaction conditions i.e. temperature, pressure and $\mathrm{pH}$

4. The removal of enzymes from resultant polymers is not very necessary since enzymes are recyclable and non-toxic materials
5. The polymerization can also be carried out in bulk media, organic media and various interfaces

The enzyme catalyzed reaction takes a long reaction time to achieve a complete conversion of monomer. Generally, low molecular weight polymers are obtained in this method with a low polydispersity index. An enzyme catalyzed polycondensation reactions involves three step: first step is a initial rapid transesterification, followed by the second step that involves a significant increase in molecular weight and finally third step that is a very slow polymerization reaching the limiting molecular weight of the polymer [142-144].

The enzyme catalyzed ring opening polymerization initiate with a complex formation between carbonyl oxygen and enzyme followed by the ring opening that leads to the formation of the acyl-enzyme intermediate or enzyme-activated monomer. This is a rate determining step of enzyme catalyzed ring opening polymerization. This step is followed by the propagation step where, hydroxyl group of monomer undergo in a nucleophilic attack on the enzyme-activated monomer and thus the incorporation of monomer is started and regenerate the active centre for next monomer unit [142-143, 145-146].

\subsubsection{Enzyme Catalyzed Polycondensation Reactions}

A variety of polyesters have been synthesized using different diacids and diols by enzyme catalyzed polycondensation reactions. Kobayashi at. el. have synthesized a lipase catalyzed low molecular weight polymer using sebacic acid and 1,8-octanediol [147]. Aliphatic polyesters under mild conditions have been synthesized by Tsujimoto et al. using divinyl sebacate or adipate with glycerol. This study revealed that such polymerizations provide high yield and molecular weight when carried out under reduced pressure [148]. Mahapatro at. el. have prepared polyesters using linear hydroxyacids of variable chain length catalyzed by Novozyme-435, where it was found that present of water in the polycondensation system facilitated to increase the molecular weight [149]. Moreover, Iwata et al. have demonstrated that polymerization of caprolactone with 11-mercapto undecanoic acid and 3mercapto propionic acid yield polyesters containing thioester groups using Novozyme-435 [150].

2.2.4.2. Enzyme Catalyzed Ring-Opening Polymerization

Enzyme catalyzed ring-opening polymerization is one more attractive way to prepare various kinds of 
new biodegradable polymers by ring opening of lactones, lactides and macrolides. Panova et al. have synthesized novel polymers based on propyl malolactonate, a four membered lactone in the presence of candida rugosa lipase, using toluene as a solvent. The study revealed that rate of polymerization enhanced when reaction carried out at 45 or $60^{\circ} \mathrm{C}$ as compared to room temperature [151].

Uyama et al. have demonstrated that the initial rate of polymerization depends on the ring size of the monomer and found it increased with increase in ring size. The polymerization of 13-membered lactone carried out much faster as compared to caprolactone. Also, a high temperature $\left(75^{\circ} \mathrm{C}\right)$ facilitated to achieve polymer with high molecular weight [152]. Kumar et al. have synthesized diblock copolymers using lipase catalyzed polymerization. In this study ring opening polymerization of lactone were carried out in the presence of novozyme-435, using toluene as a solvent. Where mono-terminate hydroxyl groups of polybutadiene of varying chain length were employed as an initiator for ring opening that resulted in a series of diblock copolymers [153].

2.2.4.3. Factors Influence the Enzyme Catalyzed Polymerization

Various reaction parameters like water content of reaction, solvent, enzyme concentration, temperature, and source of enzyme have crucial effect over the molecular weight of the synthesized polymers [142143]. The conformational flexibility of an enzyme regulates by the water bound to the enzyme surface or the reaction water content of the enzyme catalyzed polymerization. The researchers have demonstrated that the rate of monomer conversion increased with increases in water content. However, after a certain range of water content the number average molecular weight of the product decreased with increases in water content [142-143, 154].

Solvent has a vital role in an enzyme catalyzed polymerization since it determines the enzyme stability and regulates the screening of substrates and products. Moreover, the rate of polymerization depends on the solubility and viscosity of the monomers and resultant polymer in a particular solvent. Since it determine the conformation and diffusivity of the polymer in the solution, which alter the reactivity towards an activated monomer or chain end. The nature of solvent is also a decisive factor for the enzyme catalytic activity. For example, hydrophilic solvents deprive the hydration water from the enzyme, thereby disfigure the catalytic conformation and reduce the enzyme catalytic activity. On the other, hydrophobic solvents allows the water to remain over the enzyme surface, thus retain enzyme catalytic activity [142-143].

Different researchers have studied the effect of enzyme concentration on the rate of polymerization [147]. It has been found that the increasing the enzyme concentration increases the rate of monomer conversion but at the same time decreases the number average molecular weight of the polymer. The effect of temperature on the rate of enzyme catalyzed polymerization depends on the thermal stability of the enzyme at that temperature. Various methods such as immobilization of enzyme and selection of solvent provide possibility to drive an enzyme polymerization at elevated temperatures. The effect of temperatures ranging from 60 to $105{ }^{\circ} \mathrm{C}$ on caprolactone polymerization has been studied by the Gross at al. and demonstrated that the rate of monomer conversion increased with an increase in temperature [155-156].

\section{PHYSICAL PROPERTIES OF BIODEGRADABLE POLYMERS}

This section describes the physical properties of most widely used biodegradable polymers derived from nature for example cellulose and starch and synthesized in laboratory such as poly(glycolide), poly(L-lactide), poly( $\varepsilon$-caprolactone), poly(butylene succinate), etc. There are various factors which govern the physical properties of biodegradable polymer for example, composition of the repeat units, flexibility of the polymer chains, presence of polar groups, degree of branching, molar mass, crystallinity, orientation, etc.

Cellulose $\left(\mathrm{C}_{6} \mathrm{H}_{10} \mathrm{O}_{5}\right)_{n}$ is a polysaccharide containing a linear chain of ringed glucose molecules with 1-4 glycoside linkages and exists in interchangeable crystalline structures. It has a unique ribbon-like conformation. Starch is semi-crystalline polysaccharide containing glycoside linkages consisting of branched amylopectin as well as helical and linear amylose [157].

Poly(glycolide) is a simplest linear aliphatic polyester in terms of chemical structure. It is thermoplastic crystalline material with a degree of crystallinity lie from $45-55 \%$. PGA is insoluble in the most of the organic solvents, however it can be dissolved in fluorinated solvents such as hexafluoroisopropanol and hexafluoroacetone. It has a $T_{\mathrm{g}}$ of $36-40{ }^{\circ} \mathrm{C}$ above room temperature and a very high $T_{\mathrm{m}}$ of $220-225^{\circ} \mathrm{C}$. The low solubility and high $T_{\mathrm{m}}$ of 
PGA limits its application in drug delivery devices [85$86,158]$

Poly(L-lactide) (PGA) is semicrystalline thermoplastic polymer. Since lactic acid has a chiral nature, therefore the properties poly(lactide)s depend on the stereoisomer used for their preparation. For example, poly(L-lactide) and poly(D-lactide) are semicrystalline material whereas poly(DL-lactide) is an amorphous polymer. It has a degree of crystallinity of $37 \%$ and soluble in halogenated hydrocarbons, tetrahydrofuran, dioxane, hot benzene etc. Poly(Llactide) is a white fibrous material with a $T_{\mathrm{g}}$ of $55-65^{\circ} \mathrm{C}$ and $T_{\mathrm{m}}$ of $160-180{ }^{\circ} \mathrm{C}[81,84-86,158-162]$.

Poly( $\varepsilon$-caprolactone) is a tough, semicrystalline polymer with a degree of crystallinity of $50 \%$. PCL drew much attention as a biomaterial due to its flexibility that combines with biodegradability. It has a $T_{\mathrm{m}}$ of $60{ }^{\circ} \mathrm{C}$ and $T_{\mathrm{g}}$ of $-60{ }^{\circ} \mathrm{C}$ and can be employed in injection molding, extrusion, and film blowing. It is a potential candidate for controlled drug release applications, since it has low $T_{\mathrm{m}}$ and show permeability to low molecular species $[85-86,158]$.

Poly(butylene succinate) (PBS) is a white crystalline thermoplastic with a crystallinity of $57 \%$. It is soluble in halogenated hydrocarbons, DMSO, DMF, THF, dioxane, etc. It has good processability with a $T_{\mathrm{g}}$ of -37 ${ }^{\circ} \mathrm{C}$ and $T_{\mathrm{m}}$ of $116{ }^{\circ} \mathrm{C}$. It can be processed in various molded product, for example, injected, extruded and blown materials [163]. Figure 4 schematically represents the salient physical properties of widely used biodegradable polymers.
Poly(butyrate adipate -co-butylene terephthalate) (PBAT) is a random copolymer which has low crystallinity, thus, exhibiting high flexibility and toughness properties. The $T_{\mathrm{g}}$ value for PBAT are reported to be -30 to $-35{ }^{\circ} \mathrm{C}$ and has a wide melting point range from $110-120^{\circ} \mathrm{C}$ [164].

Some other examples of aliphatic biodegradable polyesters are poly(1,4-dioxan-2-one) and poly(1,5dioxapan-2-one) which include both ester and ether linkages. The former is a crystalline material whereas latter is amorphous. Poly(1,4-dioxan-2-one) has good tenacity, flexibility and elasticity similar to those of human tissues that make it a potential material for biomedical applications. In contrast, poly(1,5-dioxapan2-one) is a sticky and gel like material at body temperature [85-86].

\section{WATER SOLUBLE BIODEGRADABLE POLYMER}

Water soluble polymers are a distinct class of biodegradable polymers having biomedical applications due to their enhanced biodegradability. The most versatile example of such kind of polymers is Poly (vinyl alcohol) (PVA). Many other polycarbonates, polyester-carbonates and polyesters are also reported as water soluble polymers. PVA is a biodegradable, semi-crystalline thermoplastic polymer with a high hydrophilic character due to the ability of forming hydrogen bonding with water molecules. PVA has good thermal stability and chemical resistance but highly hydrophilic characteristics results in poor mechanical and barrier properties. To make such polymers appropriate for packaging applications their blends

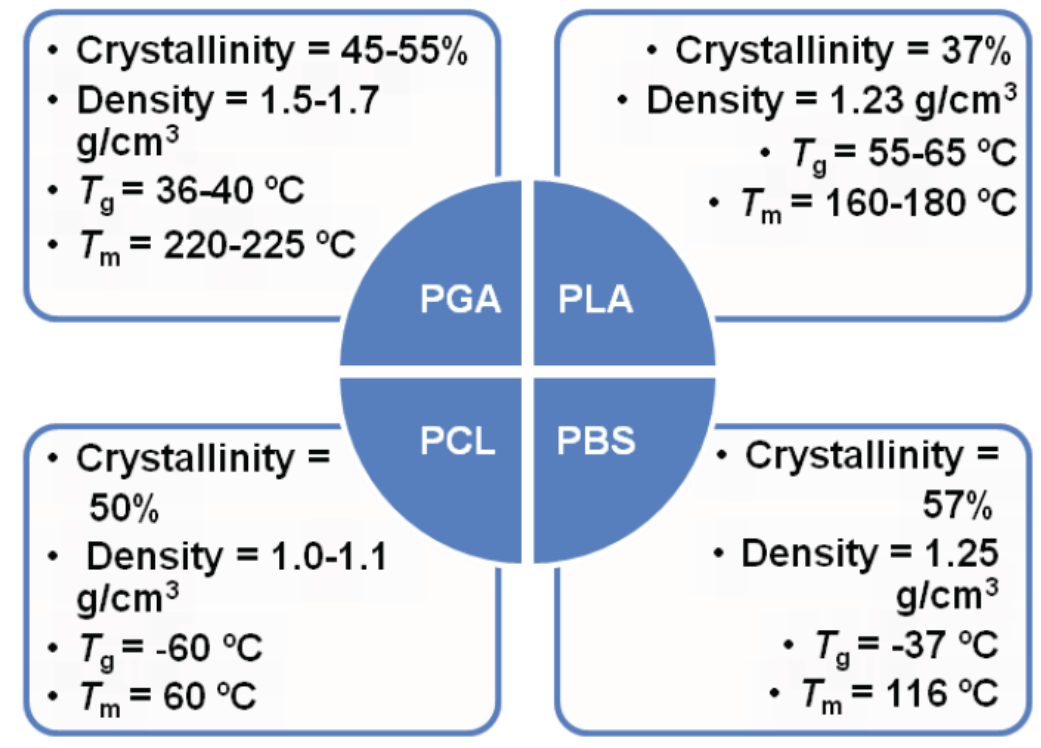

Figure 4: Physical properties of widely used biodegradable polymers [85-86, 158-162]. 
have been made incorporating fillers such as cellulose etc. that improves its physical and barrier properties. This section emphasized on the polymers, blends and composites of water soluble polymers that make them different from other non-water soluble biodegradable polymers in-terms of properties and degradation pattern.

Rashid et al. synthesized environment friendly packaging material from blends of carboxymethyl cellulose (CMC) and poly (vinyl alcohol) (PVA) using casting method. CMC is a cellulose ether and a copolymer of b-D-glucose and b-D-glucopyranose 2-O(carboxymethyl) monosodium salts. In this work CMC/PVA blend films with and without $\mathrm{HCl}$ with different compositions were prepared and films have shown good biodegradability [165]. Moreover, PVA and CMC bioactive films prepared by Fasihi et al. and stabilized them via a Pickering emulsion to improve its antioxidant and antimicrobial properties. The polymer blend was emulsified with oleic acid (OE) and incorporated with rosemary essential oil (REO). Essential oils contain phenolic and terpenoid compounds, which show high antimicrobial properties. Therefore, the application of essential oils in active packaging is important in-view of preservative free foods and its packagings to control the microbial growth of food products [166].

An electrospinning technique was adopted by Chahal et al. for nanofibers from modified cellulose (MC) and polyvinyl alcohol (PVA) for a scaffolding material in bone tissue engineering. PVA present in the blend increased the spinnability as well as improved the mechanical and thermal properties of the nanofibers. As the percentage of PVA in the nanofibers decreased, the crystallinity of the nanofibers decreased, thus, making them suitable for scaffolding applications. The nanofibers are non-woven in nature, thus, the pores are interconnected making the nanofibers suitable for cell attachment and nutrient transfer [167].

A biodegradable polymer blends containing cellulose and PVA has been synthesized by Hameed et al. using solvent as an ionic liquid, 1-butyl-3methylimidazolium Chloride (BMIM)Cl which can be used for food packaging applications. In this work cellulose and PVA were dissolved in the ionic liquid separately and then mixed followed by the precipitation in excess of ethanol. Ionic liquid is soluble in ethanol and recover afterwards. The blends were made in the form of films, rectangular blocks and fibres and out of the three forms, the film showed optical transparency over the entire film composition. (BMIM)Cl was recycled in this process thus making it eco-friendly and cost-effective [168].

Qiu et al. synthesized biodegradable composites containing microfibrillated cellulose (MFC) suspension and PVA which can be used as a substitute for nonbiodegradable plastics. Glyoxal is considered to be a suitable crosslinking agent for the blend due to its low toxicity and good biodegradability. Glyoxal was added to the blend to make PVA partially insoluble and to give chemical crosslinking between pure PVA, pure MFC and MFC-PVA to improve the mechanical and thermal properties of the blend. MFC were obtained by shearing and homogenization processes carried over cellulose fibres thus giving short length MFCs. It was demonstrated that nanofibrillated and microfibrillated cellulose caused inhibition to crystallization of PVA [169].

Susane et al. synthesized composites containing polyvinyl alcohol (PVA) and reinforcement material such as cellulose in trifluoroacetic acid (TFA) which acts a plasticizer. The blend formed has hydrogen bonds between hydroxyl groups present in the polymers which gives well blended composites. TFA tends to react with the hydroxyl groups present in the cellulose to give trichloroacetate derivatives and solubilizes cellulose. Hence, the intermolecular and intramolecular hydrogen bonds between the cellulose molecules break and hydrophobicity of the composite increases. Thus, produced composites can be used as hydrophobic plastics or films [170].

The composite films for food packaging application using PVA, chitosan and cellulose nanocrystals (CNC) prepared by $\mathrm{E}$. Fortunati et al using solvent casting method. The nanocrystals used were derived from barley straw and husk using two different techniques, enzymatic and chemical alkaline pretreatment followed by acid hydrolysis. The composite have applications as food packaging material [171].

Robert et al. prepared two biodegradable polymer blends containing cellulose acetate (CA) and two water soluble polymers, namely, bio-sourced hydroxyethyl cellulose (HEC) and PVA. Plasticization of CA was carried out by triacetin, PVA by glycerol and that of HEC using a two-step method with an appropriate plasticizer to achieve better properties and processability [172]. 
The degradation pattern of PVA has enzymatic degradation methodology where due to the presence of dehydrogenase and oxidase enzymes, PVA initially undergoes specific oxidation of 1,3-hydroxyl groupsto give (beta)-hydroxilketones and 1,3- diketone moieties. Then the moieties undergo carbon-carbon bond cleavage due to the presence of specific (beta)diketone hydrolase to give methyl and carboxyl ketone end group compounds [173].

Many researchers have reported on water soluble polycarbonates having applications in biomedical field. Wang et al. reported on a functionalized water soluble polycarbonate useful for biomedical applications. The reported polymers are amorphous in nature and soluble in water and most of the organic solvent and have relatively faster hydrolytic degradation rate [174]. Lee at el. reported on water-soluble poly(estercarbonate) having pendent amino and carboxylic groups on the main-chain carbon through melt ringopening/condensation reaction of trans-4-hydroxy-Nbenzyloxycarbonyl-L-proline (N-CBz-Hpr) with 5methyl-5-benzyloxycarbonyl-1,3-dioxan-2-one (MBC). The author studied the effects of monomer compositions on the glass-transition temperature. The values of $T_{\mathrm{g}}$ of the copolymers depended on the molar fractions of cyclic carbonate and it is reported that decrease in cyclic carbonate fraction increases the $T_{\mathrm{g}}$. [112]. Zhang et al. reported on a water-soluble polycarbonate poly(2-dimethylaminotrimethylene carbonate) with dimethyl amino pendant groups using Novozym-435 as a catalyst through ROP of six membered monomer dimethylaminotrimethylene carbonate. The authors studied the in vitro cytotoxicity assay that showed polycarbonate with low cytotoxicity [175].

A novel class of water soluble polyesters are reported by Dhamaniya et al. based on tartaric acid derivatives. The hydroxyl functionalized polymers are soluble in water and solubility vary with the diol chain length in polymer structure. These polymers could have applications in controlled drug delivery [58].

\section{BIODEGRADABLE POLYMERS BASED ON $\mathrm{CO}_{2}$}

$\mathrm{CO}_{2}$, a greenhouse gas significant contribution to air pollution and also has a sizable contribution to global warming and greenhouse effect. Therefore, utilizing and thus, consuming $\mathrm{CO}_{2}$ through various process has been one of the primary research topics recently. Carrying out copolymerization $\mathrm{CO}_{2}$ as a monomer along with epoxides to give biodegradable polycarbonates has been considered to be one of the solutions to this problem. The use of epoxide has proven to make the polymer multi-functional. Double metal cyanide complexes have been commonly used as a catalyst for polymerization, however, novel catalysts have also been put in use for this purpose. The use of epoxides for various catalysts, reaction conditions or additional monomers have been used for polymerization in order to improve the polymerization efficiency, to improve the biocompatibility and biodegradability or to make the polymer suitable for diversified applications in electronics, biomedical or other allied fields. This section have the methods, catalysts used for polycarbonate synthesis as well as various blends formed by the $\mathrm{CO}_{2}$ based polymer with other biodegradable polymers and their applications [24, 176-177].

Kim et al. prepared polycarbonates by copolymerizing $\mathrm{CO}_{2}$ and several epoxides, in the presence of double metal cyanide (DMC) as the catalyst. However, it was demonstrated DMC is a more suitable catalyst for copolymerization for epoxides of alicylic oxide type rather than the alkylene oxide type [21]. On the contrary, a series of novel catalysts based on Chromium Schiff complexes were used by Niu et al. to carry out alternate co-polymerization of racemic propylene oxide along with carbon dioxide in the presence of (4-dimethylamino) pyridine to produce polycarbonates. The catalyst when subjected to $40{ }^{\circ} \mathrm{C}$ and under $1.5 \mathrm{MPa}$ with the binary catalyst system molar ratio of $1: 1$ during the reaction gave maximum efficiency. When N,N'-bis(3,5-di-tert-butylsalicylidene)1,2-phenylenediamino chromium III $\left(\mathrm{NO}_{3}\right)$ was used as a catalyst, product with highest selectivity was obtained, whereas, N,N'-bis(3,5-dichlorosalicylidene)1,2-phenylenediimino chromium III $\left(\mathrm{NO}_{3}\right)$ catalyst gave highest activity during polymerization [178].

Moreover, polymerization of carbon dioxide and cyclohexane oxide was carried out by Cuesta-Aluja et al. using two catalysts, namely, 5,10,15,20-tetra(2,6difluorophenyl)porphyrinatomanganese(III) acetate complexes and 5,10,15,20-tetra(2,6 dichlorophenyl) porphyrinatomanganese(III) acetate to give poly(cyclohexane carbonate). Co-catalyst was not used for the polymerization. The catalysts were highly effective for both, cyclo-addition of terminal epoxides with high selectivity with $\mathrm{CO}_{2}$ using substrates such as epichlorohydrin, propylene oxide, styrene oxide and 1,2-epoxytetradecane as well as for selective copolymerization of cyclic epoxides with $\mathrm{CO}_{2}$. The author also suggested that the presence of halogen 
atom in the catalyst can be one of the reasons for the good performance of the catalyst [22]. Another novel catalyst was used by $\mathrm{Lu}$ et al. to carry out polymerization of $\mathrm{CO}_{2}$ and a mixture of racemic epoxides to produce propylene carbonates. A catalyst based on chiral salenCo-(III)/quaternary ammonium halide was used and it was proven that the catalyst action was effective giving a good yield. Since, mild conditions were prevalent in the system and no organic solvent was used for the reaction, the polymerization reaction was considered to be environment friendly [23].

Liu et al. also used a new catalyst to polymerize a copolymer containing $\mathrm{CO}_{2}$ and four epoxides to give poly (vinyl cyclohexene carbonate) (PVCHC). The four epoxides used were cyclohexene, allyl glycidyl, propylene oxide and 4-vinyl-cylcohexene-1,2-epoxide. The catalyst was basically based on (3,3'dithiodipropionic acid) DTDPA starter along with (salen) CoTFA/[bis(triphenylphosphine)iminium ([PPN]TFA) binary system. The synthesized polymer can be further sulphonated to make the polymer suitable to be used as a polymer surfactant. The disulphite bond in the sulphonated PCCMA polymer can be broken under mild reductive conditions, thereby, making the polymer redox responsive in nature [179].

Synthesis of novel biodegradable polycarbonates using $\mathrm{CO}_{2}$ along with soyabean oil-based terminal epoxides (SOTE) was reported by Chang et al. Several additives such as epichlorohydrin and soap in the ratio of $17.3: 1$ along with $2.4 \%$ cetyltrimethylaluminium bromide (CTAB) (taken with respect to $1 \mathrm{~mol}$ soap) were added during the reaction. The reaction was carried out for 28.4 min under reflux conditions using a Box-Behnken experimental design. All of these parameters together gave optimum properties to the polycarbonates. The synthesized polycarbonates found applications in packaging materials [180]. Biodegradable polycarbonates (PC-g-EGm) were prepared using $\mathrm{CO}_{2}$ along with methoxyethoxy (MEMO) or (methoxyethoxy)ethoxy (ME2MO) and binary (salen)Co(III)-Cl/PPNCl as the catalyst by Zhou et al. The polycarbonate derived from two units of oligoethylene glycol also denoted as PC-g-EG2 was soluble in water at room temperature to give a clear solution. The synthesized polycarbonates were thermosensitive. Thus, they could degrade at temperatures equivalent to body temperatures, thereby, making them suitable for biomedical applications [176].

Polycarbonates used in biomedical applications could also be synthesized from $\mathrm{CO}_{2}$ and propylene oxide with an alternate arrangement of $\mathrm{CO}_{2}$ and the epoxide was reported by Geschwind et al. The polymer was also incorporated with (1,2-epoxy-5-hexene) $\mathrm{EH}$ to enhance the properties. Thus, this process can be a facile alternative to the ring opening polymerization using six-membered cyclic groups to synthesize a similar polymer. Double bonds can be introduced to the polymer chain using this technique. PLA can be incorporated in the chain to make the polymer biodegradable, thus, making the polymer suitable for biomedical application [24].

Moreover, a novel multi-arm polymer derived from hyperbranched poly (propylene oxide) (hbPPO) along with poly(propylene carbonate) (PPC) was prepared by Hilf et al. The hbPPO was the core and PPC formed the flexible arms. The flexible arms were formed by copolymerization using glycidol, macroinitiator hbPPO along with $\mathrm{CO}_{2}$ and propylene oxide (PO) as the monomers. (R, R)-(salcy)CoOBzF5 was used as a catalyst for efficient polymerization. The synthesized polycarbonate contained polyols, thus, making it suitable for polyurethane synthesis along with a compound containing isocyanate group [25]. Whereas, Liu synthesized polycarbonates (PPCMA) using $\mathrm{CO}_{2}$, propylene oxide and maleic anhydride as the comonomers and zinc adipate ( $\mathrm{ZnAA})$ as the catalyst to give upto $30 \%$ ester content [26]. Moreover, aliphatic polycarbonates (PPCIAn) were synthesized by Song et al. by copolymerizing $\mathrm{CO}_{2}$, propylene oxide $(\mathrm{PO})$ and itaconic anhydride (IAn). IAn was incorporated in PPC to increase the molecular weight and the polymer yield. The polycarbonates consisting of upto $5 \%(\mathrm{~mol} \%)$ IAn in comparison with the $\mathrm{PO}$ content exhibited optimum mechanical and thermal properties. These polymers are crosslinkable and degradable in nature, thus, they are suitable for biomedical applications or can be used as plastics [181].

The polycarbonates (PC) can be combined to form blends or composites with biodegradable polymers, thus, making the synthesized polymer degradable. Since, the PC derived from $\mathrm{CO}_{2}$ consume one of the major air pollutants and $\mathrm{PC} /$ biodegradable polymer blend is degradable, these polymer blends can be used a substitute for various non-biodegradable polymers and plastics used in biomedical, packaging and other allied applications.

Liu et al. used a bimetallic catalyst supported over a polymer to polymerize $\mathrm{CO}_{2}, \mathrm{PLA}$ and propylene oxide to give biodegradable polycarbonates (PPCLA). Thus, the synthesized polymer finds applications in controlled 
drug delivery [182]. Whereas, Lee et al. synthesized PLA and PC blends (70/30 wt \%) using various compatibilizers. It was demonstrated that on incorporation of $5 \mathrm{phr}$ SAN-g-MAH compatibilizer, the blend exhibited optimum mechanical, rheological and morphological properties. As the blend containing SANg-MAH has enhanced tensile and impact strength, the hydrolytic degradation of the blend took longer time as compared to other blends containing other compatibilizers [177]. A study on degradation characteristics was carried out by Yuryev et al. and polycarbonate/PLA polymer blends where exposed to deionized water. It was demonstrated that the hydrolytic degradation of the blend took place in two stages: 1) water diffusion and pit formation. 2) water transportation through pits causing PLA degradation accompanied with water absorption. As the PLA undergoes degradation, the $\mathrm{pH}$ of the solution reduces thereby, causing degradation of the polycarbonate component [30].

On the other hand, another biodegradable polymer, namely PHBV was blended with PPC using the solution casting method as reported by Tao and was subjected to various conditions conducive to degradation of the blend to observe its degradation properties. It was observed that the blend components were immiscible and the PPC component was amorphous, whereas, PHBV exhibited higher degree of crystallinity. It was further demonstrated that the thermal stability of the blend enhanced on incorporation of PHBV. It was proven that PHBV was more susceptible to natural environment, thus, causing it to degrade under the action of enzymes in the soil suspension. However, the PPC component was prone to simulated conditions, since, on hydrolysis PPC underwent random chain scission causing degradation. The author further stated that PLA can be incorporated in the blend to improve the blend characteristics [27].

Hwang et al. synthesized polycarbonates using propylene oxide and $\mathrm{CO}_{2}$ using zinc glutarate as the catalyst. The process was made environment friendly by using $\mathrm{PO}$ as the reaction medium, thereby, not generating any organic solvent waste. $\mathrm{PCL}$ was incorporated in the blend because of its compatibility with the comonomers and biodegradation properties to form poly(propylene carbonate-co-caprolactone). It was demonstrated that the polymer degrades under enzymatic degradation conditions using lipase enzyme. It was further demonstrated that PCL degrades to more extent than the other polymers present in the blend, thus, making the polymer suitable for biomedical applications [28].

\section{BIODEGRADABLE POLYMERS AS 3D MATERIALS}

3D printing, alternatively called as additive manufacturing is basically a printing operation carried out using computer controlled devices to produce 3D objects by laying layers of material over one another. The data of the required product is stored in an additive manufacturing file in the computer. The most commonly used technique for biopolymers for 3D printing is the fused deposition modelling (FDM). A filament derived from a thermoplastic material is fed into an extruder which has a heating unit attached to it. The heated filament extruded from the printer is laid in the form of the required object and which hardens immediately to give rigid layers.

Biodegradable polymers, particularly, PLA has been extensively used as a filament for 3D printing. PLA and other biodegradable polymer filaments can be incorporated with nanoparticles or nanofillers to form a blend or a composite, in order to enhance the properties of the filament and thus, of the final printed object. 3D printing has a major application in the formation of scaffolds and in other tissue engineering applications. Since, the scaffolds are derived from biodegradable polymer filaments, they are biocompatible and biodegradable under enzymatic action. Thus, these scaffolds undergo degradation after a specific time period and thereby, saves the cost and risk of carrying out a second surgery for the implant or scaffold removal. The pore size, size distribution and geometry of the scaffold can be varied using $3 \mathrm{D}$ printing technique which is not possible using the other conventional techniques. The 3D structure can appropriately mimic the extracellular matrix and can be synthesized as per the requirement of the patient, thus, making it best suited for the patient's body aiding in acceptance by the body and faster recovery [31, 183185].

\subsection{PLA as a 3D Printing Material}

Sabatina et al. used PLA filaments as the input to inexpensive fused deposition method (FDM) 3D printing technique to print different woven and knitted textile substrates. The prints had good quality and adhesion properties and thus, the printed samples could be used to manufacture garments [29]. Similarly, wearable electronics, medical braces, foot insoles were printed by using FDM 3D printing technique various 
knitted and woven cotton, wool and other substrates using PLA filament as reported by Pei et al. [186]. A novel electro-hydrodynamic jet printing with FDM technique (E-FDM) was employed by Zhang et al. to prepare 3D printed tissue regeneration scaffolds with using poly(lactic acid) PLA filaments with different structure sizes. The 3D printing technique gave high speed and high resolution prints i.e. upto submicron level and directly used PLA filament [187].

3D scaffolds used in bone tissue engineering applications could also be prepared using FDM 3D printing of PLA as reported by Wang et al. These scaffolds were further given inexpensive cold atmospheric plasma (CAP) surface treatment to incorporate nano-scale extracellular matrix properties and biocompatibility in them. CAP consists of several ionized gases such as reactive oxygen and nitrogen species, electrons, ions, free radicals, etc. The treatment initially consists of application of high voltage to the surface in presence of helium gas followed by treatment at room temperature. The CAP surface modification improves wound healing and sterilization properties of the printed specimen aiding in bone regeneration and cell attachment [188].

Zhuang et al. synthesized conductive graphene doped polylactic acid (G-PLA) composites using programmed mixing printing method. These G-PLA were used in 3D printing to yield products with good anisotropic heat and resistance distribution. These properties exhibited by the printed objects were dependent on the extrusion ratio as well as the mix ratio used during the printing operation. It was observed that, with increase in the G-PLA content in the printed sample, the resistance of the sample reduced, thus, reducing the heating of the material on exposure to electric field. These composites can be used to 3D print different plastics with custom modified properties or polymer materials which have applications in different fields such as architecture, engineering, etc. [183].

Moreover, FDM 3D printing carried out using grapheme incorporated PLA filament also produced patient specific implants and orthopedic scaffolds with graded porosity and optimum density as reported by Bustillos et al. The polymeric chains were restricted by graphene giving reduction in crystallinity, enhancement in the creep resistance and other mechanical properties. The 3D sample prepared from these composites exhibited superior wear and creep resistance as compared to that prepared using pure
PLA filaments [189]. Sanatgar et al. used FDM 3D printing technique to print polymers or nanocomposites to print on textile substrates such as PLA on PLA fabric, multi-wall carbon nanotubes/PLA (CNT/PLA) nanocomposites on PLA fabrics nanoparticles of carbon black/PLA (CB/PLA) on PLA fabric substrates. $\mathrm{CB}$ and $\mathrm{CNT}$ used as conductive polymer nanocomposites (CPCs), thus, the printed samples containing them can be used in static dissipative and radiation shielding applications [190].

Application of continuous fiber reinforced thermoplastic composites (CFRTPCs) in printing 3D samples which could be used in aviation and aerospace applications was carried out by Tian et al. The developed 3D printed samples were light-weight and an efficiently performing alternative to conventional materials. These CFRTPCs were formulated using polymer matrix of poly (lactic acid) (PLA) filament and reinforcement of continuous carbon fibers which were fed to fused deposition modelling (FDM) 3D printers simultaneously. Fiber content of $27 \%$ gave optimum mechanical properties to the composite. Layer thickness of $0.4 \mathrm{~mm}$ to $0.6 \mathrm{~mm}$ exhibited optimum bonding between the layers [184]. Moreover, novel PLA grafted cellulose nanofibers (PLA-g-CNFs) by grafting L-lactide monomers on cellulose nanofibers (CNFs) using ring-opening polymerization were synthesized by Dong et al. Grafting is carried out to avoid the aggregation of hydrophilic nanocellulose in hydrophobic PLA [191].

Other additives such as iron oxide $\left(\mathrm{Fe}_{2} \mathrm{O}_{3}, \mathrm{Fe}_{3} \mathrm{O}_{4}\right)$ nanoparticles were incorporated in PLA filaments to synthesize multi-well plates by $\mathrm{Su}$ et al. These plates were used for FDM 3D printing. The iron oxide nanoparticles used for the fabrication have intrinsic peroxidase properties, thus, the prepared printed samples can be used as reusable reactionware. It was also suggested that the consumption of iron oxide can be reduced if only the inner wall was printed using the functionalized multi-well plates instead of the complete reactionware using the same technique as mentioned above [192]. Guo et al. synthesized a flame retardant bionanocomposite by melting $82 \%$ PLA, $1 \%$ Cloisite 30B (C-30B) and 17\% melamine polyphosphate (MPP) to obtain optimum mechanical properties as well as to give an easy compounding and high performance formulation [193].

\subsection{PCL as a 3D Printing Material}

Hollander et al. employed PCL filaments using a model drug indomethacin in 3 concentrations using hot- 
melt extrusion technique. These modified filaments were used to print T-shaped prototypes of intrauterine system using FDM 3D printing technique. The morphology and other properties of the filament and printed samples were dependent on amount of drug loaded in the sample [31]. On the other hand, Mendoza-Buenrostro et al. embedded PCL nanofibers using electrospinning technique in FDM fabricated layers of PLA filament to produce a biodegradable 3D hybrid scaffold. Three techniques namely, FDM, micromilling and electrospinning have been combined to achieve multi-scale and multi-material manufacturing [194].

Antimicrobial wound dressing from 3D scanned templates were prepared by Hassan et al. using novel PCL based filaments reinforced with metal ions which can be used in inexpensive FDM 3D printing machine. The printed specimens contain silver and copper particles which show good bactericidal properties against common bacterium causing skin infections and aid in wound healing process, thus, the specimens can be used in producing patient specific wound dressings. The metal ions were incorporated in the filament using hot melt extrusion technique. These printed dressings were anatomically adaptable. Hence, they were more efficient than the conventional flat dressings and could be modified according to the shape, size and antimicrobial activity requirements [195]. Roncaa et al. reported $3 \mathrm{D}$ nanocomposites with poly ( $\varepsilon$-caprolactone) matrix and hydroxyapatite nanoparticles as a reinforcement using 3D fiber deposition technique. It can be demonstrated that the biological performance such as cell adhesion and spreading as well as mechanical properties of the nanocomposite improved with the incorporation of the hydroxyapatite nanoparticles. The prepared nanocomposite can be used in scaffolding applications [185].

\subsection{Other Biodegradable Polymers as a 3D Printing Material}

Use of a novel filament derived from composites from polyhydroxyalkanoate and modified palm fiber which can be used as 3D printing filament to give low cost, eco-friendly imitation wood was reported by Wu et al. PHA was modified with maleic anhydride using the grafting technique to give PHA-g-MA, whereas PF was treated with silane coupling agent to improve the mechanical properties and to increase the interfacial adhesion of the blend [196].

\section{BLENDS OF BIODEGRADABLE POLYMERS}

Polymer blending is known to be the most effective method for modification of polymer characteristic such as thermal resistance, mechanical strength, barrier properties, degradation rate etc. The obtained blends generally have properties that are not shown by their separate components. The properties of blends depend on many factors such as methodology of preparation, fractions of the components, and types and properties of added additives.

A proper homogenization of two components imparts the strong adhesion at the phase boundary. This is difficult to achieve as blending components have thermodynamic immiscibility in case of majority of polymers. Due to this immiscibility, polymer blends tend to separate into two or more distinct phases. Phase morphology have high influence on the properties of polymer blends. The end morphology of multiphase polymer blends depends on both intrinsic factors such as structure of blend composition and interfacial tension as well as extrinsic factors such as shear conditions, viscosity ratio, and processing parameters. In general, the processing of polymer blends is an easy, low-cost, scalable way to enhance the properties of the pristine polymers, therefore it is an interesting way to develop biodegradable polymer blends for applications like biomedical and packaging.

\subsection{Blends of PLA and PCL}

PLA is a most promising biodegradable polymers and its high stiffness makes the polymer very promising for medical applications but high brittleness is a serious drawback and required toughening. The increase in PLA toughness can be achieved by their blending with soft, ductile polymers with a low glass transition temperature. Thus PCL could be a good option for blending due to its biocompatibility combined with ductility and low $\mathrm{Tg}$.

Kelnar et al. used graphite nanoplatelet (GNP) for preparation of blends with PLA and PCL. The incorporated GNP works as reinforcements and electron microscopy was employed to know its presence in polymer blends [197]. Malinowski prepared PLA/PCL blends using co-rotating twin screw extruder and incorporated with triallyl isocyanurate (TAIC). These blends were exposed to electron beam irradiation which led to crosslinking of macromolecules thereby hindering the phase separation of the blend components [198]. Ostanfinska et al. reported on PLA/PCL blends of $80 / 20$ composition by varying the 
viscosity of the PLA component using the melt mixing followed by compression moulding methods. It was studied that a decrease in the PLA viscosity led to an increase in the average particle size of PCL thereby reducing the toughness properties of the matrix. The PLA component in the blend influenced the stiffness properties whereas, the PCL component in the blend influenced the toughness properties of the blend and these properties were dependent also on the particle size distribution of the components in the matrix. Thus, these blends can be converted into tailor made products which are suitable for tissue engineering applications [199].

Wachirahuttapong et al. synthesized PCL/PLA blends using Pluronic as the plasticizing agent using the melt blending technique. While Pluronic was added to the PLA/PCL blend of $90 / 10$ and $85 / 15$ composition, smaller sized PCL particles were obtained in the blend. It was demonstrated that the PLA was present in the blend in the form of spherulites [200]. Navarro-Baena et al. synthesized blends of PLA/PCL in various compositions to study their shape memory properties using the extrusion techniques. These blends can be low cost and easily processable alternatives for various agricultural, food packaging and biomedical applications. It was reported that the blend components formed different phases, since, they were immiscible [201]. Mofokeng et al. incorporated $\mathrm{TiO}_{2}$ nanoparticles in PLA/PCL blends and reported that $\mathrm{Tg}$ (lass transition temperature) of the blend was not affected by the incorporation of the nanoparticles [202].

\subsection{Blends of PLA and PHBV}

$\mathrm{Li}$ et al. reported blend fibers of PLA and PHBV using melt spinning and hot drawing method. The blend gave overall good heat resistance and mechanical properties such as softness and tensile strength due to the absence of spherulites and increase in PHBV content. It was studied that the incorporation of PHBV in the PLA matrix gave better orientation and crystallization of the matrix [203]. PHBV/PLA blends with different compositions reported by $\mathrm{Xu}$ et al. which can be used for denitrification process. It was demonstrated that the denitrification efficiency improved on increasing the weight ratio value of the blend components [204]. Yang et al. reported PLLA/PHBV blend films using the transesterification process with zinc acetate catalyst. Melt blending technique along with the efficient catalyst used for the blend formation, produced a highly miscible blend with enhanced mechanical properties. It was demonstrated that the PLLA/PHBV co-polymer, itself acted as a compatibilizer for the blend formation, thereby, further enhancing the miscibility and ductility of the blend [205].

Zembouai et al. prepared PLA/PHBV blends in 50/50 composition and $5 \mathrm{wt} \%$ of PHBV-g-MA compatibilizer and $2 \mathrm{wt} \%$ of Cloisite $30 \mathrm{~B}$ were incorporated in the blend to improve the blend properties. The blends were subjected to gamma irradiation which led to degradation of the blend. The blends can be used in applications related to packaging sterilization and food irradiation [206].

\subsection{Blends of PLA and PHB}

Arrieta et al. reported on optically transparent blend films containing PLA and PHB (Poly(hydroxybutyrate)) using the melt blending technique followed by film formation process. The PHB acted as an efficient nucleating agent which aided in PLA crystallization. $15 \%$ Acetyl (tributyl citrate) (ATBC) was added as a plasticizing agent which enhanced the processability of the films [207]. In further extension of this work Arrieta et al. reported on PLA/PHB (75:25) incorporated with CNC along with ATBC as the plasticizer by electrospinning technique. Optimum blend properties were obtained on incorporation of $15 \%$ ATBC and $1 \%$ CNC in the blend [208].

A PLA/PHB blend in 75/25 wt proportion suitable for food packaging and other one-time use applications where prepared by Abdelwahab et al. using Lapol 108 as the plasticizer. The plasticizer did not affect the properties of the pure PLA/PHB blend to a great extent. However, the addition of PLA in PHB reduced its biodegradability [209]. On the other hand, Nicosia et al. adopted the electrospinning technique to prepare novel PLA/PHB nanofibrous membranes which are suitable for biodegradable aerosol particle filtration applications. These nanofibers were further functionalized using $0.5 \%$ quaternary $[\mathrm{DDA}]\left[\mathrm{NO}_{3}\right]$ ammonium based ionic liquids, thereby, increasing their antifungal activity [210]. Armentano et al. adopted extrusion technique to prepare PLA/PHB blends using lactic acid oligomer as a plasticizer for better miscibility and properties. The author reported the use of the blends incorporated with $30 \%$ lactic acid oligomer for one-time food packaging with superior barrier properties and poor migration properties [211].

\subsection{Blends of PLA and PBAT}

Wang et al. reported on solution casting technique to prepare polymer blends of PLA and PBAT 
(Polybutylene adipate-co-butylene terephthalate). The incorporated PBAT in small amounts in the film gives flexibility, mechanical, thermal, UV screening and antifogging properties to the blend, thereby making the films suitable for fresh fruits, vegetables and other food packagings [212]. Lu et al. reported on different PLA/PBAT blends using counter-rotating twin-screw extruder by varying viscosity ratios. It was observed that the compatibility of the blend components improved on increasing the viscosity ratio thereby improving the tensile strength and other mechanical properties. Thus, the blends with viscosity ratio 1.95 exhibited enhanced impact properties whereas the blends with ratio 0.4 and 0.77 exhibited enhanced tensile properties [213].

Internal batch mixing was employed by Nofar et al. to synthesized PLA/PBAT (25 wt\%) blends incorporated with 1 and $5 \mathrm{wt} \%$ Cloisite 30B. In case of blends containing $1 \mathrm{wt} \%$, the nanoclay particles were localized in the interface and acted as a droplet coalesce barrier at the interface. On the contrary, the blending technique and parameters affected the occurrence of dispersion of $5 \mathrm{wt} \%$ nanoclay particles in the blend. Thus, the nanoclay quantity can be modified according to the requirement to modify the blend morphology [164].

Arruda et al. synthesized films from PLA/PBAT blends in two compositions, 40/60 and 60/40 along with Joncryl ADR 4368 epoxy resin compatibilizer. Two types of morphology of PLA was particularly seen in the blend. Blends with $60 \%$ PLA showed skin-core morphology and the blend along with compatibilizer showed a coarse sheet or ribbon like morphology whereas, blends with $40 \%$ PLA without compatibilizer showed elongated and fibrillar morphology [214]. Thermal stability of PLA/PBAT blends was studied by Al-Itry et al. It was reported that the individual polymer components of the blend degrade, thereby causing an overall decrease in the weight and intrinsic viscosity of the blend. It was also demonstrated that the addition of a compatibilizer Joncryl which contains glycidyl methacrylate functional groups enhanced the thermal stability of the blend [215].

\subsection{Blends of PLA and Natural Polymers}

Muller et al. reported on PLA and TPS blends using glycerol as the plasticizing agent. It was studied that maximum amount of the plasticizer was present in the starch phase and do not penetrate in PLA phase. Blending of the two components resulted in heterogeneous, two phase structure at all compositions. The two components do not exhibit strong interfacial adhesion, thus, stress cannot be transferred through the surface, thereby, giving a blend of poor strength and mechanical properties [216]. Shirai et al. reported on blends based on PLA and TPS, such that both the blend components were plasticized using different plasticizers. PLA was plasticized using two plasticizers, namely, adipate esters and citrate esters to give different blends which aided in the pellet formation which were essential to form blend films. Whereas, starch was plasticized with glycerol and PLA was plasticized with low concentration adipate esters, particularly using DEA, the blend prepared had optimum mechanical and structural properties [217].

Quintan et al. reported on blends containing PLA, cellulose acetate (CA) and PLA grafted cellulose acetate polymers (CA-g-PLA). Cellulose acetate was plasticized using triacetin as the plasticizer in a twinscrew extruder to produce thermoplastic cellulose acetate. The CA/PPLA blend was obtained by ring opening polymerization of both $D$ and L-Lactide. The plasticized PLA, CA as well as the PLA/CA copolymers gave modifiable mechanical properties to the blend. The blends containing grafted polymer exhibited higher interfacial interaction between the CA and PLA phases [218]. Wang et al. reported on carbon fibers by stabilizing and carbonizing precursors derived from Lignin/PLA blends. The presence of PLA in the fiber formed hydrogen bonds with lignin and also improved the spinnability of the blend thereby producing cylindrical shaped fibers. Thus, the presence of hydrogen bonds in the blend cancelled out the negative effect of the presence of voids in the blend formed during the volatilization of PLA, thereby, giving good tensile strength to the carbon fiber. The fiber prepared from 80/20 lignin/PLA composition gave optimum tensile strength to the fiber [219].

\subsection{Blends of PCL and Natural Polymers}

Novel blends of cornstarch and PCL were reported by Shen et al. These blends aid in denitrification process carried out in constructed wetlands by acting as an external carbon source. The blends particularly capture bacteria Bacillus $(24.25 \%)$ and Thauera $(9.36 \%)$ during the denitrification process. The blends also efficiently captured the polysaccharides which predominantly consisted of sugars [220]. Figueiredo et al. reported on a novel technique to synthesize blend films from bacteria cellulose (BC) and PCL using the in 
situ polymerization method. The first step for blend formation was to form a dispersion of PCL powder was obtained in a BC culture medium consisting of gluconacetobacter sacchari bacteria. The dispersion was then subjected to agitated incubation to form the blend. The polymer blend can be used in food packaging and biomedical applications since, no organic solvent was used for the polymer synthesis and the polymer components are biodegradable as well as biocompatible [221].

\subsection{Other Blends}

Goonoo et al. reported on novel blend films from semi-crystalline polymer matrix along with anionic sulfated polysaccharides derived from seaweeds. Two types of blend films were obtained from two pairs of combinations. The combinations were polyhydroxybutyrate (PHB) and polyhydroxybutyrateco-valerate (PHBV) with kappa-carrageenan (KCG) as well as polyhydroxybutyrate-co-valerate (PHBV) with fucoidan (FUC) giving PHB/KCG, PHBV/KCG and PHBV/FUC blends respectively. PHBV/KCG exhibited higher water uptake, demineralization potential and cellular activity amongst all the blends. The study suggests, this may be immiscibility of the polymers giving higher amount of hydrophilic biopolymer on the surface. Thus, the synthesized blend finds application in cell culture and tissue engineering field [222].

Torres-Huerta et al. reported on blends of commercial and recycled PET/PLA and PET/chitosan using the extrusion technique. The blend gave optimum mechanical properties on incorporating $5 \mathrm{wt} \%$ and $10 \mathrm{wt} \%$ of chitosan and PLA respectively. It was observed that the PET/chitosan blend had better miscibility as compared to the PET/PLA blend thereby, demonstrating that the components exhibited little interaction between them. The 95/5 PET/chitosan blend exhibited the best degradation and miscibility characteristics which were similar to those exhibited by the commercial BioPET samples [223].

\section{BIONANOCOMPOSITES}

Composites are materials which are synthesized by combining two or more materials such that the constituents remain separate and the final material exhibits enhanced properties different from the constituent materials. Nanocomposites are nothing but composites containing atleast one of the components in nanometer size. Biodegradable polymers in itself have several desirable properties however, in general, most of them exhibit poor barrier properties, brittleness and thermal stability. Such drawbacks can be overcome by combining them with other biodegradable polymers or nanoparticles which have very little or no negative effect on their biodegradability. These nanoparticles act as a reinforcement and thus, improve the strength properties as well. Nanocomposites can further be tailor-made by incorporating nanoparticles with application-specific properties such as antibacterial or anti-static properties. This review reports on nanocomposites prepared using a biodegradable polymer matrix and various nanofillers as reinforcements have been considered. Since, these nanocomposites have matrix based on biodegradable polymers, they are rendered biodegradable and biocompatible making them environment friendly and suitable for various packaging, biomedical and drug delivery applications [33, 224-227].

\subsection{PLA Based Bionanocomposites}

Pure PLA polymer exhibits poor thermal stability and mechanical properties such as brittleness and toughness. PLA matrix can be reinforced with other polymers or additives in nanometric sizes to overcome the drawbacks of pure PLA and further enhance the composite properties. PLA and graphene oxide based nanocomposites were reported by Kuang et al. by solution blending using supercritical $\mathrm{CO}_{2}$ as a physical blow agent [32].

The solution casting technique was employed by Madkour et al. to prepare bionanocomposites containing MWCNT and graphene nanoplatelet as the reinforcements incorporated in PLA matrices using the solution casting method. The graphene nanofillers exhibited enhanced mechanical as well as thermal properties [224]. Use of pristine functionalized multiwalled carbon nanotubes (pMWCNTs) as a substitute for MWCNTs to prepare bionanocomposites using PLLA as the polymer matrix was reported by Amiriana et al. The pMWCNTs were synthesized by carrying out Friedel Crafts acylation on the MWCNTs to give their aromatic amine (MWCNT-NH2) products [225].

It is known that silver nanoparticles (AgNPs) are selected as the nanofillers because of their antibacterial, anticancer and wound healing properties. Sarkar et al. exploited this property to synthesize novel antimicrobial bionanocomposites using Poly-D, Llactide-co glycolide (PLGA) as the polymer matrix and AgNPs as the fillers by the solvent casting technique [226]. 
Two techniques, namely, melt compounding and film blowing techniques were adopted by Herrera et al. to synthesize novel bionanocomposites. The first step of synthesis included melt compounding of $5 \mathrm{wt} \%$ chitin nanocrystals (ChNCs), 75 wt\% PLA and 20 wt $\%$ glycerol triacetate plasticizer (GTA). The product from the first step was further diluted to $1 \mathrm{wt} \%$ ChNCs with PBAT and PLA and subsequently film blowing to give the bionanocomposite. The incorporation of chitin nanocrystals in the bionanocomposite, led to an enhancement in the mechanical, barrier properties, however, it led to a reduction in the fungal activity of the bionanocomposite [227].

A novel bionanocomposite was synthesized using electrospun 50:50 poly(L-lactide-co-caprolactone) as the matrix and was incorporated silver nanoparticles as the nanofillers by Samberg et al. The bionanocomposite exhibits antimicrobial properties due to the presence of silver nanoparticle fillers in it. The technique of the electrospinning the nanofibrous polymer gives a three-dimensional structure to the bionanocomposite which is similar to the natural environment present in the body and it can be easily modified according to the requirements. The separately synthesized silver nanoparticles are incorporated in the polymer solution which is followed by electrospinning. The prepared bionanocomposites can be used as scaffolds in skin tissue engineering operations [228].

Moreover, another PLA/PCL bionanocomposite was prepared by Esmaeilzadeh et al. using the solventevaporation method with a polymer matrix containing $80 \%$ of PDLLA and $20 \%$ of PCL (w/w) and bioactive glass nanoparticles $(0,1,3$ and $6 w t \%)$ as the reinforcements. PLA matrix is blended with the PCL matrix to overcome the poor mechanical properties of the PLA. Furthermore, inorganic nanoparticles such as bioactive nanoglass fillers are added to overcome the limitations of the polymer matrix blend [34].

\subsection{PCL Based Bionanocomposites}

3D scaffolds derived from a bionanocomposite using PCL matrix reinforced with hydroxyapatite (HA) nanorods can be prepared using an in situ solvothermal process as reported by Moeini et al. It was demonstrated that the strength of the bionanocomposites prepared using this in-situ method were stronger than those prepared by the conventional method. HA nanorods are well dispersed in the biodegradable polymer matrixes to overcome the limitations of PCL matrix. The HA reinforcments in the bionanocomposite exhibit chemical properties similar to the inorganic components present in the bone structure. HA also shows osteoconductive properties. Thus, the synthesized bionanocomposites find applications in preparing 3D scaffolds aiding in tissue and bone regeneration [229].

Guaras et al. have synthesized biodegradable polymer/clay bionanocomposites with anhydridefunctional polycaprolactone (PCL-gMA) polymer matrix incorporated with thermoplastic starch (TPS). Three types of nanoclays were used as fillers in the composite: two organo-modified montmorillonites with a quaternary ammonium salt $(\mathrm{C} 20 \mathrm{~A}$ and $\mathrm{C} 30 \mathrm{~B})$ and a natural montmorillonite. The bionanocomposite films were synthesized by melt intercalation and successive compression molding. The TPS was synthesized by adding a plasticizer to starch followed by application of heat and shear forces to it. In order improve the mechanical properties of the composite, a compatibilizer like maleic anhydride is added to the composite [230].

\subsection{Other Polymer Substrates for Bionanocomposites}

Bionanocomposites which find applications as packaging materials for several industrial products, especially in the food packaging applications have been synthesized by Reis et al. These bionanocomposites contain PHBV matrix and modified vermiculite (VMTO) and natural vermiculite (VMT) as the reinforcement using the melt intercalation method. The pure polymer as well as the natural vermiculite bionanocomposite exhibited higher biodegradability and better thermal stability as compared to the modified vermiculite bionanocomposite. By using nanoclay fillers the several limitations of PHBV pure polymer can be overcome. Vermiculite is the most suitable choice of nanofiller since, it shows a higher tendency to expand at high temperatures to become a lightweight material as compared to other lamellar nanoclay fillers [231].

Gumel et al. prepared a bionanocomposite with medium-chain-length poly-3-hydroxyalkanoate matrix and reinforced it with carbon nanofibers (CNFs) having high surface-to-volume ratio. CNFs present in the bionanocomposite help to overcome the drawbacks of the matrix. In order to enhance the construction of the bionanocomposite, acoustic sonication was used which led to a uniform distribution of CNFs in the matrix giving an improved physical morphology and thermo-chemical 
properties of the bionanocomposite. These properties render the synthesized bionanocomposites suitable for applications in drug delivery devices, biosensors and organic electroconductive materials [232].

Moreover, novel bionanocomposites were developed by Ahmadizadegan et al. consisting of polyimide/cellulose/TiO 2 (PI/BNCs) using inexpensive ultrasonic irradiation process [233].

\section{BIODEGRADABILITY OF POLYMERS}

There are a number of factors that contribute to the degradation rate of aliphatic polymers. The physical properties of polymer as well as its chemical structure have a crucial effect on the biodegradation of polymers. Various physical parameters such as molecular weight, crystallinity, molecular orientation, surface area, and glass transition temperature etc. determine the rate of degradation in a given set of degradation conditions. For example, PLGA, which is amorphous and hydrophilic in nature, degrades faster as compared to PCL which is crystalline and hydrophobic polymer [ 86 , 234-235]. The chemical structure is also a governing factor for the rate of degradation, for example, polymers with side functional groups, such as, amino, hydroxyl, carboxyl, etc. are more degradable since the presence of functional groups increase the hydrophilicity of polymer backbone that facilitate the attack of water molecules at the labile bonds.

The homogeneous hydrolytic degradation of aliphatic polymers comprises the bulk and surface erosion of polymeric material. The former involves the erosion of material from the entire polymer volume, whereas in latter the material mainly erode from the polymer surface. The term degradation stands for the bond cleavage while erosion corresponds to the depletion of material, hence the erosion of the material is subsequent to degradation. The rate of degradation can be monitored by measuring molecular weight changes or by measuring weight loss. Moreover, there are various tools such as GC-MS, SEM, TEM etc. which can be employed to examine the characteristics of degraded products [86, 235-239].

The biodegradation is a process that degrades the polymer eventually in the water and carbon dioxide with help of microorganisms. Since the microorganisms are not able to transport long-chained, water insoluble polymeric material into the cell, therefore biodegradation initiates with excretion of the extracellular enzymes by the microorganisms. In this process microorganisms depolymerize the polymer outside the cells and produce water soluble lower molecular weight moieties. Once the microorganism intake the water soluble intermediates inside the cells various metabolic pathways are followed and as a result water, carbon dioxide and methane are produced as end product. Different test methods are used to examine the biodegradation of polymers. Here, three categories of test methods (1) field test, (2) simulation test and (3) laboratory test have been described which are broadly used [240-241].

The field test involves a degradation procedure where practical environmental conditions are employed and polymeric samples are subjected to degrade by burying in soil or placing in it a lake/river. This method has variable test conditions since environmental condition such as temperature, $\mathrm{pH}$, and humidity cannot be controlled. It is a disadvantage of field test that is coupled with the poor quantitative recovery of disintegrated polymeric sample from the test site. To overcome the limitations of field tests, simulation tests are employed, where the environment is close to the field test and experiments are carried out in laboratory reactors so that the external parameters such as temperature, $\mathrm{pH}$ and humidity can be controlled. The examples of simulation tests are soil burial tests, aqueous aquarium tests, control composting tests etc. The mostly used biodegradable tests are laboratory tests, since environmental conditions are well defined. These tests are carried out in synthetic media and examples are enzymatic degradation tests, clear-zone tests, sturm-tests etc. [213, 240-245].

Luzi et al. reported on bionanocomposites using poly (lactic acid) (PLA) as the matrix reinforced with modified and un-modified nanocellulose crystals (CNC) derived from marine waste. The cellulose nanocrystals were modified using a surfactant to improve their dispersion the PLA matrix. The prepared bionanocomposites were then subjected to enzymatic degradation in aerobic condition, $50 \%$ relative humidity at $58{ }^{\circ} \mathrm{C}$ in the presence of the enzyme proteinase $\mathrm{K}$. It was reported that enzyme could only degrade the Llactic acid molecules from the matrix and not the Dlactic acid molecules and complete degradation was observed within 14 days [246]. Pelegrini et al. synthesized novel composites having poly (lactic acid) (PLA) as the matrix reinforced with buriti fiber and triacetin was used as a coupling agent using the compression moulding technique. The composite was subjected to simulated marine environment such as fish, algae and coral for 600 days to study the 
degradation trend. It was reported that the degradation of PLA improved on addition of the natural fiber in the matrix, due to the greater accessibility to the PLA matrix to water exhibited by the natural fiber reinforcement. It was further observed that the plasticizer inhibits degradation only upto 45 days. The algae Bacillariophyceae Fragilariophyceae class and diatoms present led to the degradation of the composite. The degradation was initiated by the absorption of water by the matrix which was followed by the hydrolysis process leading to complete degradation [247].

Zhao synthesized composites from PLA matrix reinforced with magnesium particles of varied concentrations using solvent casting technique. The composite was then subjected to in vitro degradation process using mouse osteoblastic cells. It was demonstrated that the magnesium particles enhanced the biodegradability of the composite as well as the magnesium ions could neutralise the acid products formed due to the degradation of PLA thereby, further supporting the degradation process [248]. Breche et al. synthesized a triblock polymer using PLA and poly(ethylene glycol) (PEG) to give PLA- $b$-PEG- $b$-PLA triblock copolymer. The block copolymer was then subjected to in vitro degradation at $37{ }^{\circ} \mathrm{C}$ in aqueous medium. It was demonstrated that the hydrolytic degradation lead to formation of water soluble oligomers [249]. Huang et al. synthesized a composite containing PLA as the matrix and natural rubber as the reinforcement using the compression molding and melt blending techniques. The composite was subjected to hydrolytic biodegradation at $58{ }^{\circ} \mathrm{C}$ using deionized water and the incorporated natural rubber did not show any effect on the biodegradation process [250].

\subsection{Hydrolytic Degradation}

Rocca-Smith et al. subjected food packaging grade PLA to different wet conditions such as $50 \%$ and $100 \%$ relative humidity at $50{ }^{\circ} \mathrm{C}$ and when the sample was immersed in water and saturated vapor for two months. It was observed that the polymer nature changed from glassy to rubbery in the temperature range of $55-60{ }^{\circ} \mathrm{C}$. It was demonstrated that the sample treated at $50^{\circ} \mathrm{C}$ in conditions $100 \%$ relative humidity underwent hydrolysis whereas the sample in the conditions of $50 \%$ relative humidity underwent physical ageing only. It was observed that the sample immersed in water released lactic acid an oligomers whereas the sample kept in saturated vapor retained these degraded products thereby catalyzing the degradation process. It was demonstrated that water also acts as a plasticizer thereby aiding the degradation process [251]. Franco et al. treated PLA to hydrolytic degradation by immersing the polymer in pure water and ethanol of two concentrations $50 \%$ and $95 \%$ for 180 days. The polymer immersed in $50 \%$ ethanol solution exhibited higher crystallinity and higher water absorption, thus, giving faster and efficient hydrolysis and degradation. It was demonstrated that the PLA matrix undergoes degradation with concurrent solvent induced crystallization i.e. the PLA molecules when immersed in organic solvent will crystallize and plasticize and increase their chain mobility [252].

\subsection{Enzymatic Degradation}

Karamanlioglu et al. studied the degradation of PLA using sterile compost for 54 days, microorganism rich compost for 57 days and soil extract for 54 days at 50 ${ }^{\circ} \mathrm{C}$. It was demonstrated that degradation rates were faster in microorganism rich compost i.e. using biotic soluble factors than in soil extract or sterile compost. The degradation trend was also observed in soil, microorganism rich compost and sterile water at different temperatures such as varying to 25 to $55^{\circ} \mathrm{C}$. It was observed that efficient degradation took place at a temperature at or above $45^{\circ} \mathrm{C}$ at specific humidity and environmental conditions. It was also reported that the degradation process enhanced by using microbial conditions than by using chemical hydrolytic degradation process [253]. Karamanlioglu et al. treated PLA samples to various fungi using incubation treatment at $25{ }^{\circ} \mathrm{C}$ and $50{ }^{\circ} \mathrm{C}$ for 8 weeks in soil or compost to study the degradation of PLA. It was observed that incubation at $50{ }^{\circ} \mathrm{C}$ gave efficient disintegration of PLA due to the involvement of extracellular esterases and presence of fungi such as Aspergillus fumigatus and Thermomyces lanuginosus [254]. Meischel et al. synthesized novel biocomposites containing poly(hydroxyl butyrate) as the matrix reinforced with zirconium dioxide. The composite was subjected to in-vivo degradation using femora of growing rats for 36 weeks. However, it was reported that the composite did not degrade completely in 36 weeks [255].

\section{APPLICATIONS OF BIODEGRADABLE POLYMERS}

Biodegradable polymers have various applications ranging from biomedical applications to agriculture implements. These applications are discussed in following sub-sections- 
1. Biomaterials

2. Pharmaceuticals

3. Tissue engineering and surgical uses

4. Packaging and agriculture uses

5. Applications in fibers \& textiles

\subsection{Biomaterials}

Non-toxicity, sterilizability, effectiveness and biocompatibility are the minimum requirements of biomaterials for their end applications in human body. Various biomedical applications of synthetic aliphatic polyesters are listed in Figure 5 [256-264].

\subsection{Pharmaceuticals}

Controlled drug delivery has versatile application in medicine, veterinary and agrochemical fields. Drug delivery system is an efficient way to release drugs for a desired duration with an optimum dose at the diseased sites in the body. The aim of drug delivery system involves a sustained release of drugs. Since the polymer is no longer required when the drug delivery has been accomplished therefore employed polymers should be absorbable. Different shapes of drug carriers such as nanospheres, microspheres, beads, cylinders and discs are used nowadays, out of them microsphere is widely used shape [158]. Solvent evaporation method is generally used for preparation of microspheres using polymers and copolymers such as, poly( $\varepsilon$-caprolactone), poly(L-lactide) and poly(glycolideco-lactide) [85-86, 265-268].

\subsection{Tissue Engineering and Surgical Uses}

Tissue engineering is a technology to generate biological tissues for replacements of defective tissues when the lost part of the tissue is so large that it cannot be cured by conventional therapeutic methods. Biodegradable polymers are required to fabricate scaffolds for tissue regeneration for that it is necessary that employed polymers should have a sustained release of growth factors. Generally, scaffolds used in tissue engineering are porous and three-dimensional to support infiltration of a large number of cells into the scaffolds [256, 259, 264]. Various biodegradable polymers such as poly(L-lactide), poly(glycolide), and their copolymers poly(L-lactide-co-glycolide) have been used to fabricate cell scaffolds for engineering musculoskeletal tissue such as cartilage and bone [85, 260, 269-272].

Sutures are the most prominent use of biodegradable polymers and Dexon is the most widely used absorbable suture. Vicryl is the other example that is a copolymer compose of PLLA (8\%)-co-PGA $(92 \%)$ and PDS, poly(p-dioxanone) [265]. The other surgical use of biodegradable polymers is in fixation of fractured bones. Different other applications of biodegradable polymers in surgery are for hemostasis, sealing and adhesion to tissues [85-86, 158, 265].

\subsection{Packaging and Agriculture Uses}

The needs such as consumer products, packaging materials food processing and agriculture films can be accomplished through non-degradable polymers which are obtained from petroleum and oil based monomers. Since non-degradable polymers are biostable plastics

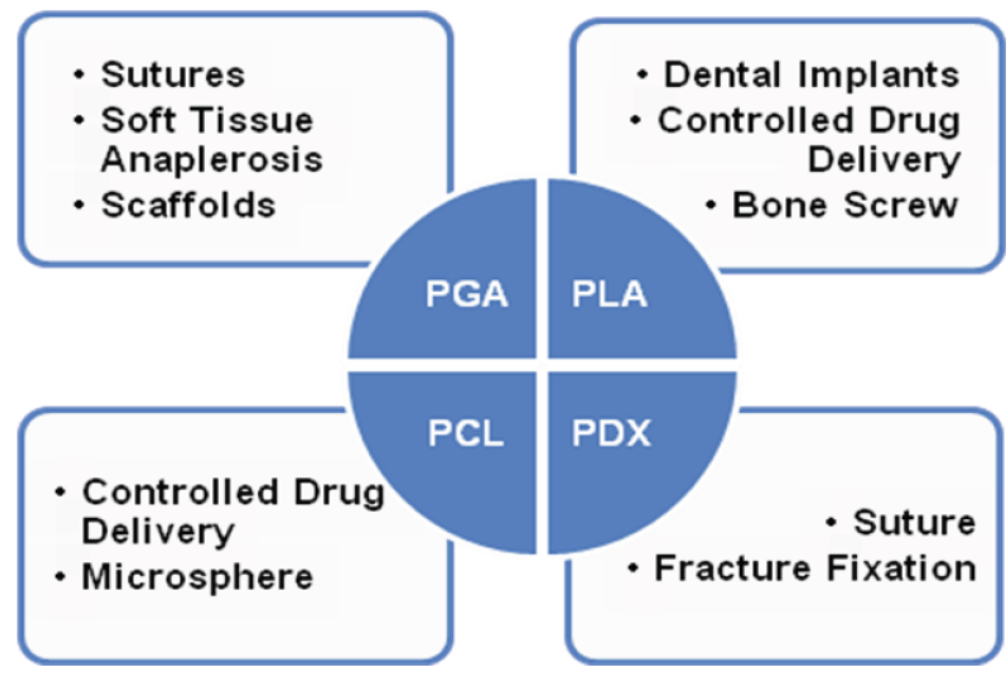

Figure 5: Biomedical applications of synthetic aliphatic polyesters [256-264]. 


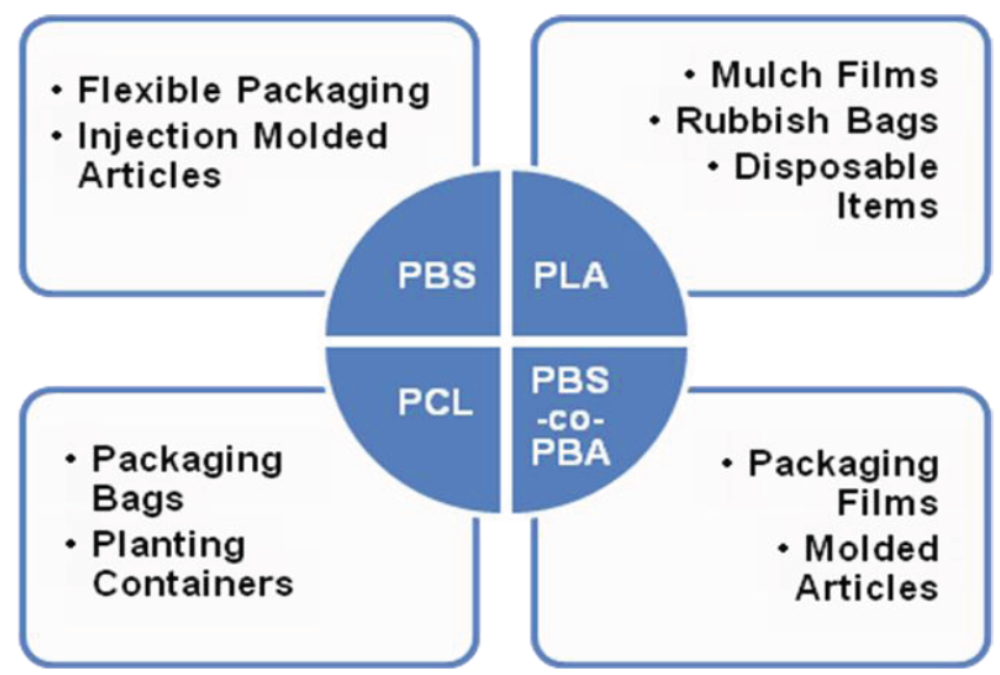

Figure 6: Packaging and agriculture applications of synthetic aliphatic polyesters [84, 86, 158, 163, 265].

and cause serious environmental pollution, therefore plastic recycling is an effective method to resolve the problem. However this method consumes a considerable amount of thermal energy and deplete the oil resources hence it would be indispensable to use biodegradable polymers. Generally, used synthetic aliphatic polyesters for packaging and agriculture are shown in Figure 6 [84, 86, 158, 163, 265].

\subsection{Applications in Fibers \& Textiles}

Textile industry is one of the most prominent and never dying industry. Any product which is either derived from a fibre, yarn or fabric or has the final outcome in these forms is covered under textile applications. Polymer science and textile technology have various overlapping applications and use of both synthetic and natural biodegradable polymers to produce smart textiles is one of them. Due to the biocompatibility of the biodegradable polymers, they can be used as medical suture material or wound dressings in medical textiles, whereas, the rapid biodegradability of these polymers make them suitable for agrotextile applications. Similarly, the ease of production, availability and low cost of these polymers have made them suitable for various other textile applications such as packaging, e-textiles, etc. thereby, reducing the negative impact of the conventional textile polymers on the environment [273-276].

\section{CONCLUSION}

Biodegradable polymers have their great importance in biomedical and pharmaceutical field. The recent advances show that various new synthetic pathways have potential to make novel polymers for new biomedical applications, since their chemical modification and functionalization can be easily done. Moreover, synthetic functional polymers are a new class of biomaterials that open a scope for totally new biomedical applications. In this way synthetic biodegradable polymers are future material that can immensely contribute to the development of biomedical field. Similarly, biodegradable polymers derived from natural sources provide new alternatives for synthesizing bio-based polymers. Using reaction byproducts such as $\mathrm{CO}_{2}$ as monomers for subsequent polymerization is one of the highlights of the recent discoveries. Moreover, water soluble polymers are being considered as suitable alternatives to polyethylene and other plastics for one-time use bottles packaging materials. Another substitute for petroleumbased non-biodegradable polymers is by preparation of blends or composite polymers of biodegradable polymers with properties equivalent to the commercially non-biodegradable ones. The use of 3D printing technology, have further bolstered the use of biodegradable polymers in biomedical applications in the form of tailor-made scaffolds and grafts. These polymers are also found to be suitable for several other applications such as in the fields of green packaging and textile industry in the form of both fibres and fabrics. Thus, there is an extensive scope for further academic and industrial research of studying and commercially developing various products from these polymers suitable for different applications.

\section{ACKNOWLEDGEMENT}

The authors thank Reliance Industries Limited, India for providing facilities and financial support. 


\section{REFERENCES}

[1] Nair LS, Laurencin CT. Biodegradable polymers as biomaterials. Progress in polymer science 2007; 32(8-9): 762-98.

https://doi.org/10.1016/j.progpolymsci.2007.05.017

[2] Chandra RU. Biodegradable polymers. Progress in polymer science 1998; 23: 1273-335.

https://doi.org/10.1016/S0079-6700(97)00039-7

[3] Sudesh K, Abe H, Doi Y. Synthesis, structure and properties of polyhydroxyalkanoates: biological polyesters. Progress in polymer science 2000; 25(10): 1503-55. https://doi.org/10.1016/S0079-6700(00)00035-6

[4] Rai R, Tallawi M, Grigore A, Boccaccini AR. Synthesis, properties and biomedical applications of poly (glycerol sebacate)(PGS): a review. Progress in polymer science 2012; 37(8): 1051-78.

https://doi.org/10.1016/j.progpolymsci.2012.02.001

[5] Vert M. Polymeric biomaterials: strategies of the past vs. strategies of the future. Progress in Polymer Science 2007; 32(8-9): 755-61. https://doi.org/10.1016/j.progpolymsci.2007.05.006

[6] Pasut G, Veronese FM. Polymer-drug conjugation, recent achievements and general strategies. Progress in polymer science 2007; 32(8-9): 933-61.

https://doi.org/10.1016/j.progpolymsci.2007.05.008

[7] Varma IK, Albertsson AC, Rajkhowa R, Srivastava RK. Enzyme catalyzed synthesis of polyesters. Progress in Polymer Science 2005; 30(10): 949-81. https://doi.org/10.1016/j.progpolymsci.2005.06.010

[8] Rasal RM, Janorkar AV, Hirt DE. Poly (lactic acid) modifications. Progress in polymer science 2010; 35(3): 33856 https://doi.org/10.1016/i.progpolymsci.2009.12.003

[9] Okada M. Chemical syntheses of biodegradable polymers. Progress in polymer science 2002; 27(1): 87-133. https://doi.org/10.1016/S0079-6700(01)00039-9

[10] Yu L, Dean K, Li L. Polymer blends and composites from renewable resources. Progress in polymer science 2006; 31(6): $576-602$.

https://doi.org/10.1016/j.progpolymsci.2006.03.002

[11] Södergård $A$, Stolt $M$. Properties of lactic acid based polymers and their correlation with composition. Progress in polymer science 2002; 27(6): 1123-63. https://doi.org/10.1016/S0079-6700(02)00012-6

[12] Fenouillot F, Rousseau A, Colomines G, Saint-Loup R, Pascault JP. Polymers from renewable 1, 4: 3, 6dianhydrohexitols (isosorbide, isomannide and isoidide): A review. Progress in Polymer Science 2010; 35(5): 578-622. https://doi.org/10.1016/j.progpolymsci.2009.10.001

[13] Nishat N, Malik A. Biodegradable coordination polymer: Polycondensation of glutaraldehyde and starch in complex formation with transition metals Mn (II), Co (II), Ni (II), Cu (II) and Zn (II). Arabian Journal of Chemistry 2016; 9: S1824-32.

[14] Lima KO, Biduski B, da Silva WM, Ferreira SM, Montenegro LM, Dias AR, Bianchini D. Incorporation of tetraethylorthosilicate (TEOS) in biodegradable films based on bean starch (Phaseolus vulgaris). European Polymer Journal 2017; 89: 162-73.

https://doi.org/10.1016/j.eurpolymj.2017.02.008

[15] Mendes JF, Paschoalin RT, Carmona VB, Neto AR, Marques AC, Marconcini JM, Mattoso LH, Medeiros ES, Oliveira JE. Biodegradable polymer blends based on corn starch and thermoplastic chitosan processed by extrusion. Carbohydrate polymers 2016 ; $137: 452-8$. https://doi.org/10.1016/j.carbpol.2015.10.093

[16] Gołacki K, Stropek Z, Kołodziej P, Gładyszewska B, Rejak A, Mościcki L, Boryga M. Studies on stress relaxation process in biodegradable starch film. Agriculture and Agricultural Science Procedia 2015; 7: 80-6.

https://doi.org/10.1016/j.aaspro.2015.12.038

[17] Farah $\mathrm{NH}$, Salmah H, Marliza M. Effect of butyl methacrylate on properties of regenerated cellulose coconut shell biocomposite films. Procedia Chemistry 2016; 19: 335-9. https://doi.org/10.1016/j.proche.2016.03.020

[18] Zailuddin NL, Husseinsyah S. Tensile properties and morphology of oil palm empty fruit bunch regenerated cellulose biocomposite films. Procedia Chemistry 2016; 19: 366-72.

https://doi.org/10.1016/j.proche.2016.03.025

[19] Mostafa NA, Farag AA, Abo-dief HM, Tayeb AM. Production of biodegradable plastic from agricultural wastes. Arabian journal of chemistry 2015.

[20] Pelissari FM, Andrade-Mahecha MM, do Amaral Sobral PJ, Menegalli FC. Nanocomposites based on banana starch reinforced with cellulose nanofibers isolated from banana peels. Journal of colloid and interface science 2017; 505 : 154-67. https://doi.org/10.1016/j.jcis.2017.05.106

[21] Kim I, Yi MJ, Byun SH, Park DW, Kim BU, Ha CS. Biodegradable polycarbonate synthesis by copolymerization of carbon dioxide with epoxides using a heterogeneous zinc complex. InMacromolecular Symposia 2005 Apr (Vol. 224, No. 1, pp. 181-192). Weinheim: WILEY-VCH Verlag

[22] Cuesta-Aluja L, Castilla J, Masdeu-Bultó AM, Henriques CA Calvete MJ, Pereira MM. Halogenated meso-phenyl Mn (III) porphyrins as highly efficient catalysts for the synthesis of polycarbonates and cyclic carbonates using carbon dioxide and epoxides. Journal of Molecular Catalysis A: Chemical 2016; 423: 489-94.

https://doi.org/10.1016/j.molcata.2015.10.025

[23] Lu XB, Liang B, Zhang YJ, Tian YZ, Wang YM, Bai CX, Wang $\mathrm{H}$, Zhang R. Asymmetric catalysis with CO2: Direct synthesis of optically active propylene carbonate from racemic epoxides. Journal of the American Chemical Society 2004; 126(12): 3732-3. https://doi.org/10.1021/ja049734s

[24] Geschwind J, Wurm F, Frey H. From CO2-Based Multifunctional Polycarbonates With a Controlled Number of Functional Groups to Graft Polymers. Macromolecular Chemistry and Physics 2013; 214(8): 892-901. https://doi.org/10.1002/macp.201200608

[25] Hilf J, Schulze P, Seiwert J, Frey H. Controlled Synthesis of Multi-Arm Star Polyether-Polycarbonate Polyols Based on Propylene Oxide and CO2. Macromolecular rapid communications 2014; 35(2): 198-203. https://doi.org/10.1002/marc.201300663

[26] Liu Y, Deng K, Wang S, Xiao M, Han D, Meng Y. A novel biodegradable polymeric surfactant synthesized from carbon dioxide, maleic anhydride and propylene epoxide. Polymer Chemistry 2015; 6(11): 2076-83. https://doi.org/10.1039/C4PY01801J

[27] Tao J, Song C, Cao M, Hu D, Liu L, Liu N, Wang S. Thermal properties and degradability of poly (propylene carbonate)/ poly ( $\beta$-hydroxybutyrate-co- $\beta$-hydroxyvalerate)(PPC/PHBV) blends. Polymer Degradation and Stability 2009; 94(4): 57583.

https://doi.org/10.1016/j.polymdegradstab.2009.01.017

[28] Hwang Y, Jung J, Ree M, Kim H. Terpolymerization of CO2 with propylene oxide and $\varepsilon$-caprolactone using zinc glutarate catalyst. Macromolecules 2003; 36(22): 8210-2. https://doi.org/10.1021/ma034498b

[29] Sabantina L, Kinzel F, Ehrmann A, Finsterbusch K Combining 3D printed forms with textile structuresmechanical and geometrical properties of multi-material systems. InIOP Conference Series: Materials Science and Engineering 2015 (Vol. 87, No. 1, p. 012005). IOP Publishing. 
[30] Yuryev Y, Mohanty AK, Misra M. Hydrolytic stability of polycarbonate/poly (lactic acid) blends and its evaluation via poly (lactic) acid median melting point depression. Polymer Degradation and Stability 2016; 134: 227-36.

https://doi.org/10.1016/j.polymdegradstab.2016.10.011

[31] Holländer J, Genina N, Jukarainen H, Khajeheian M, Rosling A, Mäkilä E, Sandler N. Three-dimensional printed PCLbased implantable prototypes of medical devices for controlled drug delivery. Journal of pharmaceutical sciences 2016; 105(9): 2665-76.

https://doi.org/10.1016/j.xphs.2015.12.012

[32] Kuang TR, Mi HY, Fu DJ, Jing X, Chen BY, Mou WJ, Peng XF. Fabrication of poly (lactic acid)/graphene oxide foams with highly oriented and elongated cell structure via unidirectional foaming using supercritical carbon dioxide. Industrial \& Engineering Chemistry Research 2015; 54(2): 758-68.

https://doi.org/10.1021/ie503434q

[33] Zhou Y, Lei L, Yang B, Li J, Ren J. Preparation of PLA-based nanocomposites modified by nano-attapulgite with good toughness-strength balance. Polymer Testing 2017; 60: 7883.

https://doi.org/10.1016/j.polymertesting.2017.03.007

[34] Esmaeilzadeh J, Hesaraki S, Hadavi SM, Ebrahimzadeh MH, Esfandeh M. Poly (d/l) lactide/polycaprolactone/bioactive glasss nanocomposites materials for anterior cruciate ligament reconstruction screws: The effect of glass surface functionalization on mechanical properties and cell behaviors. Materials Science and Engineering: C 2017; 77: 978-89.

https://doi.org/10.1016/j.msec.2017.03.134

[35] Seoane IT, Manfredi LB, Cyras VP. Properties and processing relationship of polyhydroxybutyrate and cellulose biocomposites. Procedia Materials Science 2015; 8: 807-13. https://doi.org/10.1016/j.mspro.2015.04.139

[36] Nishat N, Malik A. Synthesis, spectral characterization thermal stability, antimicrobial studies and biodegradation of starch-thiourea based biodegradable polymeric ligand and its coordination complexes with [Mn (II), Co (II), Ni (II), Cu (II), and Zn (II)] metals. Journal of Saudi Chemical Society 2016; 20: S7-15.

https://doi.org/10.1016/j.jscs.2012.07.017

[37] Souza AC, Benze RF, Ferrão ES, Ditchfield C, Coelho AC, Tadini CC. Cassava starch biodegradable films: Influence of glycerol and clay nanoparticles content on tensile and barrier properties and glass transition temperature. LWT-Food Science and Technology 2012; 46(1): 110-7. https://doi.org/10.1016/j.Iwt.2011.10.018

[38] Li Y, Tan Y, Xu K, Lu C, Wang P. A biodegradable starch hydrogel synthesized via thiol-ene click chemistry. Polymer Degradation and Stability 2017; 137: 75-82.

https://doi.org/10.1016/j.polymdegradstab.2016.07.015

[39] Biduski B, da Silva FT, da Silva WM, El Halal SL, Pinto VZ, Dias AR, da Rosa Zavareze E. Impact of acid and oxidative modifications, single or dual, of sorghum starch on biodegradable films. Food chemistry 2017; 214 : 53-60. https://doi.org/10.1016/j.foodchem.2016.07.039

[40] Arolkar GA, Salgo MJ, Kelkar-Mane V, Deshmukh RR. The study of air-plasma treatment on corn starch/poly $(\varepsilon-$ caprolactone) films. Polymer Degradation and Stability 2015; 120: 262-72.

https://doi.org/10.1016/j.polymdegradstab.2015.07.016

[41] Brandelero RP, Grossmann MV, Yamashita F. Effect of the method of production of the blends on mechanical and structural properties of biodegradable starch films produced by blown extrusion. Carbohydrate Polymers 2011; 86(3): 1344-50.

https://doi.org/10.1016/j.carbpol.2011.06.045

[42] Andrade-Mahecha MM, Pelissari FM, Tapia-Blácido DR, Menegalli FC. Achira as a source of biodegradable materials:
Isolation and characterization of nanofibers. Carbohydrate polymers 2015; 123: 406-15.

https://doi.org/10.1016/j.carbpol.2015.01.027

[43] Barari B, Pillai KM. Green composites made from cellulose nanofibers and bio-based epoxy: Processing, performance, and applications. In Natural Fiber-Reinforced Biodegradable and Bioresorbable Polymer Composites 2017 (pp. 31-49).

[44] Balakrishnan P, Sreekala MS, Kunaver M, Huskić M, Thomas S. Morphology, transport characteristics and viscoelastic polymer chain confinement in nanocomposites based on thermoplastic potato starch and cellulose nanofibers from pineapple leaf. Carbohydrate polymers 2017; 169: 176-88.

https://doi.org/10.1016/j.carbpol.2017.04.017

[45] Zhang CW, Li FY, Li JF, Wang LM, Xie Q, Xu J, Chen S. A new biodegradable composite with open cell by combining modified starch and plant fibers. Materials \& Design 2017; 120: 222-9

\section{https://doi.org/10.1016/j.matdes.2017.02.027}

[46] Carothers WH. Studies on polymerization and ring formation. I. An introduction to the general theory of condensation polymers. Journal of the American Chemical Society 1929; 51(8): 2548-59.

https://doi.org/10.1021/ja01383a041

[47] Bikiaris DN, Achilias DS. Synthesis of poly (alkylene succinate) biodegradable polyesters I. Mathematical modelling of the esterification reaction. Polymer 2006; 47(13): 4851-60. https://doi.org/10.1016/j.polymer.2006.04.044

[48] Bikiaris DN, Achilias DS. Synthesis of poly (alkylene succinate) biodegradable polyesters, Part II: Mathematical modelling of the polycondensation reaction. Polymer 2008; 49(17): 3677-85. https://doi.org/10.1016/j.polymer.2008.06.026

[49] Gümther B, Zachmann HG. Influence of molar mass and catalysts on the kinetics of crystallization and on the orientation of poly (ethylene terephthalate). Polymer 1983; 24(8): 1008-14

https://doi.org/10.1016/0032-3861(83)90152-0

[50] Tomita K, Ida H. Studies on the formation of poly (ethylene terephthalate): 2. Rate of transesterification of dimethyl terephthalate with ethylene glycol. Polymer 1973; 14(2): 5560

https://doi.org/10.1016/0032-3861(73)90096-7

[51] Shah TH, Bhatty JI, Gamlen GA, Dollimore D. Aspects of the chemistry of poly (ethylene terephthalate): 5 . Polymerization of bis (hydroxyethyl) terephthalate by various metallic catalysts. Polymer 1984; 25(9): 1333-6.

https://doi.org/10.1016/0032-3861(84)90386-0

[52] Pang K, Kotek R, Tonelli A. Review of conventional and novel polymerization processes for polyesters. Progress in polymer science 2006; 31(11): 1009-37. https://doi.org/10.1016/j.progpolymsci.2006.08.008

[53] Evtushenko YM, Krushevskii GA, Miroshnikov YP, Zaitsev $\mathrm{BE}$, Konstant OD. Tetrabutoxytitanium adduct formation in esterification reactions. Theoretical Foundations of Chemical Engineering 2009; 43(5): 771 https://doi.org/10.1134/S0040579509050285

[54] Deming TJ. Synthetic polypeptides for biomedical applications. Progress in Polymer Science 2007; 32(8-9): 858-75. https://doi.org/10.1016/j.progpolymsci.2007.05.010

[55] Yu M, Nowak AP, Deming TJ, Pochan DJ. Methylated monoand diethyleneglycol functionalized polylysines: nonionic, $\alpha-$ helical, water-soluble polypeptides. Journal of the American Chemical Society 1999; 121(51): 12210-1. https://doi.org/10.1021/ja993637v

[56] Guo J, Huang $Y$, Jing $X$, Chen $X$. Synthesis and characterization of functional poly ( $\mathrm{Y}$-benzyl-I- 
glutamate)(PBLG) as a hydrophobic precursor. Polymer 2009; 50(13): 2847-55.

https://doi.org/10.1016/j.polymer.2009.04.016

[57] Dhamaniya S, Jacob J. Synthesis and characterization of copolyesters based on tartaric acid derivatives. Polymer bulletin 2012; 68(5): 1287-304. https://doi.org/10.1007/s00289-011-0606-9

[58] Dhamaniya S, Jacob J. Synthesis and characterization of polyesters based on tartaric acid derivatives. Polymer 2010; 51(23): 5392-9.

https://doi.org/10.1016/j.polymer.2010.09.034

[59] Feldmann J, Koebernick H, Richter K, Woelk HU, inventors; Unilever Bestfoods North America Inc, assignee. Process for recovering pure crystalline monoanhydrohexitols and dianhydrohexitols. United States patent US 4,564,692 1986 Jan 14

[60] Okada M, Okada Y, Tao A, Aoi K. Biodegradable polymers based on renewable resources: Polyesters composed of 1, 4: 3, 6-dianhydrohexitol and aliphatic dicarboxylic acid units. Journal of applied polymer science 1996; 62(13): 2257-65. https://doi.org/10.1002/(SICl)10974628(19961226)62:13<2257::AID-APP10>3.0.CO;2-0

[61] Okada M, Tsunoda K, Tachikawa K, Aoi K. Biodegradable polymers based on renewable resources. IV. Enzymatic degradation of polyesters composed of 1, 4: 3.6-dianhydro-D-glucitol and aliphatic dicarboxylic acid moieties. Journal of applied polymer science 2000; 77(2): 338-46.

https://doi.org/10.1002/(SICl)1097-

4628(20000711)77:2<338::AID-APP9>3.0.CO;2-C

[62] Okada M, Aoi K. Biodegradable polymers from 1, 4: 3, 6dianhydro-D-glucitol(Isosorbide) and its related compounds. Current Trends in Polymer Science 2002; 7: 57-70.

[63] Braun D, Bergmann M. Polyesters with 1.4: 3.6-dianhydrosorbitol as polymeric plasticizers for PVC. Die Angewandte Makromolekulare Chemie: Applied Macromolecular Chemistry and Physics 1992; 199(1): 191205

https://doi.org/10.1002/apmc.1992.051990115

[64] Kricheldorf HR, Gomourachvili Z. Polyanhydrides 10. Aliphatic polyesters and poly (ester-anhydride) $s$ by polycondensation of silylated aliphatic diols. Macromolecular Chemistry and Physics 1997; 198(10): 3149-60. https://doi.org/10.1002/macp.1997.021981013

[65] Kricheldorf HR, Masri MA. New polymer syntheses. LXXXII. Syntheses of poly (ether-sulfone) s from silylated aliphatic diols including chiral monomers. Journal of Polymer Science Part A: Polymer Chemistry 1995; 33(15): 2667-71. https://doi.org/10.1002/pola.1995.080331513

[66] Okada M, Tachikawa K, Aoi K. Biodegradable polymers based on renewable resources. II. Synthesis and biodegradability of polyesters containing furan rings. Journal of Polymer Science Part A: Polymer Chemistry 1997; 35(13): 2729-37. https://doi.org/10.1002/(SICl)10990518(19970930)35:13<2729::AID-POLA18>3.0.CO;2-D

[67] Okada M, Tachikawa K, Aoi K. Biodegradable polymers based on renewable resources. III. copolyesters composed of 1, 4: 3, 6-dianhydro-D-glucitol, 1, 1-bis (5-carboxy-2-furyl) ethane and aliphatic dicarboxylic acid units. Journal of applied polymer science 1999; 74(14): 3342-50.

https://doi.org/10.1002/(SICl)1097-

4628(19991227)74:14<3342::AID-APP7>3.0.CO;2-U

[68] Vogt S, Larcher Y, Beer B, Wilke I, Schnabelrauch M. Fabrication of highly porous scaffold materials based on functionalized oligolactides and preliminary results on their use in bone tissue engineering. Eur Cell Mater 2002; 4: 30-8. https://doi.org/10.22203/eCM.v004a03

[69] Noordover BA, van Staalduinen VG, Duchateau R, Koning $C E$, van Benthem RA, Mak $M$, Heise $A$, Frissen $A E$, van
Haveren J. Co-and terpolyesters based on isosorbide and succinic acid for coating applications: synthesis and characterization. Biomacromolecules 2006; 7(12): 3406-16. https://doi.org/10.1021/bm060713v

[70] Noordover, B.A.J.; Sablong, R.J.; Duchateau, R.; Benthem, R.A.T.M. van; Ming, W.; Konning, C.; Haveren, J. van Process for the production of a dianhydrohexitol based polyester WO. Pat 2008031592, 2008

[71] Van Haveren J, Oostveen EA, Micciche F, Noordover BA Koning CE, Van Benthem RA, Frissen AE, Weijnen JG. Resins and additives for powder coatings and alkyd paints, based on renewable resources. Journal of Coatings Technology and Research 2007; 4(2): 177-86. https://doi.org/10.1007/s11998-007-9020-5

[72] Okada M, Yamada M, Yokoe M, Aoi K. Biodegradable polymers based on renewable resources. V. Synthesis and biodegradation behavior of poly (ester amide) $s$ composed of 1, 4: 3, 6-dianhydro-d-glucitol, a-amino acid, and aliphatic dicarboxylic acid units. Journal of applied polymer science 2001; 81(11): 2721-34.

\section{https://doi.org/10.1002/app.1718}

[73] Gomurashvili Z, Kricheldorf HR, Katsarava R. Amino acid based bioanalogous polymers. Synthesis and study of new poly (ester amide) s composed of hydrophobic a-amino acids and dianhydrohexitoles 2000; 37: 215.

[74] Okada M, Yokoe M, Aoi K. Biodegradable polymers based on renewable resources. VI. Synthesis and biodegradability of poly (ester carbonate) $s$ containing 1, 4: 3, 6-dianhydro-d-glucitol and sebacic acid units. Journal of applied polymer science 2002; 86(4): 872-80 https://doi.org/10.1002/app.10995

[75] Kricheldorf HR, Sun SJ, Gerken A, Chang TC. Polymers of carbonic acid. 22. Cholesteric polycarbonates derived from (S)-((2-methylbutyl) thio) hydroquinone or isosorbide. Macromolecules 1996; 29(25): 8077-82 https://doi.org/10.1021/ma960494d

[76] Okada M, Yokoe M, Aoi K. Biodegradable polymers based on renewable resources. VI. Synthesis and biodegradability of poly (ester carbonate) $s$ containing $1,4: 3$, 6-dianhydro-d-glucitol and sebacic acid units. Journal of applied polymer science 2002; 86(4): 872-80.

https://doi.org/10.1002/app.10995

[77] Yokoe M, Aoi K, Okada M. Biodegradable polymers based on renewable resources. VII. Novel random and alternating copolycarbonates from 1, 4: 3, 6-dianhydrohexitols and aliphatic diols. Journal of Polymer Science Part A: Polymer Chemistry 2003; 41(15): 2312-21. https://doi.org/10.1002/pola.10772

[78] Yokoe M, Aoi K, Okada M. Biodegradable polymers based on renewable resources VIII. Environmental and enzymatic degradability of copolycarbonates containing 1, 4: 3 , 6-dianhydrohexitols. Journal of applied polymer science 2005; 98(4): 1679-87. https://doi.org/10.1002/app.22339

[79] Yokoe M, Aoi K, Okada M. Biodegradable polymers based on renewable resources. IX. Synthesis and degradation behavior of polycarbonates based on 1, 4: 3 , 6-dianhydrohexitols and tartaric acid derivatives with pendant functional groups. Journal of Polymer Science Part A: Polymer Chemistry 2005; 43(17): 3909-19. https://doi.org/10.1002/pola.20830

[80] Saiyasombat W, Molloy R, Nicholson TM, Johnson AF, Ward IM, Poshyachinda S. Ring strain and polymerizability of cyclic esters. Polymer 1998; 39(23): 5581-5. https://doi.org/10.1016/S0032-3861(97)10370-6

[81] Williams CK. Synthesis of functionalized biodegradable polyesters. Chemical Society Reviews 2007; 36(10): 157380.

https://doi.org/10.1039/b614342n 
[82] Kamber NE, Jeong W, Waymouth RM, Pratt RC, Lohmeijer BG, Hedrick JL. Organocatalytic ring-opening polymerization. Chemical reviews 2007; 107(12): 5813-40. https://doi.org/10.1021/cr068415b

[83] Robert JL, Aubrecht KB. Ring-opening polymerization of lactide to form a biodegradable polymer. Journal of chemical education 2008; 85(2): 258.

https://doi.org/10.1021/ed085p258

[84] Gupta AP, Kumar V. New emerging trends in synthetic biodegradable polymers-Polylactide: A critique. European polymer journal 2007; 43(10): 4053-74. https://doi.org/10.1016/j.eurpolymj.2007.06.045

[85] Albertsson AC, Varma IK. Recent developments in ring opening polymerization of lactones for biomedical applications. Biomacromolecules 2003; 4(6): 1466-86. https://doi.org/10.1021/bm034247a

[86] Albertsson AC, Varma IK. Aliphatic polyesters: synthesis, properties and applications. InDegradable Aliphatic Polyesters 2002 (pp. 1-40). Springer, Berlin, Heidelberg.

[87] Wu JC, Huang BH, Hsueh ML, Lai SL, Lin CC. Ring-opening polymerization of lactide initiated by magnesium and zinc alkoxides. Polymer 2005; 46(23): 9784-92. https://doi.org/10.1016/j.polymer.2005.08.009

[88] Gowda RR, Chakraborty D. Zinc acetate as a catalyst for the bulk ring opening polymerization of cyclic esters and lactide. Journal of Molecular Catalysis A: Chemical 2010; 333(1-2): 167-72.

https://doi.org/10.1016/j.molcata.2010.10.013

[89] Umare PS, Tembe GL, Rao KV, Satpathy US, Trivedi B. Catalytic ring-opening polymerization of I-lactide by titanium biphenoxy-alkoxide initiators. Journal of Molecular Catalysis A: Chemical 2007; 268(1-2): 235-43. https://doi.org/10.1016/j.molcata.2006.12.028

[90] Kim E, Shin EW, Yoo IK, Chung JS. Characteristics of heterogeneous titanium alkoxide catalysts for ring-opening polymerization of lactide to produce polylactide. Journal of Molecular Catalysis A: Chemical 2009; 298(1-2): 36-9. https://doi.org/10.1016/j.molcata.2008.09.029

[91] Stolt M, Södergård A. Use of monocarboxylic iron derivatives in the ring-opening polymerization of L-lactide. Macromolecules 1999; 32(20): 6412-7. https://doi.org/10.1021/ma9902753

[92] Deng X, Yuan M, Li X, Xiong C. Polymerization of lactides and lactones: VII. Ring-opening polymerization of lactide by rare earth phenyl compounds. European Polymer Journal 2000; 36(6): 1151-6. https://doi.org/10.1016/S0014-3057(99)00172-X

[93] Chisholm MH, Gallucci JC, Krempner C. Ring-opening polymerization of I-lactide by organotin (IV) alkoxides, $\mathrm{R}_{2} \mathrm{Sn}(\mathrm{OPr}-\mathrm{i})$ 2: Estimation of the activation parameters. Polyhedron 2007; 26(15): 4436-44. https://doi.org/10.1016/j.poly.2007.06.002

[94] Wu J, Pan X, Tang N, Lin CC. Synthesis, characterization of aluminum complexes and the application in ring-opening polymerization of I-lactide. European Polymer Journal 2007; 43(12): 5040-6. https://doi.org/10.1016/j.eurpolymj.2007.06.041

[95] Kricheldorf HR, Kreiser-Saunders I, Stricker A. Polylactones 48. SnOct2-initiated polymerizations of lactide: a mechanistic study. Macromolecules 2000; 33(3): 702-9. https://doi.org/10.1021/ma991181w

[96] Kowalski A, Libiszowski J, Biela T, Cypryk M, Duda A, Penczek S. Kinetics and mechanism of cyclic esters polymerization initiated with tin (II) octoate. Polymerization of $\varepsilon$-caprolactone and L, L-Lactide co-initiated with primary amines. Macromolecules 2005; 38(20): 8170-6. https://doi.org/10.1021/ma050752j

[97] Kowalski A, Duda A, Penczek S. Kinetics and mechanism of cyclic esters polymerization initiated with tin (II) octoate. 3.
Polymerization of L, L-dilactide. Macromolecules 2000; 33(20): 7359-70.

https://doi.org/10.1021/ma000125o

[98] Tian H, Tang Z, Zhuang X, Chen X, Jing X. Biodegradable synthetic polymers: preparation, functionalization and biomedical application. Progress in Polymer Science 2012; 37(2): $237-80$.

https://doi.org/10.1016/j.progpolymsci.2011.06.004

[99] Kimura Y, Shirotani K, Yamane H, Kitao T. Ring-opening polymerization of 3 (S)-[(benzyloxycarbonyl) methyl]-1, 4dioxane-2, 5-dione: a new route to a poly (. alpha.-hydroxy acid) with pendant carboxyl groups. Macromolecules 1988; 21(11): 3338-40. https://doi.org/10.1021/ma00189a037

[100] Trollsås M, Lee VY, Mecerreyes D, Löwenhielm P, Möller M, Miller RD, Hedrick JL. Hydrophilic aliphatic polyesters: design, synthesis, and ring-opening polymerization of functional cyclic esters. Macromolecules 2000; 33(13): 461927.

https://doi.org/10.1021/ma992161x

[101] Gerhardt WW, Noga DE, Hardcastle KI, Garcia AJ, Collard DM, Weck M. Functional lactide monomers: Methodology and polymerization. Biomacromolecules 2006; 7(6): 1735-42. https://doi.org/10.1021/bm060024j

[102] Tian D, Dubois P, Grandfils C, Jérôme R. Ring-opening polymerization of 1, 4, 8-trioxaspiro [4.6]-9-undecanone: A new route to aliphatic polyesters bearing functional pendent groups. Macromolecules 1997; 30(3): 406-9. https://doi.org/10.1021/ma961631+

[103] Tian D, Dubois $P$, Jérôme R. Macromolecular engineering of polylactones and polylactides. 22. Copolymerization of $\varepsilon$ caprolactone and 1, 4, 8-trioxaspiro [4.6]-9-undecanone initiated by aluminum isopropoxide. Macromolecules 1997; 30(9): 2575-81.

https://doi.org/10.1021/ma961567w

[104] Tian D, Dubois $P$, Jérôme R. Macromolecular engineering of polylactones and polylactides. 23. Synthesis and characterization of biodegradable and biocompatible homopolymers and block copolymers based on 1, 4, 8-trioxa [4.6] spiro-9-undecanone. Macromolecules 1997; 30(7): 1947-54.

https://doi.org/10.1021/ma961614k

[105] Tian D, Halleux O, Dubois $P$, Jérôme R, Sobry R, Van den Bossche G. Poly (2-oxepane-1, 5-dione): A highly crystalline modified poly ( $\varepsilon$-caprolactone) of a high melting temperature. Macromolecules 1998; 31(3): 924-7. https://doi.org/10.1021/ma9709031

[106] Liu XQ, Wang MX, Li ZC, Li FM. Synthesis and ring-opening polymerization of $\alpha$-chloromethyl- $\alpha$-methyl- $\beta$-propiolactone. Macromolecular Chemistry and Physics 1999; 200(2): 46873. https://doi.org/10.1002/(SICl)15213935(19990201)200:2<468::AID-MACP468>3.0.CO;2-N

[107] Mecerreyes D, Atthoff $B$, Boduch KA, Trollsås M, Hedrick JL. Unimolecular combination of an atom transfer radical polymerization initiator and a lactone monomer as a route to new graft copolymers. Macromolecules 1999; 32(16): 517582.

https://doi.org/10.1021/ma982005a

[108] Al-Azemi TF, Bisht KS. Novel functional polycarbonate by lipase-catalyzed ring-opening polymerization of 5-methyl-5benzyloxycarbonyl-1, 3-dioxan-2-one. Macromolecules 1999; 32(20): 6536-40. https://doi.org/10.1021/ma990639r

[109] Liu ZL, Zhou Y, Zhuo RX. Synthesis and properties of functional aliphatic polycarbonates. Journal of Polymer Science Part A: Polymer Chemistry 2003; 41(24): 4001-6. https://doi.org/10.1002/pola.11001 
[110] Sanda F, Kamatani J, Endo T. Synthesis and anionic ringopening polymerization behavior of amino acid-derived cyclic carbonates. Macromolecules 2001; 34(6): 1564-9. https://doi.org/10.1021/ma0013307

[111] $\mathrm{Hu} X$, Chen $X$, Xie Z, Cheng $H$, Jing $X$. Aliphatic poly (ester-carbonate) $s$ bearing amino groups and its RGD peptide grafting. Journal of Polymer Science Part A: Polymer Chemistry 2008; 46(21): 7022-32. https://doi.org/10.1002/pola.23008

[112] Lee RS, Yang JM, Lin TF. Novel, biodegradable, functional poly (ester-carbonate) $\mathrm{S}$ by copolymerization of trans-4-hydroxy-L-proline with cyclic carbonate bearing a pendent carboxylic group. Journal of Polymer Science Part A: Polymer Chemistry 2004; 42(10): 2303-12. https://doi.org/10.1002/pola.20052

[113] Wang XL, Zhuo RX, Liu LJ, He F, Liu G. Synthesis and characterization of novel aliphatic polycarbonates. Journal of Polymer Science Part A: Polymer Chemistry 2002; 40(1): 70https://doi.org/10.1002/pola.10088

[114] Yang J, Hao Q, Liu X, Ba C, Cao A. Novel biodegradable aliphatic poly (butylene succinate-co-cyclic carbonate)s with functionalizable carbonate building blocks. 1. Chemical synthesis and their structural and physical characterization. Biomacromolecules 2004; 5(1): 209-18.

https://doi.org/10.1021/bm0343242

[115] Guan HL, Xie ZG, Zhang PB, Wang X, Chen XS, Wang XH, Jing $X B$. Synthesis and characterization of novel biodegradable block copolymer poly (ethylene glycol)block-poly (L-lactide-co-2-methyl-2-carboxyl-propylene carbonate). Journal of Polymer Science Part A: Polymer Chemistry 2005; 43(20): 4771-80.

https://doi.org/10.1002/pola.20942

[116] Xie Z, Hu X, Chen X, Sun J, Shi Q, Jing X. Synthesis and characterization of novel biodegradable poly (carbonate ester) $s$ with photolabile protecting groups. Biomacromolecules 2007; 9(1): 376-80. https://doi.org/10.1021/bm700906k

[117] Hu X, Chen X, Cheng H, Jing X. Cinnamate-functionalized poly (ester-carbonate): Synthesis and its UV irradiation-induced photo-crosslinking. Journal of Polymer Science Part A: Polymer Chemistry 2009; 47(1): 161-9. https://doi.org/10.1002/pola.23134

[118] Xie Z, Lu C, Chen X, Chen L, Wang Y, Hu X, Shi Q, Jing X. Synthesis and characterization of novel poly (ester carbonate) $s$ based on pentaerythritol. Journal of Polymer Science Part A: Polymer Chemistry 2007; 45(9): 1737-45. https://doi.org/10.1002/pola.21941

[119] Chen X, McCarthy SP, Gross RA. Synthesis, characterization, and epoxidation of an aliphatic polycarbonate from 2, 2-(2-pentene-1, 5-diyl) trimethylene carbonate (cHTC) ring-opening polymerization. Macromolecules 1997; 30(12): 3470-6. https://doi.org/10.1021/ma961821k

[120] Chen X, McCarthy SP, Gross RA. Synthesis, modification, and characterization of L-lactide/2, 2-[2-pentene-1, 5-diyl] trimethylene carbonate copolymers. Macromolecules 1998; 31(3): 662-8.

https://doi.org/10.1021/ma9712880

[121] He F, Wang YP, Liu G, Jia HL, Feng J, Zhuo RX. Synthesis, characterization and ring-opening polymerization of a novel six-membered cyclic carbonate bearing pendent allyl ether group. Polymer 2008; 49(5): 1185-90. https://doi.org/10.1016/j.polymer.2008.01.025

[122] Cunningham A, Ko NR, Oh JK. Synthesis and reductionresponsive disassembly of PLA-based mono-cleavable micelles. Colloids and Surfaces B: Biointerfaces 2014; 122: 693-700.

https://doi.org/10.1016/j.colsurfb.2014.08.002
[123] Xu J, Luan S, Qin B, Wang Y, Wang K, Qi P, Song S. Backbone-hydrazone-containing biodegradable copolymeric micelles for anticancer drug delivery. Journal of Nanoparticle Research 2016; 18(11): 316.

https://doi.org/10.1007/s11051-016-3626-4

[124] Petrova S, Venturini CG, Jäger $A$, Jäger $E$, Černoch $P$, Kereïche $S$, Kováčik L, Raška I, Štěpánek P. Novel thermoresponsive double-hydrophilic and hydrophobic MPEO-bPEtOx-b-PCL triblock terpolymers: Synthesis, characterization and self-assembly studies. Polymer 2015; 59: $215-25$ https://doi.org/10.1016/j.polymer.2015.01.009

[125] Xiong D, Yao N, Gu H, Wang J, Zhang L. Stimuli-responsive shell cross-linked micelles from amphiphilic four-arm star copolymers as potential nanocarriers for " $\mathrm{pH} /$ redox-triggered" anticancer drug release. Polymer 2017; 114: 161-72. https://doi.org/10.1016/j.polymer.2017.03.002

[126] Wang Y, Yang J, Yang J. Synthesis and self-assembly of novel amphiphilic copolymers poly (lactic acid)-block-poly (ascorbyl acrylate). Journal of Polymer Science Part A: Polymer Chemistry 2011; 49(18): 3988-96. https://doi.org/10.1002/pola.24840

[127] Guo Y, Liu J, Zhang K, Zhang H, Li Y, Lei Z. Synthesis of stimuli-responsive support material for pectinase immobilization and investigation of its controllable tailoring of enzymatic activity. Biochemical Engineering Journal 2017; 121: $188-95$.

https://doi.org/10.1016/j.bej.2017.02.010

[128] Kim JK, Basavaraja C, Umashankar M. Effect of honeycombpatterned structure on electrical and magnetic behaviors of poly ( $\varepsilon$-caprolactone)/capped magnetic nanoparticle composite films. Polymer 2016; 87: 138-47. https://doi.org/10.1016/j.polymer.2016.01.052

[129] Mao L, Liu YJ, Bai YK, Wu HQ, Liu XC. Poly ( $\varepsilon$-caprolactone) nanocomposites with layered double hydroxides modified by in situ grafting polymerization: Structure characterization and barrier properties. Journal of Applied Polymer Science 2017; 134(38): 45320.

https://doi.org/10.1002/app.45320

[130] Park JY, Male U, Huh D. Reversible change of wettability in poly ( $\varepsilon$-caprolactone/azobenzene) honeycomb-patterned films by UV and visible light illumination. Polymer Bulletin 2017; 74(10): 4235-49.

https://doi.org/10.1007/s00289-017-1948-8

[131] Yuan F, Gu Z, Li L, Sha L. Novel cerium (IV)-diolate complex with a 13-nuclear cerium (IV)-oxo core: Synthesis, molecular structure and catalytic property for $\varepsilon$-caprolactonepolymerization. Polyhedron 2017; 133: 393-7. https://doi.org/10.1016/j.poly.2017.06.001

[132] Njogu EM, Omondi B, Nyamori VO. Silver (I)-pyridinyl Schiff base complexes: Synthesis, structural characterization and reactivity in ring-opening polymerisation of $\varepsilon$-caprolactone. Inorganica Chimica Acta 2017; 457: 160-70. https://doi.org/10.1016/j.ica.2016.12.019

[133] Roymuhury SK, Chakraborty D, Ramkumar V. Aluminium complexes bearing $\mathrm{N}, \mathrm{O}$-aminophenol ligands as efficient catalysts for the ring opening polymerization of lactide. European Polymer Journal 2015; 70: 203-14. https://doi.org/10.1016/j.eurpolymj.2015.07.025

[134] Rosen T, Goldberg I, Venditto V, Kol M. Tailor-made stereoblock copolymers of poly (lactic acid) by a truly living polymerization catalyst. Journal of the American Chemical Society 2016; 138(37): 12041-4. https://doi.org/10.1021/jacs.6b07287

[135] Phillips DJ, Gibson MI. Biodegradable poly (disulfide) s derived from RAFT polymerization: monomer scope, glutathione degradation, and tunable thermal responses. Biomacromolecules 2012; 13(10): 3200-8. https://doi.org/10.1021/bm300989s 
[136] Gatti S, Agostini A, Ferrari R, Moscatelli D. Synthesis and nanoprecipitation of HEMA-CLn based polymers for the production of biodegradable nanoparticles. Polymers 2017; 9(9): 389

https://doi.org/10.3390/polym9090389

[137] Hu K, Ou EC, Xu Q, Peng C, Li L, Bao L, Xiong YQ, Xu WJ. Light-responsive and biodegradable block polymer synthesized by RAFT polymerization and its potential drug carrier properties. Chemistry Letters 2016; 45(9): 1108-10. https://doi.org/10.1246/cl.160339

[138] Sponchioni M, Ferrari R, Morosi L, Moscatelli D. Influence of the polymer structure over self-assembly and thermo-responsive properties: The case of PEG-b-PCL grafted copolymers via a combination of RAFT and ROP. Journal of Polymer Science Part A: Polymer Chemistry 2016; 54(18): 2919-31. https://doi.org/10.1002/pola.28177

[139] Cui L, Wang R, Ji X, Hu M, Wang B, Liu J. Template-assisted synthesis of biodegradable and $\mathrm{pH}$-responsive polymer capsules via RAFT polymerization for controlled drug release. Materials Chemistry and Physics 2014; 148(1-2): 8795.

https://doi.org/10.1016/j.matchemphys.2014.07.016

[140] Guégain E, Michel JP, Boissenot T, Nicolas J. Tunable Degradation of Copolymers Prepared by Nitroxide-Mediated Radical Ring-Opening Polymerization and Point-by-Point Comparison with Traditional Polyesters. Macromolecules 2018; 51(3): 724-36. https://doi.org/10.1021/acs.macromol.7b02655

[141] Kukut M, Karal-Yilmaz O, Yagci Y. Synthesis, characterisation and drug release properties of microspheres of polystyrene with aliphatic polyester side-chains. Journal of microencapsulation 2014; 31(3): 254-61. https://doi.org/10.3109/02652048.2013.834993

[142] Gross RA, Kumar A, Kalra B. Polymer synthesis by in vitro enzyme catalysis. Chemical Reviews 2001; 101(7): 2097-124. https://doi.org/10.1021/cr0002590

[143] Varma IK, Albertsson AC, Rajkhowa R, Srivastava RK. Enzyme catalyzed synthesis of polyesters. Progress in Polymer Science 2005; 30(10): 949-81. https://doi.org/10.1016/j.progpolymsci.2005.06.010

[144] Chaudhary AK, Beckman EJ, Russell AJ. Biocatalytic polyester synthesis: Analysis of the evolution of molecular weight and end group functionality. Biotechnology and bioengineering 1997; 55(1): 227-39.

https://doi.org/10.1002/(SICl)10970290(19970705)55:1<227::AID-BIT23>3.0.CO;2-H

[145] Uyama H, Namekawa S, Kobayash S. Mechanistic studies on the lipase-catalyzed ring-opening polymerization of lactones. Polymer journal 1997; 29(3): 299.

https://doi.org/10.1295/polymj.29.299

[146] Namekawa S, Suda S, Uyama H, Kobayashi S. Lipasecatalyzed ring-opening polymerization of lactones to polyesters and its mechanistic aspects. International journal of biological macromolecules 1999; 25(1-3): 145-51.

https://doi.org/10.1016/S0141-8130(99)00028-8

[147] Kobayashi S, Uyama H, Namekawa S. In vitro biosynthesis of polyesters with isolated enzymes in aqueous systems and organic solvents. Polymer degradation and stability 1998; 59(1-3): 195-201.

https://doi.org/10.1016/S0141-3910(97)00178-X

[148] Tsujimoto T, Uyama H, Kobayashi S. Enzymatic synthesis and curing of biodegradable crosslinkable polyesters. Macromolecular Bioscience 2002; 2(7): 329-35. https://doi.org/10.1002/1616-5195(200209)2:7<329::AIDMABI329>3.0.CO;2-H

[149] Mahapatro A, Kumar A, Gross RA. Mild, Solvent-Free $\omega$ Hydroxy Acid Polycondensations Catalyzed by Candida a ntarctica Lipase B. Biomacromolecules 2004; 5(1): 62-8. https://doi.org/10.1021/bm0342382
[150] Iwata S, Toshima K, Matsumura S. Enzyme-catalyzed preparation of aliphatic polyesters containing thioester linkages. Macromolecular rapid communications 2003; 24(7): 467-71. https://doi.org/10.1002/marc.200390070

[151] Panova AA, Taktak S, Randriamahefa S, Cammas-Marion S, Guerin P, Kaplan DL. Polymerization of Propyl Malolactonate in the Presence of Candida $r$ ugosa Lipase. Biomacromolecules 2003; 4(1): 19-27. https://doi.org/10.1021/bm0255746

[152] Uyama H, Takeya K, Hoshi N, Kobayashi S. Lipasecatalyzed ring-opening polymerization of 12-dodecanolide. Macromolecules 1995; 28(21): 7046-50 https://doi.org/10.1021/ma00125a002

[153] Kumar A, Gross RA, Wang Y, Hillmyer MA. Recognition by lipases of $\omega$-hydroxyl macroinitiators for diblock copolymer synthesis. Macromolecules 2002; 35(20): 7606-11. https://doi.org/10.1021/ma020060k

[154] Dong H, Cao SG, Li ZQ, Han SP, You DL, Shen JC. Study on the enzymatic polymerization mechanism of lactone and the strategy for improving the degree of polymerization. Journal of Polymer Science Part A: Polymer Chemistry 1999; 37(9): 1265-75.

https://doi.org/10.1002/(SICI)10990518(19990501)37:9<1265::AID-POLA6>3.0.CO;2-I

[155] Deng F, Gross RA. Ring-opening bulk polymerization of $\varepsilon$ caprolactone and trimethylene carbonate catalyzed by lipase Novozym 435. International journal of biological macromolecules 1999; 25(1-3): 153-9. https://doi.org/10.1016/S0141-8130(99)00029-X

[156] Kumar A, Gross RA. Candida a ntartica Lipase B Catalyzed Polycaprolactone Synthesis: Effects of Organic Media and Temperature. Biomacromolecules 2000; 1(1): 133-8. https://doi.org/10.1021/bm990510p

[157] Moon RJ, Martini A, Nairn J, Simonsen J, Youngblood J. Cellulose nanomaterials review: structure, properties and nanocomposites. Chemical Society Reviews 2011; 40(7): 3941-94.

https://doi.org/10.1039/c0cs00108b

[158] Ikada $\mathrm{Y}$, Tsuji $\mathrm{H}$. Biodegradable polyesters for medical and ecological applications. Macromolecular rapid communications 2000; 21(3): 117-32.

https://doi.org/10.1002/(SICl)1521 3927(20000201)21:3<117::AID-MARC117>3.0.CO;2-X

[159] Inkinen S, Hakkarainen $M$, Albertsson AC, Södergård $A$. From lactic acid to poly (lactic acid)(PLA): characterization and analysis of PLA and its precursors. Biomacromolecules 2011; 12(3): 523-32. https://doi.org/10.1021/bm101302t

[160] Garlotta D. A literature review of poly (lactic acid). Journal of Polymers and the Environment 2001; 9(2): 63-84. https://doi.org/10.1023/A:1020200822435

[161] Lim LT, Auras R, Rubino M. Processing technologies for poly (lactic acid). Progress in polymer science 2008; 33(8): 82052.

https://doi.org/10.1016/j.progpolymsci.2008.05.004

[162] Woodruff MA, Hutmacher DW. The return of a forgotten polymer-polycaprolactone in the 21st century. Progress in polymer science $2010 ; 35(10): 1217-56$. https://doi.org/10.1016/j.progpolymsci.2010.04.002

[163] Fujimaki T. Processability and properties of aliphatic polyesters, 'BIONOLLE', synthesized by polycondensation reaction. Polymer degradation and stability 1998; 59(1-3): 209-14. https://doi.org/10.1016/S0141-3910(97)00220-6

[164] Nofar M, Heuzey MC, Carreau PJ, Kamal MR. Effects of nanoclay and its localization on the morphology stabilization of PLA/PBAT blends under shear flow. Polymer 2016; 98: 353-64.

https://doi.org/10.1016/j.polymer.2016.06.044 
[165] Harun-or-Rashid MD, Rahaman S, Enamul Kabir S, Khan MA. Effect of hydrochloric acid on the properties of biodegradable packaging materials of carboxymethylcellulose/poly (vinyl alcohol) blends. Journal of Applied Polymer Science 2016; 133(2).

[166] Fasihi H, Fazilati M, Hashemi M, Noshirvani N. Novel carboxymethyl cellulose-polyvinyl alcohol blend films stabilized by Pickering emulsion incorporation method. Carbohydrate polymers 2017; 167: 79-89. https://doi.org/10.1016/j.carbpol.2017.03.017

[167] Chahal S, Hussain FS, Yusoff MB. Characterization of modified cellulose (MC)/poly (vinyl alcohol) electrospun nanofibers for bone tissue engineering. Procedia Engineering 2013; 53: 683-8. https://doi.org/10.1016/j.proeng.2013.02.088

[168] Hameed N, Xiong R, Salim NV, Guo Q. Fabrication and characterization of transparent and biodegradable cellulose/poly (vinyl alcohol) blend films using an ionic liquid. Cellulose 2013; 20(5): 2517-27.

https://doi.org/10.1007/s10570-013-0017-1

[169] Qiu K, Netravali AN. Fabrication and characterization of biodegradable composites based on microfibrillated cellulose and polyvinyl alcohol. Composites Science and Technology 2012; 72(13): 1588-94.

https://doi.org/10.1016/j.compscitech.2012.06.010

[170] Guzman-Puyol S, Ceseracciu L, Heredia-Guerrero JA, Anyfantis GC, Cingolani R, Athanassiou A, Bayer IS. Effect of trifluoroacetic acid on the properties of polyvinyl alcohol and polyvinyl alcohol-cellulose composites. Chemical Engineering Journal 2015; 277: 242-51.

https://doi.org/10.1016/j.cej.2015.04.092

[171] Fortunati E, Benincasa P, Balestra GM, Luzi F, Mazzaglia A, Del Buono D, Puglia D, Torre L. Revalorization of barley straw and husk as precursors for cellulose nanocrystals extraction and their effect on PVA_CH nanocomposites. Industrial Crops and Products 2016; 92: 201-17. https://doi.org/10.1016/j.indcrop.2016.07.047

[172] Quintana R, Persenaire O, Lemmouchi Y, Bonnaud L, Dubois P. Compatibilization of co-plasticized cellulose acetate/water soluble polymers blends by reactive extrusion. Polymer Degradation and Stability 2016; 126: 31-8. https://doi.org/10.1016/j.polymdegradstab.2015.12.023

[173] Cano Al, Cháfer M, Chiralt A, González-Martínez C. Biodegradation behavior of starch-PVA films as affected by the incorporation of different antimicrobials. Polymer Degradation and Stability 2016; 132: 11-20. https://doi.org/10.1016/j.polymdegradstab.2016.04.014

[174] Wang HF, Su W, Zhang C, Luo XH, Feng J. Biocatalytic fabrication of fast-degradable, water-soluble polycarbonate functionalized with tertiary amine groups in backbone. Biomacromolecules 2010; 11(10): 2550-7. https://doi.org/10.1021/bm1001476

[175] Zhang X, Cai M, Zhong Z, Zhuo R. A water-soluble polycarbonate with dimethylamino pendant groups prepared by enzyme-catalyzed ring-opening polymerization. Macromolecular rapid communications 2012; 33(8): 693-7. https://doi.org/10.1002/marc.201100765

[176] Zhou Q, Gu L, Gao Y, Qin Y, Wang X, Wang F. Biodegradable CO2-based polycarbonates with rapid and reversible thermal response at body temperature. Journal of Polymer Science Part A: Polymer Chemistry 2013; 51(9): 1893-8. https://doi.org/10.1002/pola.26583

[177] Lee JB, Lee YK, Choi GD, Na SW, Park TS, Kim WN. Compatibilizing effects for improving mechanical properties of biodegradable poly (lactic acid) and polycarbonate blends. Polymer degradation and stability 2011 ; 96(4): 553-60. https://doi.org/10.1016/j.polymdegradstab.2010.12.019

[178] Niu Y, Zhang W, Li H, Chen X, Sun J, Zhuang X, Jing X. Carbon dioxide/propylene oxide coupling reaction catalyzed by chromium salen complexes. Polymer 2009; 50(2): 441-6. https://doi.org/10.1016/j.polymer.2008.11.008
[179] Liu S, Zhao X, Guo H, Qin Y, Wang X, Wang F. Construction of Well-Defined Redox-Responsive CO2-Based Polycarbonates: Combination of Immortal Copolymerization and Prereaction Approach. Macromolecular rapid communications 2017; 38(9): 1600754. https://doi.org/10.1002/marc.201600754

[180] Chang C, Qin Y, Luo X, Li Y. Synthesis and process optimization of soybean oil-based terminal epoxides for the production of new biodegradable polycarbonates via the intergration of CO2. Industrial crops and products 2017; 99: 34-40.

\section{https://doi.org/10.1016/j.indcrop.2017.01.032}

[181] Song P, Mao X, Zhang X, Zhu X, Wang R. A one-step strategy for cross-linkable aliphatic polycarbonates with high degradability derived from $\mathrm{CO} 2$, propylene oxide and itaconic anhydride. RSC Advances 2014; 4(30): 15602-5. https://doi.org/10.1039/C4RA01514B

[182] Liu S, Wang J, Huang K, Liu Y, Wu W. Synthesis of poly (propylene-co-lactide carbonate) and hydrolysis of the terpolymer. Polymer bulletin 2011; 66(3): 327-40.

https://doi.org/10.1007/s00289-010-0283-0

[183] Zhuang Y, Song W, Ning G, Sun X, Sun Z, Xu G, Zhang B, Chen $Y$, Tao S. 3D-printing of materials with anisotropic heat distribution using conductive polylactic acid composites. Materials \& Design 2017; 126: 135-40. https://doi.org/10.1016/j.matdes.2017.04.047

[184] Tian X, Liu T, Yang C, Wang Q, Li D. Interface and performance of $3 D$ printed continuous carbon fiber reinforced PLA composites. Composites Part A: Applied Science and Manufacturing 2016; 88: 198-205. https://doi.org/10.1016/j.compositesa.2016.05.032

[185] Ronca D, Langella F, Chierchia M, D'Amora U, Russo T, Domingos M, Gloria A, Bartolo P, Ambrosio L. Bone tissue engineering: 3D PCL-based nanocomposite scaffolds with tailored properties. Procedia CIRP 2016; 49: 51-4. https://doi.org/10.1016/j.procir.2015.07.028

[186] Pei E, Shen J, Watling J. Direct 3D printing of polymers onto textiles: experimental studies and applications. Rapid Prototyping Journal 2015; 21(5): 556-71. https://doi.org/10.1108/RPJ-09-2014-0126

[187] Zhang B, Seong B, Nguyen V, Byun D. 3D printing of highresolution PLA-based structures by hybrid electrohydrodynamic and fused deposition modeling techniques. Journal of Micromechanics and Microengineering 2016; 26(2): 025015. https://doi.org/10.1088/0960-1317/26/2/025015

[188] Wang M, Favi P, Cheng X, Golshan NH, Ziemer KS, Keidar $\mathrm{M}$, Webster TJ. Cold atmospheric plasma (CAP) surface nanomodified 3D printed polylactic acid (PLA) scaffolds for bone regeneration. Acta biomaterialia 2016; 46: 256-65 https://doi.org/10.1016/j.actbio.2016.09.030

[189] Bustillos J, Montero D, Nautiyal P, Loganathan A, Boesl B, Agarwal A. Integration of graphene in poly (lactic) acid by 3D printing to develop creep and wear-resistant hierarchical nanocomposites. Polymer Composites 2017. https://doi.org/10.1002/pc.24422

[190] Sanatgar RH, Campagne C, Nierstrasz V. Investigation of the adhesion properties of direct 3D printing of polymers and nanocomposites on textiles: Effect of FDM printing process parameters. Applied Surface Science 2017; 403: 551-63. https://doi.org/10.1016/j.apsusc.2017.01.112

[191] Dong J, Li M, Zhou L, Lee S, Mei C, Xu X, Wu Q. The influence of grafted cellulose nanofibers and postextrusion annealing treatment on selected properties of poly (lactic acid) filaments for $3 \mathrm{D}$ printing. Journal of Polymer Science Part B: Polymer Physics 2017; 55(11): 847-55. https://doi.org/10.1002/polb.24333

[192] Su CK, Chen JC. Reusable, 3D-printed, peroxidase mimicincorporating multi-well plate for high-throughput glucose 
determination. Sensors and Actuators B: Chemical 2017; 247: 641-7.

https://doi.org/10.1016/j.snb.2017.03.054

[193] Guo Y, Chang CC, Halada G, Cuiffo MA, Xue Y, Zuo X, Pack $S$, Zhang L, He S, Weil E, Rafailovich MH. Engineering flame retardant biodegradable polymer nanocomposites and their application in 3D printing. Polymer Degradation and Stability 2017; 137: 205-15.

https://doi.org/10.1016/j.polymdegradstab.2017.01.019

[194] Mendoza-Buenrostro C, Lara H, Rodriguez C. Hybrid fabrication of a 3D printed geometry embedded with PCL nanofibers for tissue engineering applications. Procedia Engineering 2015; 110: 128-34.

https://doi.org/10.1016/j.proeng.2015.07.020

[195] Muwaffak Z, Goyanes A, Clark V, Basit AW, Hilton ST, Gaisford S. Patient-specific 3D scanned and 3D printed antimicrobial polycaprolactone wound dressings. International journal of pharmaceutics 2017; 527(1-2): 161-70. https://doi.org/10.1016/j.ijpharm.2017.04.077

[196] Wu CS, Liao HT, Cai YX. Characterisation, biodegradability and application of palm fibre-reinforced polyhydroxyalkanoate composites. Polymer Degradation and Stability 2017; 140: 55-63.

https://doi.org/10.1016/j.polymdegradstab.2017.04.016

[197] Kelnar I, Kratochvíl J, Kaprálková L, Zhigunov A, Nevoralová M. Graphite nanoplatelets-modified PLA/PCL: Effect of blend ratio and nanofiller localization on structure and properties. Journal of the mechanical behavior of biomedical materials 2017; 71: 271-8.

https://doi.org/10.1016/j.jmbbm.2017.03.028

[198] Malinowski R. Mechanical properties of PLA/PCL blends crosslinked by electron beam and TAIC additive. Chemical Physics Letters 2016; 662: 91-6. https://doi.org/10.1016/j.cplett.2016.09.022

[199] Ostafinska A, Fortelný I, Hodan J, Krejčíková S, Nevoralová M, Kredatusová J, Kruliš Z, Kotek J, Šlouf M. Strong synergistic effects in PLA/PCL blends: Impact of PLA matrix viscosity. Journal of the mechanical behavior of biomedical materials 2017; 69: 229-41.

https://doi.org/10.1016/j.jmbbm.2017.01.015

[200] Wachirahuttapong S, Thongpin C, Sombatsompop N. Effect of PCL and compatibility contents on the morphology, crystallization and mechanical properties of PLA/PCL blends. Energy Procedia 2016; 89: 198-206. https://doi.org/10.1016/j.egypro.2016.05.026

[201] Navarro-Baena I, Sessini V, Dominici F, Torre L, Kenny JM, Peponi L. Design of biodegradable blends based on PLA and PCL: From morphological, thermal and mechanical studies to shape memory behavior. Polymer Degradation and Stability 2016; 132: 97-108.

https://doi.org/10.1016/j.polymdegradstab.2016.03.037

[202] Mofokeng JP, Luyt AS. Dynamic mechanical properties of PLA/PHBV, PLA/PCL, PHBV/PCL blends and their nanocomposites with $\mathrm{TiO} 2$ as nanofiller. Thermochimica Acta 2015; 613: 41-53.

https://doi.org/10.1016/j.tca.2015.05.019

[203] Li L, Huang W, Wang B, Wei W, Gu Q, Chen P. Properties and structure of polylactide/poly (3-hydroxybutyrate-co-3hydroxyvalerate)(PLA/PHBV) blend fibers. Polymer 2015; 68: 183-94.

https://doi.org/10.1016/j.polymer.2015.05.024

[204] Xu Z, Chai X. Effect of weight ratios of PHBV/PLA polymer blends on nitrate removal efficiency and microbial community during solid-phase denitrification. International Biodeterioration \& Biodegradation 2017; 116: 175-83. https://doi.org/10.1016/j.ibiod.2016.10.033

[205] Yang J, Zhu H, Zhang C, Jiang Q, Zhao Y, Chen P, Wang D. Transesterification induced mechanical properties enhancement of PLLA/PHBV bio-alloy. Polymer 2016; 83: 230-8. https://doi.org/10.1016/j.polymer.2015.12.025
[206] Zembouai I, Kaci M, Bruzaud S, Dumazert L, Bourmaud A, Mahlous M, Lopez-Cuesta JM, Grohens Y. Gamma irradiation effects on morphology and properties of PHBV/PLA blends in presence of compatibilizer and Cloisite 30B. Polymer Testing 2016; 49: 29-37. https://doi.org/10.1016/j.polymertesting.2015.11.003

[207] Arrieta MP, Fortunati E, Dominici F, López J, Kenny JM. Bionanocomposite films based on plasticized PLA$\mathrm{PHB} /$ cellulose nanocrystal blends. Carbohydrate polymers 2015; 121: 265-75. https://doi.org/10.1016/j.carbpol.2014.12.056

[208] Arrieta MP, López J, López D, Kenny JM, Peponi L. Biodegradable electrospun bionanocomposite fibers based on plasticized PLA-PHB blends reinforced with cellulose nanocrystals. Industrial Crops and Products 2016; 93: 290301. https://doi.org/10.1016/j.indcrop.2015.12.058

[209] Abdelwahab MA, Flynn A, Chiou BS, Imam S, Orts W, Chiellini E. Thermal, mechanical and morphological characterization of plasticized PLA-PHB blends. Polymer Degradation and Stability 2012; 97(9): 1822-8. https://doi.org/10.1016/j.polymdegradstab.2012.05.036

[210] Nicosia A, Gieparda W, Foksowicz-Flaczyk J, Walentowska J, Wesołek D, Vazquez B, Prodi F, Belosi F. Air filtration and antimicrobial capabilities of electrospun PLA/PHB containing ionic liquid. Separation and Purification Technology 2015; 154: 154-60.

https://doi.org/10.1016/j.seppur.2015.09.037

[211] Armentano I, Fortunati E, Burgos N, Dominici F, Luzi F, Fiori $\mathrm{S}$, Jiménez A, Yoon $\mathrm{K}$, Ahn J, Kang $\mathrm{S}$, Kenny JM. Processing and characterization of plasticized PLA/PHB blends for biodegradable multiphase systems. Express Polymer Letters 2015; 9(7). https://doi.org/10.3144/expresspolymlett.2015.55

[212] Wang LF, Rhim JW, Hong SI. Preparation of poly (lactide)/poly (butylene adipate-co-terephthalate) blend films using a solvent casting method and their food packaging application. LWT-Food Science and Technology 2016; 68: 454-61.

https://doi.org/10.1016/j.Iwt.2015.12.062

[213] Lu X, Zhao J, Yang X, Xiao P. Morphology and properties of biodegradable poly (lactic acid)/poly (butylene adipate-coterephthalate) blends with different viscosity ratio. Polymer Testing 2017; 60: 58-67. https://doi.org/10.1016/j.polymertesting.2017.03.008

[214] Arruda LC, Magaton M, Bretas RE, Ueki MM. Influence of chain extender on mechanical, thermal and morphological properties of blown films of PLA/PBAT blends. Polymer Testing 2015; 43: 27-37. https://doi.org/10.1016/j.polymertesting.2015.02.005

[215] Al-Itry R, Lamnawar K, Maazouz A. Improvement of thermal stability, rheological and mechanical properties of PLA, PBAT and their blends by reactive extrusion with functionalized epoxy. Polymer Degradation and Stability 2012; 97(10): 1898-914. https://doi.org/10.1016/j.polymdegradstab.2012.06.028

[216] Müller P, Bere J, Fekete E, Móczó J, Nagy B, Kállay M, Gyarmati B, Pukánszky B. Interactions, structure and properties in PLA/plasticized starch blends. Polymer 2016; 103: 9-18. https://doi.org/10.1016/j.polymer.2016.09.031

[217] Shirai MA, Grossmann MV, Mali S, Yamashita F, Garcia PS Müller CM. Development of biodegradable flexible films of starch and poly (lactic acid) plasticized with adipate or citrate esters. Carbohydrate polymers 2013; 92(1): 19-22. https://doi.org/10.1016/i.carbpol.2012.09.038

[218] Quintana R, Persenaire O, Lemmouchi $\mathrm{Y}$, Bonnaud L, Dubois $P$. Grafted $d / /$-lactide to cellulose acetate by reactive melt processing: Its role as CA/PLA blend compatibilizer. European Polymer Journal 2014; 57: 30-6. https://doi.org/10.1016/j.eurpolymj.2014.05.003 
[219] Wang S, Li Y, Xiang H, Zhou Z, Chang T, Zhu M. Low cost carbon fibers from bio-renewable lignin/poly (lactic acid)(PLA) blends. Composites Science and Technology 2015; 119: 20-5.

https://doi.org/10.1016/j.compscitech.2015.09.021

[220] Shen Z, Zhou Y, Liu J, Xiao Y, Cao R, Wu F. Enhanced removal of nitrate using starch/PCL blends as solid carbon source in a constructed wetland. Bioresource technology 2015; 175: 239-44.

https://doi.org/10.1016/j.biortech.2014.10.006

[221] Figueiredo AR, Silvestre AJ, Neto CP, Freire CS. In situ synthesis of bacterial cellulose/polycaprolactone blends for hot pressing nanocomposite films production. Carbohydrate polymers 2015 ; 132 : 400-8.

https://doi.org/10.1016/j.carbpol.2015.06.001

[222] Goonoo N, Bhaw-Luximon A, Passanha P, Esteves S, Schönherr $H$, Jhurry $D$. Biomineralization potential and cellular response of PHB and PHBV blends with natural anionic polysaccharides. Materials Science and Engineering: C 2017; 76: 13-24.

https://doi.org/10.1016/j.msec.2017.02.156

[223] Torres-Huerta AM, Palma-Ramírez D, Dominguez-Crespo MA, Del Angel-López D, De La Fuente D. Comparative assessment of miscibility and degradability on PET/PLA and PET/chitosan blends. European Polymer Journal 2014; 61: 285-99.

https://doi.org/10.1016/j.eurpolymj.2014.10.016

[224] Madkour TM, Fadl S, Dardir MM, Mekewi MA. High performance nature of biodegradable polymeric nanocomposites for oil-well drilling fluids. Egyptian Journal of Petroleum 2016; 25(2): 281-91.

https://doi.org/10.1016/j.ejpe.2015.09.004

[225] Amirian M, Chakoli AN, Cai W, Sui J. Effect of functionalized multiwalled carbon nanotubes on thermal stability of poly (LLACTIDE) biodegradable polymer. Scientia Iranica 2013; 20(3): 1023-7.

[226] Sankar R, Shivashangari KS, Ravikumar V. Integrated poly$\mathrm{D}$, L-lactide-co-glycolide/silver nanocomposite: synthesis, characterization and wound healing potential in Wistar Albino rats. RSC Advances 2016; 6(27): 22728-36.

https://doi.org/10.1039/C5RA23212K

[227] Herrera N, Roch H, Salaberria AM, Pino-Orellana MA, Labidi $\mathrm{J}$, Fernandes SC, Radic D, Leiva A, Oksman K. Functionalized blown films of plasticized polylactic acid/chitin nanocomposite: Preparation and characterization. Materials \& Design 2016; 92: 846-52.

https://doi.org/10.1016/j.matdes.2015.12.083

[228] Samberg ME, Mente P, He T, King MW, Monteiro-Riviere NA. In vitro biocompatibility and antibacterial efficacy of a degradable poly (L-lactide-co-epsilon-caprolactone) copolymer incorporated with silver nanoparticles. Annals of biomedical engineering 2014; 42(7): 1482-93.

https://doi.org/10.1007/s10439-013-0929-9

[229] Moeini S, Mohammadi MR, Simchi A. In-situ solvothermal processing of polycaprolactone/hydroxyapatite nanocomposites with enhanced mechanical and biological performance for bone tissue engineering. Bioactive materials 2017; 2(3): 146-55. https://doi.org/10.1016/j.bioactmat.2017.04.004

[230] Guarás MP, Alvarez VA, Ludueña LN. Biodegradable nanocomposites based on starch/polycaprolactone/ compatibilizer ternary blends reinforced with natural and organo-modified montmorillonite. Journal of Applied Polymer Science 2016; 133(44).

https://doi.org/10.1002/app.44163

[231] da Costa Reis DC, de Oliveira TA, de Carvalho LH, Soares Alves T, Barbosa R. Biodegradability of and interaction in the packaging of poly (3-hydroxybutyrate-co-3-hydroxyvalerate)vermiculite bionanocomposites. Journal of Applied Polymer Science 2017; 134(15).

https://doi.org/10.1002/app.44700
[232] Gumel AM, Annuar MS, Ishak KA, Ahmad N. Carbon nanofibers-poly-3-hydroxyalkanoates nanocomposite: ultrasound-assisted dispersion and thermostructural properties. Journal of Nanomaterials 2014; 2014: 123. https://doi.org/10.1155/2014/264206

[233] Ahmadizadegan $H$. Surface modification of $\mathrm{TiO} 2$ nanoparticles with biodegradable nanocellolose and synthesis of novel polyimide/cellulose/TiO2 membrane. Journal of colloid and interface science 2017; 491: 390-400. https://doi.org/10.1016/j.jcis.2016.11.043

[234] Winzenburg G, Schmidt C, Fuchs S, Kissel T. Biodegradable polymers and their potential use in parenteral veterinary drug delivery systems. Advanced drug delivery reviews 2004; 56(10): 1453-66. https://doi.org/10.1016/j.addr.2004.02.008

[235] von Burkersroda F, Schedl L, Göpferich A. Why degradable polymers undergo surface erosion or bulk erosion. Biomaterials 2002; 23(21): 4221-31.

https://doi.org/10.1016/S0142-9612(02)00170-9

[236] Tokiwa Y, Calabia BP. Biodegradability and biodegradation of polyesters. Journal of Polymers and the Environment 2007; 15(4): 259-67. https://doi.org/10.1007/s10924-007-0066-3

[237] Henton DE, Gruber P, Lunt J, Randall J. Polylactic acid technology. Natural fibers, biopolymers, and biocomposites 2005; 16: 527-77. https://doi.org/10.1201/9780203508206.ch16

[238] Siepmann J, Göpferich A. Mathematical modeling of bioerodible, polymeric drug delivery systems. Advanced drug delivery reviews 2001; 48(2-3): 229-47. https://doi.org/10.1016/S0169-409X(01)00116-8

[239] Elsawy MA, Kim KH, Park JW, Deep A. Hydrolytic degradation of polylactic acid (PLA) and its composites. Renewable and Sustainable Energy Reviews 2017; 79: 1346-52.

https://doi.org/10.1016/..rser.2017.05.143

[240] Shah AA, Hasan F, Hameed A, Ahmed S. Biological degradation of plastics: a comprehensive review. Biotechnology advances 2008; 26(3): 246-65. https://doi.org/10.1016/j.biotechadv.2007.12.005

[241] Lucas N, Bienaime C, Belloy C, Queneudec M, Silvestre F, Nava-Saucedo JE. Polymer biodegradation: Mechanisms and estimation techniques-A review. Chemosphere 2008; 73(4): 429-42.

https://doi.org/10.1016/j.chemosphere.2008.06.064

[242] Göpferich A. Mechanisms of polymer degradation and erosion. Biomaterials 1996; 17(2): 103-14. https://doi.org/10.1016/0142-9612(96)85755-3

[243] Rizzarelli P, Puglisi C, Montaudo G. Soil burial and enzymatic degradation in solution of aliphatic co-polyesters. Polymer degradation and stability $2004 ; 85(2): 855-63$. https://doi.org/10.1016/j.polymdegradstab.2004.03.022

[244] Kijchavengkul T, Auras R, Rubino M, Alvarado E, Montero JR, Rosales JM. Atmospheric and soil degradation of aliphatic-aromatic polyester films. Polymer Degradation and Stability 2010; 95(2): 99-107. https://doi.org/10.1016/j.polymdegradstab.2009.11.048

[245] Augusta J, Müller RJ, Widdecke H. A rapid evaluation platetest for the biodegradability of plastics. Applied microbiology and biotechnology 1993; 39(4-5): 673-8. https://doi.org/10.1007/BF00205073

[246] Luzi F, Fortunati E, Puglia D, Petrucci R, Kenny JM, Torre L. Study of disintegrability in compost and enzymatic degradation of PLA and PLA nanocomposites reinforced with cellulose nanocrystals extracted from Posidonia Oceanica. Polymer Degradation and Stability 2015; 121: 105-15. https://doi.org/10.1016/j.polymdegradstab.2015.08.016

[247] Pelegrini K, Donazzolo I, Brambilla V, Coulon Grisa AM, Piazza D, Zattera AJ, Brandalise RN. Degradation of PLA 
and PLA in composites with triacetin and buriti fiber after 600 days in a simulated marine environment. Journal of Applied Polymer Science 2016; 133(15). https://doi.org/10.1002/app.43290

[248] Zhao C, Wu H, Ni J, Zhang S, Zhang X. Development of PLA/Mg composite for orthopedic implant: Tunable degradation and enhanced mineralization. Composites Science and Technology 2017; 147: 8-15.

https://doi.org/10.1016/j.compscitech.2017.04.037

[249] Breche Q, Chagnon G, Machado G, Girard E, Nottelet B, Garric X, Favier D. Mechanical behaviour's evolution of a PLA-b-PEG-b-PLA triblock copolymer during hydrolytic degradation. Journal of the mechanical behavior of biomedical materials 2016; 60 : 288-300. https://doi.org/10.1016/j.jmbbm.2016.02.015

[250] Huang Y, Zhang C, Pan Y, Zhou Y, Jiang L, Dan Y. Effect of NR on the hydrolytic degradation of PLA. Polymer degradation and stability 2013; 98(5): 943-50.

https://doi.org/10.1016/j.polymdegradstab.2013.02.018

[251] Rocca-Smith JR, Chau N, Champion D, Brachais $\mathrm{CH}$, Marcuzzo E, Sensidoni A, Piasente F, Karbowiak T, Debeaufort $F$. Effect of the state of water and relative humidity on ageing of PLA films. Food Chemistry 2017; 236: 109-19. https://doi.org/10.1016/j.foodchem.2017.02.113

[252] Iniguez-Franco F, Auras R, Burgess G, Holmes D, Fang X, Rubino M, Soto-Valdez H. Concurrent solvent induced crystallization and hydrolytic degradation of PLA by waterethanol solutions. Polymer 2016; 99: 315-23. https://doi.org/10.1016/j.polymer.2016.07.018

[253] Karamanlioglu M, Robson GD. The influence of biotic and abiotic factors on the rate of degradation of poly (lactic) acid (PLA) coupons buried in compost and soil. Polymer degradation and stability 2013; 98(10): 2063-71. https://doi.org/10.1016/j.polymdegradstab.2013.07.004

[254] Karamanlioglu M, Houlden A, Robson GD. Isolation and characterisation of fungal communities associated with degradation and growth on the surface of poly (lactic) acid (PLA) in soil and compost. International Biodeterioration \& Biodegradation 2014; 95: 301-10.

https://doi.org/10.1016/j.ibiod.2014.09.006

[255] Meischel M, Eichler J, Martinelli E, Karr U, Weigel J, Schmöller G, Tschegg EK, Fischerauer S, Weinberg AM, Stanzl-Tschegg SE. Adhesive strength of bone-implant interfaces and in-vivo degradation of PHB composites for load-bearing applications. Journal of the mechanical behavior of biomedical materials 2016; 53: 104-18. https://doi.org/10.1016/j.jmbbm.2015.08.004

[256] Cima LG, Vacanti JP, Vacanti C, Ingber D, Mooney D, Langer R. Tissue engineering by cell transplantation using degradable polymer substrates. Journal of biomechanical engineering 1991; 113(2): 143-51. https://doi.org/10.1115/1.2891228

[257] Greisler HP. Growth factor release from vascular grafts. Journal of controlled release 1996; 39(2-3): 267-80. https://doi.org/10.1016/0168-3659(95)00159-X

[258] Greisler HP, Gosselin C, Ren D, Kang SS, Kim DU. Biointeractive polymers and tissue engineered blood vessels. Biomaterials 1996; 17(3): 329-36. https://doi.org/10.1016/0142-9612(96)85571-2

[259] Brekke JH, Toth JM. Principles of tissue engineering applied to programmable osteogenesis. Journal of biomedical materials research 1998; 43(4): 380-98.

https://doi.org/10.1002/(SICl)10974636(199824)43:4<380::AID-JBM6>3.0.CO;2-D

[260] Evans GR, Brandt K, Widmer MS, Lu L, Meszlenyi RK, Gupta PK, Mikos AG, Hodges J, Williams J, Gürlek A, Nabawi A. In vivo evaluation of poly (L-lactic acid) porous conduits for peripheral nerve regeneration. Biomaterials 1999; 20(12): 1109-15.

https://doi.org/10.1016/S0142-9612(99)00010-1
[261] Rodríguez FJ, Gómez N, Perego G, Navarro X. Highly permeable polylactide-caprolactone nerve guides enhance peripheral nerve regeneration through long gaps. Biomaterials 1999; 20(16): 1489-500. https://doi.org/10.1016/S0142-9612(99)00055-1

[262] Jagur-Grodzinski J. Polymers for tissue engineering, medical devices, and regenerative medicine. Concise general review of recent studies. Polymers for advanced technologies 2006; 17(6): 395-418.

https://doi.org/10.1002/pat.729

[263] Bos RR, Rozema FB, Boering G, Nijenhius AJ, Pennings AJ, Verwey $A B$, Nieuwenhuis $P$, Jansen HW. Degradation of and tissue reaction to biodegradable poly (L-lactide) for use as internal fixation of fractures: a study in rats. Biomaterials 1991; 12(1): 32-6. https://doi.org/10.1016/0142-9612(91)90128-W

[264] Ishaug-Riley SL, Crane-Kruger GM, Yaszemski MJ, Mikos AG. Three-dimensional culture of rat calvarial osteoblasts in porous biodegradable polymers. Biomaterials 1998; 19(15): 1405-12.

https://doi.org/10.1016/S0142-9612(98)00021-0

[265] Amass W, Amass A, Tighe B. A review of biodegradable polymers: uses, current developments in the synthesis and characterization of biodegradable polyesters, blends of biodegradable polymers and recent advances in biodegradation studies. Polymer international 1998; 47(2): 89-144.

https://doi.org/10.1002/(SICI)10970126(1998100)47:2<89::AID-PI86>3.0.CO;2-F

[266] Edlund U, Albertsson AC. Novel drug delivery microspheres from poly (1, 5-dioxepan-2-one-co-L-lactide). Journal of Polymer Science Part A: Polymer Chemistry 1999; 37(12): 1877-84.

https://doi.org/10.1002/(SICI)10990518(19990615)37:12<1877::AID-POLA17>3.0.CO;2-4

[267] Rizzarelli P, Carroccio S. Modern mass spectrometry in the characterization and degradation of biodegradable polymers. Analytica chimica acta 2014; 808: 18-43.

https://doi.org/10.1016/j.aca.2013.11.001

[268] Newman D, Bello A, Laredo E. Moisture effects on dielectric relaxations of poly ( $\varepsilon$-caprolactone)/starch biodegradable blends: Local, interfacial and segmental. Carbohydrate polymers 2015 ; 131 : $15-22$.

https://doi.org/10.1016/j.carbpol.2015.05.056

[269] Flemming RG, Murphy CJ, Abrams GA, Goodman SL, Nealey PF. Effects of synthetic micro-and nano-structured surfaces on cell behavior. Biomaterials 1999; 20(6): 573-88. https://doi.org/10.1016/S0142-9612(98)00209-9

[270] Ishaug SL, Crane GM, Miller MJ, Yasko AW, Yaszemski MJ, Mikos AG. Bone formation by three-dimensional stromal osteoblast culture in biodegradable polymer scaffolds. Journal of biomedical materials research 1997; 36(1): 17-28. https://doi.org/10.1002/(SICI)10974636(199707)36:1<17::AID-JBM3>3.0.CO;2-O

[271] Agrawal CM, Best J, Heckman JD, Boyan BD. Protein release kinetics of a biodegradable implant for fracture nonunions. Biomaterials 1995; 16(16): 1255-60.

https://doi.org/10.1016/0142-9612(95)98133-Y

[272] Vunjak-Novakovic G, Martin I, Obradovic B, Treppo S, Grodzinsky AJ, Langer R, Freed LE. Bioreactor cultivation conditions modulate the composition and mechanical properties of tissue-engineered cartilage. Journal of Orthopaedic Research 1999; 17(1): 130-8. https://doi.org/10.1002/jor.1100170119

[273] Xu F, Weng B, Gilkerson R, Materon LA, Lozano K. Development of tannic acid/chitosan/pullulan composite nanofibers from aqueous solution for potential applications as wound dressing. Carbohydrate polymers 2015; 115: 1624 https://doi.org/10.1016/j.carbpol.2014.08.081 
[274] Ferreira A, Ferreira F, Paiva MC. Textile sensor applications with composite monofilaments of polymer/carbon nanotubes. InAdvances in Science and Technology 2013 (Vol. 80, pp. 65-70). Trans Tech Publications.

[275] Kim IA, Rhee SH. Preparation of a non-woven poly ( $\varepsilon$-caprolactone) fabric with partially embedded apatite surface for bone tissue engineering applications by partial surface melting of poly ( $\varepsilon$-caprolactone) fibers. Journal of Biomedical Materials Research Part A 2017; 105(7): 197383.

https://doi.org/10.1002/jbm.a.36069
[276] Torres A, llabaca E, Rojas A, Rodríguez F, Galotto MJ, Guarda A, Villegas C, Romero J. Effect of processing conditions on the physical, chemical and transport properties of polylactic acid films containing thymol incorporated by supercritical impregnation. European Polymer Journal 2017; 89: 195-210.

https://doi.org/10.1016/j.eurpolymj.2017.01.019 